San Jose State University

SJSU ScholarWorks

Master's Theses

Master's Theses and Graduate Research

Spring 2016

\title{
Effects of global change on algal biomineralization and benthic community interactions on California's temperate rocky reefs
}

Emily Marie Donham

San Jose State University

Follow this and additional works at: https://scholarworks.sjsu.edu/etd_theses

\section{Recommended Citation}

Donham, Emily Marie, "Effects of global change on algal biomineralization and benthic community interactions on California's temperate rocky reefs" (2016). Master's Theses. 4685.

DOI: https://doi.org/10.31979/etd.cwhz-2v25

https://scholarworks.sjsu.edu/etd_theses/4685

This Thesis is brought to you for free and open access by the Master's Theses and Graduate Research at SJSU ScholarWorks. It has been accepted for inclusion in Master's Theses by an authorized administrator of SJSU ScholarWorks. For more information, please contact scholarworks@sjsu.edu. 
EFFECTS OF GLOBAL CHANGE ON ALGAL BIOMINERALIZATION AND BENTHIC COMMUNITY INTERACTIONS ON CALIFORNIA'S TEMPERATE ROCKY REEFS

\author{
A Thesis \\ Presented to \\ The Faculty of the Department of Marine Science \\ San José State University
}

In Partial Fulfillment

of the Requirements for the Degree

Master of Science

by

Emily Donham

May 2016 
(C) 2016

Emily Donham

ALL RIGHTS RESERVED 
The Designated Thesis Committee Approves the Thesis Titled EFFECTS OF GLOBAL CHANGE ON ALGAL BIOMINERALIZATION AND BENTHIC COMMUNITY INTERACTIONS ON CALIFORNIA'S TEMPERATE ROCKY REEFS

by

Emily Donham

APPROVED FOR THE DEPARTMENT OF MARINE SCIENCE

SAN JOSÉ STATE UNIVERSITY

May 2016

Dr. Scott Hamilton

Moss Landing Marine Laboratories

Dr. Michael Graham

Moss Landing Marine Laboratories

Dr. Ivano Aiello

Moss Landing Marine Laboratories

Dr. Nichole Price

Bigelow Laboratories for Ocean Science 


\title{
ABSTRACT \\ EFFECTS OF GLOBAL CHANGE ON ALGAL BIOMINERALIZATION AND BENTHIC COMMUNITY INTERACTIONS ON CALIFORNIA'S TEMPERATE ROCKY REEFS
}

\author{
By Emily Donham
}

Marine ecosystems are threatened by $\mathrm{CO}_{2}$-driven global change, such as ocean warming and acidification (OA). The primary objectives of this study were to: 1) assess the response of the coralline red alga, Calliarthron cheilosporioides, to global change; and 2) investigate the responses of California's kelp forest communities to $\mathrm{OA}$ and sea urchin grazing. Results indicated that $C$.

cheilosporioides growth and calcification were reduced under both increased temperatures and increased $p \mathrm{CO}_{2}$ despite increased photosynthetic rates in high $p \mathrm{CO}_{2}$ conditions. Mineralogy did not differ among treatments as a function of warming or acidification. Differences were observed in $\mathrm{Mg}$ incorporation into calcified walls of different cell types. Impacts of OA and sea urchin grazing on community structure differed in central and southern CA. In central CA, community structure, calcification and juvenile kelp density showed strong effects of grazing, but no effect of $p \mathrm{CO}_{2}$. Conversely, southern $\mathrm{CA}$ showed minor effects of grazing, but strong effects of $p \mathrm{CO}_{2}$ on community structure and calcification, with the strength of response depending on the initial assemblage. These findings suggest that some species of coralline algae may be negatively affected by increased $p \mathrm{CO}_{2}$ and temperature and that the emergent effects of ocean acidification may differ both within a reef as well as across broad spatial scales. 


\section{ACKNOWLEDGEMENTS}

First and foremost, I would like to thank the most amazing graduate advisor that any student could hope for, Dr. Scott Hamilton. Over the past 5 years Dr. Hamilton's endless support and belief in me has helped me develop into the budding scientist that I am today. Scott, I can't thank you enough for your constant willingness to teach, your patience, and kindness. I would like to thank Dr. Ivano Aiello for his geological expertise that was critical to my understanding of the biogeochemical foundations of my research. Ivano, I will never forget the hours that you spent working with me in that tiny SEM room. I would like to thank Dr. Nichole Price for her close mentorship while conducting my experiments at Scripps Institution of Oceanography and for teaching me so much about climate change. Nichole, your insightful comments and support that have been crucial to the completion of this thesis. I would like to thank Dr. Mike Graham for teaching me so much about Ecology and Phycology. I would also like to thank Dr. Graham for his attention to detail in the final stages of preparing my thesis.

I would like to thank Lindsay Bonito, Christian Denney, Isabella Doohan, Jeremiah Ets-Hokin, Evangeline Fachon, Will Fennie, Michael Fox, Molly Gleason, Jill Harris, Maggie Johnson, Emily Kelley, Susan Kram, Heather Kramp, Stephen Loiacono, Evan Mattiason, Matt Metzger, Arley Muth, Gabi Navas, Alex Neu, Jasmine Ruvalcaba, Lenell Sagastume, Garrett Stewart, Yuichiro Takeshita, Sara Worden, Devona Yates, and Phil Zerofski for the countless 
hours spent both on land and at sea helping me to complete my thesis. I would like to thank Danny Merritt for his engineering expertise. I would like to especially thank my family for always supporting me in whatever endeavors I may embark on. I can truly say I would be lost without you. This project would not have been possible without funding and support from California SeaGrant, the Moss Landing Marine Laboratories Scholar Award, the Dr. Earl and Ethel M. Myers Oceanographic and Marine Biology Trust, the Council on Ocean Affairs, Science, and Technology (COAST) grant, and the David and Lucile Packard Foundation.

This thesis is dedicated to my aunt, Julia Asher, who would have been terribly concerned about climate change. 


\section{TABLE OF CONTENTS}

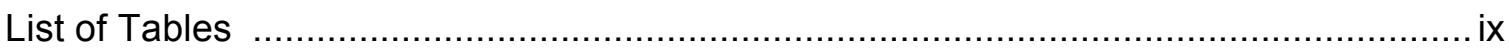

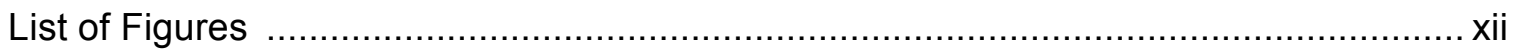

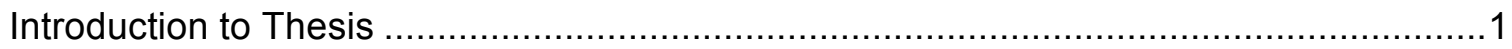

Chapter I

Single-species consequences of warming and acidification on the temperate articulated coralline alga, Calliarthron cheilosporioides

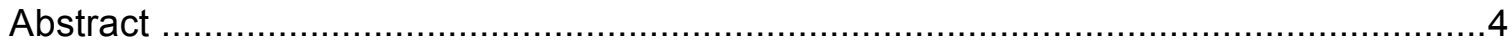

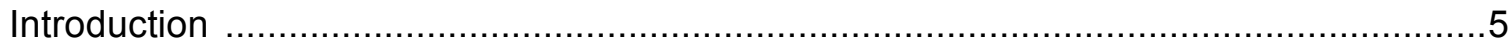

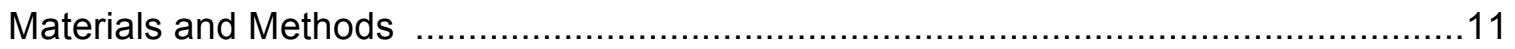

Study Site and Collections ........................................................................11

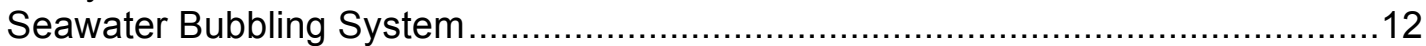

Physiological and Mineralogical Responses of Coralline Algae ...........................16

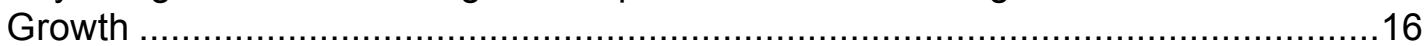

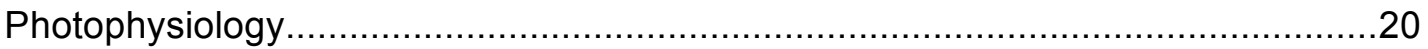

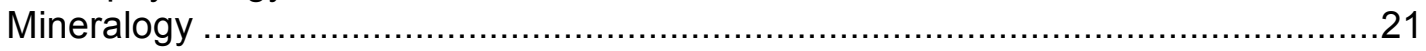

Statistical Methods for Coralline Algae Experiments …………..........................23

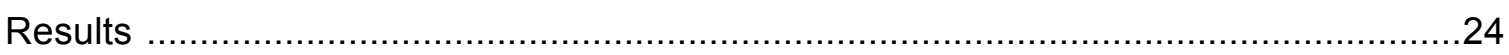

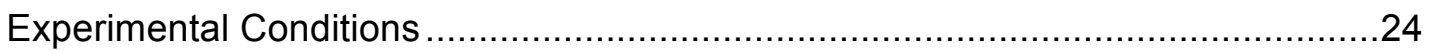

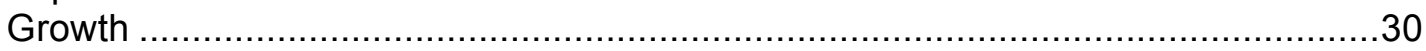

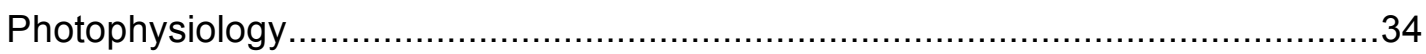

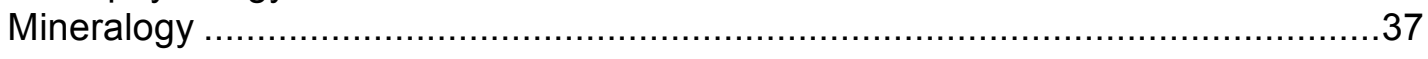

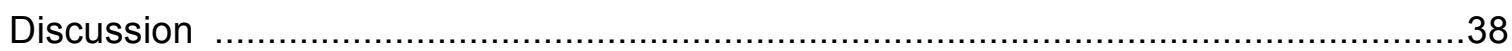

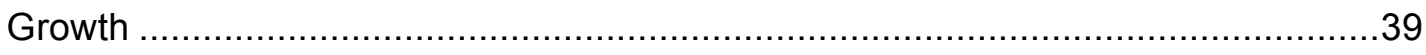

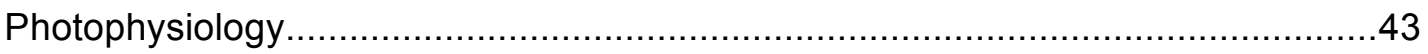

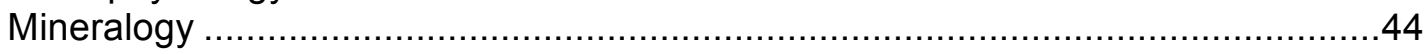

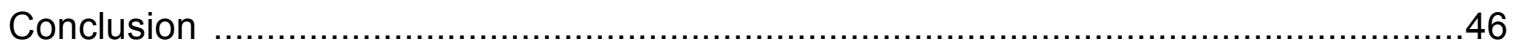

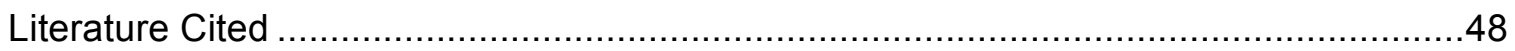

Chapter II

Effects of ocean acidification and grazing on kelp forest communities from

San Diego, CA and Carmel, CA

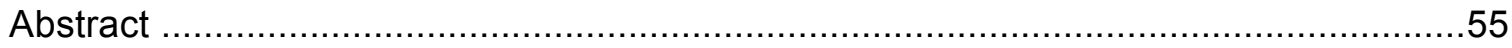

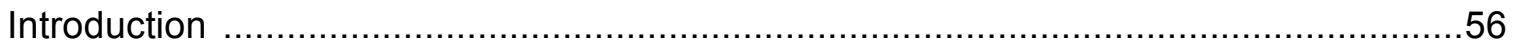

Spatio-temporal variation in seawater chemistry along the California coast ..........58 


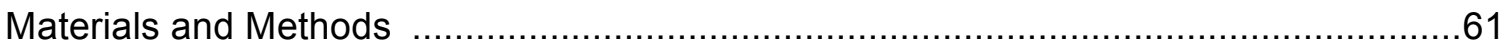

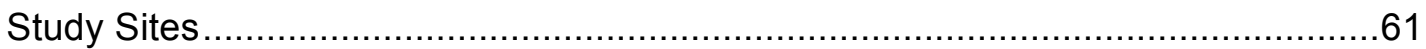

Benthic Community Structure Responses to Ocean Acidification .........................63

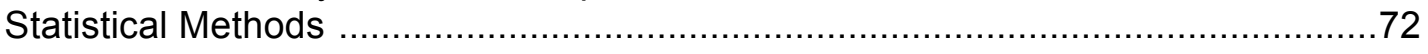

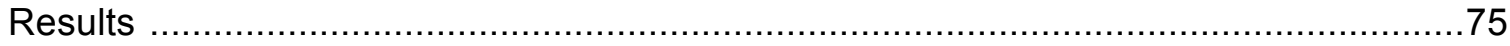

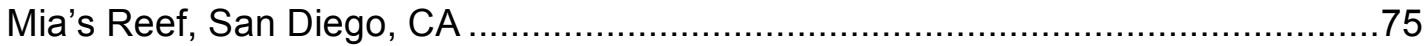

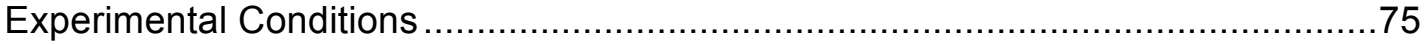

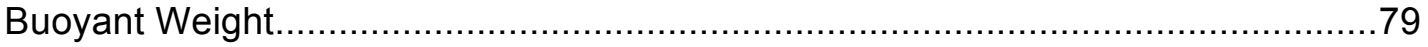

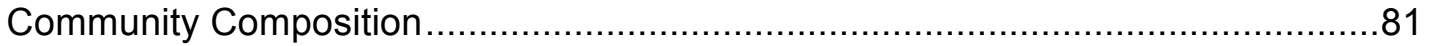

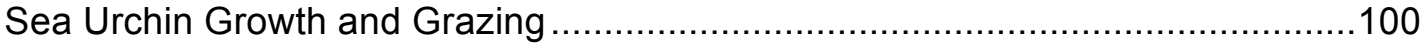

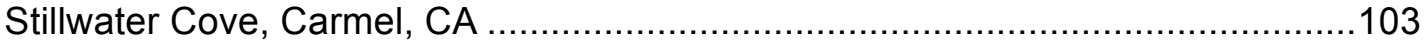

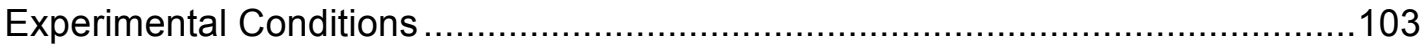

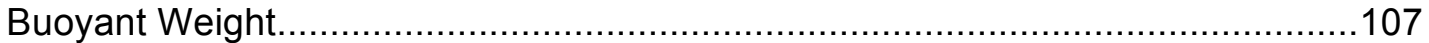

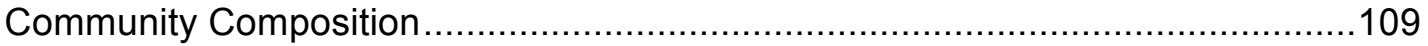

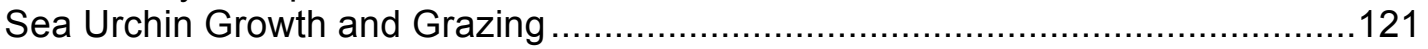

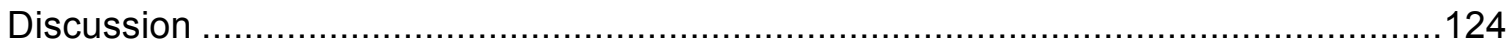

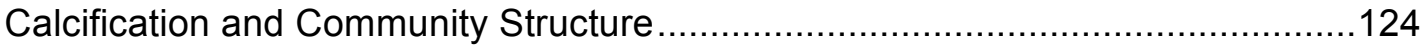

Impacts of ocean acidification on Grazing on Juvenile Kelp.............................130

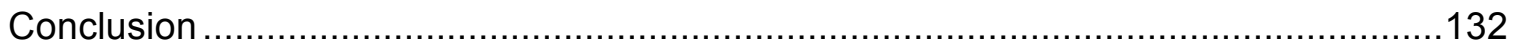

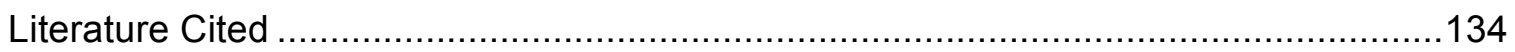

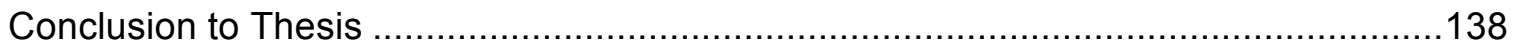

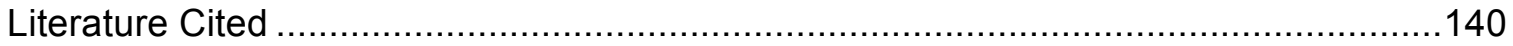




\section{LIST OF TABLES}

Chapter I

Table 1. Average environmental conditions in the field at Mia's Reef, San Diego, $\mathrm{CA}$ (collection site) and during the duration of the 28-day experiment

Table 2. Mean seawater chemistry for experimental mesocosms obtained at the beginning and end of 28-day experiment ( \pm SE). Discrete samples from mesocosms both with and without macroalgae were pooled within treatments

Table 3. ANOVA results for the effects of $\mathrm{pCO}_{2}$ (ambient and high) and temperature (ambient and high) on the change in buoyant weight of C.cheilosporioides ...30

Table 4. ANOVA results for the effects of $p \mathrm{CO}_{2}$ (ambient and high) and temperature (ambient and high) on the growth of $C$. cheilosporioides

Table 5. ANOVA results for the effects of $\mathrm{pCO}_{2}$ (ambient and high) and temperature (ambient and high) on the photophysiology of C.cheilosporioides

Table 6. Mean photophysiological parameters of $C$. cheilosporioides reared under different treatments of $p \mathrm{CO}_{2}$ (ambient and high) and temperature (ambient and high)

Table 7. ANOVA results for the effects of $\mathrm{pCO}_{2}$ (ambient and high) and temperature (ambient and high) on the mineralogy of C.cheilosporioides cortical and medullary cells 
Chapter II

Table 1. Average environmental conditions in the field and experiments for Mia's Reef, San Diego, CA

Table 2. ANOVA results for the effects of $p \mathrm{CO}_{2}$ (ambient and high), sea urchins (presence and absence), and block (A, B and $C$ ) on the change in buoyant weight of tile communities from Mia's Reef.

Table 3. PERMANOVA results of the effects of $p \mathrm{CO}_{2}$ (ambient and high), sea urchins (presence and absence), and block (A, B and $C$ ) on community composition on the tops of settlement tiles from Mia's Reef.

Table 4. PERMANOVA results of the effects of $p \mathrm{CO}_{2}$ (ambient and high) and sea urchins (presence and absence) on community composition on the top of Block A tiles from Mia's Reef .

Table 5. PERMANOVA results of the effects of $p \mathrm{CO}_{2}$ (ambient and high) and sea urchins (presence and absence) on community composition on the top of Block B tiles from Mia's Reef

Table 6. PERMANOVA results of the effects of $p \mathrm{CO}_{2}$ (ambient and high) and sea urchins (presence and absence) on community composition on the top of Block C tiles from Mia's Reef.

Table 7. PERMANOVA results of the effects of $p \mathrm{CO}_{2}$ (ambient and high), sea urchins (presence and absence), and block (A, B and C) on community composition on the bottoms of settlement tiles from Mia's Reef.....

Table 8. PERMANOVA results of the effects of $\mathrm{pCO}_{2}$ (ambient and high) and sea urchins (presence and absence) on community composition on the bottom of Block A tiles from Mia's Reef

Table 9. PERMANOVA results of the effects of $\mathrm{pCO}_{2}$ (ambient and high) and sea urchins (presence and absence) on community composition on the bottom of Block B tiles from Mia's Reef

Table 10. PERMANOVA results of the effects of $p \mathrm{CO}_{2}$ (ambient and high) and sea urchins (presence and absence) on community composition on the bottom of Block C tiles from Mia's Reef.

Table 11. ANOVA results of the effects of $\mathrm{pCO}_{2}$ (ambient and high) and sea urchins (presence and absence) on the density and biomass of juvenile kelp on settlement tiles

Table 12. Average environmental conditions in the field and experiments for Stillwater Cove, Carmel, CA 
Table 13. ANOVA results for the effects of $\mathrm{CCO}_{2}$ (ambient and high), sea urchins (presence and absence), and block (A, B and $C$ ) on the change in buoyant weight of tile communities from Stillwater Cove.

Table 14. PERMANOVA results of the effects of $\mathrm{pCO}_{2}$ (ambient and high), sea urchins (presence and absence), and block on community composition on the tops of settlement tiles from Stillwater Cove

Table 15. PERMANOVA results of the effects of $\mathrm{pCO}_{2}$ (ambient and high), sea urchins (presence and absence), and block on community composition on the bottoms of settlement tiles from Stillwater Cove

Table 16. PERMANOVA results of the effects of $\mathrm{pCO}_{2}$ (ambient and high), sea urchins (presence and absence) and block on functional group taxa on the tops of settlement tiles from Stillwater Cove

Table 17. PERMANOVA results of the effects of $p \mathrm{CO}_{2}$ (ambient and high), sea urchins (presence and absence) and block on functional group taxa on the bottoms of settlement tiles from Stillwater Cove

Table 18. ANOVA results of the effects of $\mathrm{pCO}_{2}$ (ambient and high) and sea urchins presence and absence) on the density and biomass of juvenile kelp on settlement tiles from Mia's Reef. 


\section{LIST OF FIGURES}

Chapter I

Figure 1. Calcofluor stained region is depicted as fluorescent blue arch on three growing tips from $C$. cheilosporioides. Yellow lines show linear extension measurements of new growth material during experimental rearing $(\mathrm{L} 1, \mathrm{~L} 2, \mathrm{~L} 3$ = linear extension in $\mathrm{mm})$

Figure 2. Surface area measurements of new growth material during experimental rearing. Yellow lines show planar surface area beyond the calcofluor white staining marker (PG1, PG3, and PG4+PG5 = surface area of new growth in $\mathrm{mm}^{2}$

Figure 3. Scanning electron microscopy (SEM) image at 1000x. Image depicts more circular cortical cells $(A)$ and more elongate internal medullary cells $(B) \ldots \ldots . .23$

Figure 4. In situ $\mathrm{pH}$ and temperature data collected from autonomous SeaFET sensor deployed at Mia's Reef, San Diego, CA. Instrument was deployed at $15 \mathrm{~m}$ and data were collected every $15 \mathrm{~min}$. Panel A shows temperature $\left({ }^{\circ} \mathrm{C}\right)$. Panel $\mathrm{B}$ shows $\mathrm{pH}_{\mathrm{sw}}$

Figure 5. In situ irradiance measurements (PAR) at Mia's Reef, San Diego, CA from October 6, 2013 to October 25, 2013

Figure 6. Daily experimental $\mathrm{pH}$ and temperature conditions in mesocosms for the duration of the 28-day experiment. Panel $\mathrm{A}$ shows $\mathrm{pH}_{\mathrm{sw}}$, with symbols representing average daily $\mathrm{HACH}$ pH glass electrode measurements \pm SE. Solid lines represent continuous $\mathrm{pH}$ measurements from Honeywell Durafet. Panel B shows average daily $\mathrm{HACH}$ temperature measurements $\pm \mathrm{SE}$

Figure 7. Percent change in buoyant weight of $C$. cheilosporioides in the four factorial $p \mathrm{CO}_{2}$ and temperature treatments. Shared letters below error bars indicate mean change in buoyant weight did not differ between treatments. Error bars denote \pm SE

Figure 8. Growth rates as linear extension (A) and new growth surface area (B) for $C$. cheilosporioides in the four factorial $p \mathrm{CO}_{2}$ and temperature treatments. Shared letters below error bars indicate mean change in buoyant weight did not differ between treatments. Error bars denote \pm SE.

Figure 9. Net photosynthesis versus irradiance curves for $C$. cheilosporioides after rearing in four factorial $p \mathrm{CO}_{2}$ and temperature treatments for 28 days. Net photosynthesis is expressed in terms of oxygen production

Figure 10. Mol\% Mg found in cortical and medullary cell walls for $C$. cheilosporioides in four factorial $p \mathrm{CO}_{2}$ and temperature treatments. Error bars denote $\pm \mathrm{SE}$..37 
Chapter II

Figure 1. Settlement tile array containing 18-100 $\mathrm{cm}^{2}$ PVC settlement tiles deployed in the kelp forest at Stillwater Cove, Carmel, CA (A) upon deployment and $(B)$ after $\sim 9$ months in the field

Figure 2. Autonomous SeaFET temperature and $\mathrm{pH}$ sensor deployed in a kelp forest at Stillwater Cove, Carmel, CA

Figure 3. Experimental laboratory mesocosm setup shows individual replicate glass aquaria containing a single settlement tile. Blue lines indicate gas lines bubbling either air or air- $\mathrm{CO}_{2}$ mix. Black lines indicate flow-through seawater

Figure 4. Settlement tile top (A) and bottom (B) from Mia's Reef after 56 days in experimental rearing conditions in the lab. Numbers indicate key taxa $(1=$ calcified algae, 2 = bryozoan, $3=$ fleshy macroalgae, $4=$ tunicate, $5=1$ serpulid worm, 6 = bivalve, 7 = sponge)

Figure 5. Images of representative settlement tile tops from San Diego, CA after 56 days in experimental conditions. A) ambient $p \mathrm{CO}_{2}$, -grazer; $\mathrm{B}$ ) ambient $p \mathrm{CO}_{2}$, +grazer; C) high $p \mathrm{CO}_{2}$, -grazer; and D) high $p \mathrm{CO}_{2}$, +grazer

Figure 6. Daily experimental $\mathrm{pH}$ and temperature conditions in mesocosms for the duration of the 56-day experiment with tiles from Mia's Reef. $\mathrm{pH}_{\mathrm{sw}}$, with symbols representing average daily $\mathrm{HACH}$ pH glass electrode measurements $\pm \mathrm{SE}$. Solid lines represent continuous $\mathrm{pH}$ measurements from Honeywell Durafet

Figure 7. In situ $\mathrm{pH}$ and temperature data collected from autonomous SeaFET sensor deployed at Mia's Reef, San Diego, CA. Instrument was deployed at $15 \mathrm{~m}$ and data were collected every $15 \mathrm{~min}$. Panel A shows temperature $\left({ }^{\circ} \mathrm{C}\right)$. Panel $\mathrm{B}$ shows $\mathrm{pH}_{\mathrm{sw}}$

Figure 8. In situ irradiance measurements (PAR) at Mia's Reef, San Diego, CA from October 6, 2013 to October 25, 2013

Figure 9. Percent change in buoyant weight of settlement tiles from Mia's Reef. Shared letters below error bars indicate mean change in buoyant weight did not differ between treatments. Error bars denote \pm SE

Figure 10. nMDS plots showing dissimilarities in community composition between settlement tile benthic assemblages reared in experimental $p \mathrm{CO}_{2}$ and sea urchin treatments. Points (tiles) closer together indicate communities more similar than points further apart. A-C show nMDS plots of community data from the top of tiles separated by block, D shows all community data from the top of tiles together 
Figure 11. Percent cover of functional group taxa on the top of tiles by block from Mia's Reef. Note: *, indicates a significant difference in percent cover between factor grazer; ${ }^{* *}$, a significant difference in percent cover between $p \mathrm{CO}_{2}$ treatments; ${ }^{* * *}$, a significant difference in percent cover by block $(\alpha=0.05)$. Error bars denote \pm SE

Figure 12. nMDS plots showing dissimilarities in community composition between settlement tile benthic assemblages reared in experimental $p \mathrm{CO}_{2}$ and sea urchin treatments. Points (tiles) closer together indicate communities more similar than points further apart. A-C show nMDS plots of community data from the bottom of tiles separated by block, D shows all community data from the bottom of tiles together

Figure 13. Percent cover of functional group taxa on the bottom of tiles by block from Mia's Reef. Note: *, indicates a significant difference in percent cover between factor grazer; ${ }^{* *}$, a significant difference in percent cover between $p \mathrm{CO}_{2}$ treatments; ${ }^{* * *}$, a significant difference in percent cover by block $(\alpha=0.05)$. Error bars denote \pm SE

Figure 14. Density $(A)$ and biomass $(B)$ of juvenile kelp on settlement tiles from Mia's Reef at the end of 56 days reared under different $p \mathrm{CO}_{2}$ and sea urchin grazing treatments. Shared letters below error bars indicate mean density did not differ between treatments. Error bars denote \pm SE

Figure 15. Growth rates of sea urchins reared on settlement tiles from Mia's Reef in ambient and high $p \mathrm{CO}_{2}$ conditions standardized to initial size after 56 days in experimental rearing. Error bars denote \pm SE

Figure 16. Results from grazing assay with sea urchins from settlement tiles accrued at Mia's reef after 56 days of rearing in ambient or high $p \mathrm{CO}_{2}$. A decrease in $\mathrm{g} \mathrm{day}^{-1}$ indicates a removal of algal biomass via grazing. Error bars denote \pm SE

Figure 17. Daily experimental $\mathrm{pH}$ and temperature conditions in mesocosms for the duration of the 56-day experiment. $\mathrm{pH}_{\mathrm{sw}}$, with symbols representing average daily $\mathrm{HACH} \mathrm{pH}$ glass electrode measurements $\pm \mathrm{SE}$. Solid lines represent continuous $\mathrm{pH}$ measurements from Honeywell Durafet

Figure 18. In situ $\mathrm{pH}$ and temperature data collected from autonomous SeaFET sensor deployed at Stillwater Cove, Carmel, CA. Instrument was deployed at $15 \mathrm{~m}$ and data were collected every $15 \mathrm{~min}$. Panel A shows temperature $\left({ }^{\circ} \mathrm{C}\right)$. Panel $\mathrm{B}$ shows $\mathrm{pH}_{\mathrm{sw}}$

Figure 19. In situ irradiance measurements (PAR) at Stillwater Cove, Carmel, CA from March 7, 2013 to March 26, 2013

Figure 20. Percent change in buoyant weight of settlement tiles from Stillwater 
Cove, Carmel, CA. Shared letters below error bars indicate mean change in buoyant weight did not differ between treatments. Error bars denote \pm SE

Figure 21. Settlement tile top (A) and bottom (B) from Stillwater Cove after 56 days in experimental rearing. Numbers indicate key taxa $(1=$ calcified algae, 2 = fleshy macroalgae, 3 = serpulid worm, 4 = bivalve, 5 = barnacle)

Figure 22. Images of representative settlement tile tops from Carmel, CA after 56 days in experimental conditions. A) ambient $p \mathrm{CO}_{2}$, -grazer; B) ambient $p \mathrm{CO}_{2}$, +grazer; C) high $p \mathrm{CO}_{2}$, -grazer; and D) high $p \mathrm{CO}_{2}$, +grazer

Figure 23. nMDS plots showing dissimilarities in community composition between settlement tile benthic assemblages reared in experimental $p \mathrm{CO}_{2}$ and grazer treatments. Points (tiles) closer together indicate communities more similar than points further apart. A, top of tiles; B, bottom of tiles

Figure 24. Percent cover of functional group taxa on the top (A) and bottom (B) of tiles from Stillwater Cove, Carmel, CA. Note: *, indicates a significant difference in percent cover between factor grazer; ${ }^{* *}$, a significant difference in percent cover between $p \mathrm{CO}_{2}$ treatments; ${ }^{* *}$, a significant difference in percent cover by block $(\alpha=0.05)$. Error bars denote $\pm \mathrm{SE}$

Figure 25. Density $(A)$ and biomass $(B)$ of juvenile kelp on settlement tiles in different $p \mathrm{CO}_{2}$ and grazer treatments. Error bars denote $\pm \mathrm{SE}$

Figure 26. Growth rates of urchins reared on settlement tiles from Stillwater Cove in ambient and high $p \mathrm{CO}_{2}$ conditions standardized to initial size after 56 days in experimental rearing. \pm SE

Figure 27. Results from grazing assay with sea urchins from settlement tiles accrued at Stillwater Cove after 56 days of rearing in ambient or high $p \mathrm{CO}_{2}$. A decrease in $\mathrm{g} \mathrm{day}^{-1}$ indicates a removal of algal biomass via grazing. Error bars denote \pm SE 


\section{Introduction to Thesis}

Atmospheric $\mathrm{CO}_{2}$ concentrations are currently higher than at any time in the past 800,000 years (Lüthi et al. 2008; Doney et al. 2009), largely due to increased anthropogenic $\mathrm{CO}_{2}$ emissions via the burning of fossil fuels, deforestation, and land use changes. The world's oceans have been shown to buffer these $\mathrm{CO}_{2}$ emissions and are estimated to have absorbed nearly $30 \%$ of the total anthropogenic $\mathrm{CO}_{2}$ since the beginning of the industrial revolution (Sabine et al. 2004). As dissolved concentrations of carbon dioxide (i.e., $p \mathrm{CO}_{2}$ ) in the ocean's surface waters continue to increase, the physical and chemical properties of seawater are being altered at a global scale.

When $\mathrm{CO}_{2}$ dissolves in seawater, it quickly transitions to bicarbonate, $\mathrm{HCO}_{3}{ }^{-}$, releasing $\mathrm{H}^{+}$ions and decreasing $\mathrm{pH}$. This decrease in $\mathrm{pH}$ also alters the speciation of inorganic carbon by decreasing the availability of carbonate ions, $\mathrm{CO}_{3}{ }^{-2}$, thus lowering the saturation states $(\Omega)$ of carbonate polymorphs (Feely et al. 2004). This process has been termed ocean acidification (OA) and has already resulted in a decrease in $\mathrm{pH}$ of roughly 0.1 units and a decrease in carbonate ion concentration by $\sim 30 \mu \mathrm{mol} \mathrm{kg}{ }^{-1}$ seawater (Caldeira and Wickett 2003; Hoegh-Guldberg et al. 2007). An additional drop in ocean $\mathrm{pH}$ of 0.3-0.5 units is expected by the year 2100 with a corresponding $50 \%$ decrease in carbonate ion concentrations compared to preindustrial levels (Feely et al. 2009). 
In addition to ocean acidification, strong evidence exists linking increasing concentrations of atmospheric $\mathrm{CO}_{2}$ to rising global temperatures on land and in the sea. The average global ocean temperature has increased by $0.74{ }^{\circ} \mathrm{C}$ since the beginning of the $20^{\text {th }}$ century and is predicted to rise by an additional $1-4{ }^{\circ} \mathrm{C}$ by the year 2100 (Hoegh-Guldberg et al. 2007). Although OA and warming are perhaps the most well-known consequences of $\mathrm{CO}_{2}$-induced climate change, other stressors such as sea-level rise, increased hypoxia events, significant changes to wave heights, upwelling intensity and duration, terrigenous nutrient runoff, and coastal salinity will also affect the near-shore marine landscape (Doney 2010; Gruber et al. 2012; Harley et al. 2012). Given the rapid oceanographic changes due to rising $\mathrm{CO}_{2}$ concentrations, research assessing the biological, geochemical, and community responses of marine organisms is imperative in order to better understand the socioeconomic and ecological consequences of climate change. 


\section{Chapter I}

Single-species consequences of warming and acidification on the temperate articulated coralline alga, Calliarthron cheilosporioides 


\begin{abstract}
Global climate change stressors such as warming and acidification are predicted to have negative effects on calcifying organisms. Species that precipitate more soluble forms of calcium carbonate are thought to be at higher risk to the detrimental effects of ocean acidification. Coralline red algae are abundant and ecologically important species known to precipitate the most soluble form of carbonate, high Mg-calcite. I assessed the impacts of warming and acidification on the articulated coralline red alga, Calliarthron cheilosporioides, inhabiting a temperate kelp forest in San Diego, CA. I found calcification is significantly reduced under high temperature (70\%) and further reduced by high $p \mathrm{CO}_{2}$ or high $p \mathrm{CO}_{2} \times$ temperature $(150 \%)$ conditions. Growth (as linear extension and surface area of new growth) was also significantly reduced by temperature ( $40 \%$ and $50 \%$ respectively), high $\mathrm{pCO}_{2}(20 \%$ and $40 \%$ respectively) and high $p \mathrm{CO}_{2} \times$ temperature (50\% and $75 \%$ respectively). The photophysiological parameter $\mathrm{P}_{\max }$ increased by $100 \%$ under high $p \mathrm{CO}_{2}$ conditions, but there was no effect of $p \mathrm{CO}_{2}$ or temperature on photosynthetic efficiency. Mineralogy was not affected by temperature or $p \mathrm{CO}_{2}$. However, variation in $\mathrm{Mg}$ incorporation in cell walls of different cell types (i.e., higher \%Mg in cortical than medullary cells) was documented for the first time in this species. These results support findings from a growing body of literature suggesting that coralline red algae are likely to be negatively affected by increased acidification and warming associated with climate change.
\end{abstract}




\section{Introduction}

The majority of marine research assessing the threats of $\mathrm{CO}_{2}$-driven global change has focused on the impacts of ocean acidification on marine calcifiers, such as commercially important bivalves, corals and tropical macroalgae, whose calcification has been shown to rely heavily on the saturation states of the biogenic carbonates precipitated (Kroeker et al. 2010; Ries 2011a). However, organisms inhabiting the lesser-studied subtropical and high latitude ecosystems are thought to be at higher risk for OA due to the naturally more corrosive, lower $\mathrm{pH}$, and lower saturation states of the seawater in which they live (Andersson et al. 2008). Furthermore, not all calcifying organisms are equally as vulnerable, even within the same genus (Price et al. 2011).

Calcifying organisms can differ in the relative isolation of the calcifying space and mineral composition of their skeletal material. Carbonate skeletons consisting of high Mg-calcite ( $\mathrm{mol} \% \mathrm{Mg}>4 \%$ ) are more soluble than those made of aragonite and calcite (Andersson et al. 2008). Organisms that secrete more soluble forms of calcium carbonate external to protective tissues may be even more vulnerable to the detrimental effects of OA (Ries et al. 2009). For these reasons, organisms that secrete high Mg-calcite and inhabit subtropical and high latitude ecosystems may be the first organisms to be impacted by ocean acidification.

$\mathrm{CO}_{2}$-induced global warming is predicted to have large negative impacts on many marine organisms. Temperature alters biological processes due to 
effects on metabolic rates and many physiological processes (Brown et al. 2004). Higher temperatures increase both photosynthetic (Yokohama 1973) and respiration rates, with the potential to increase calcification (Johnson and Carpenter 2012). These kinetic effects have been shown to result in higher growth rates in marine macrophytes in the field during seasonal warming (Keser et al. 2005). However, increases in temperature beyond a species' thermal optimum can also cause physiological stress and even mortality, as has been shown in temperate macroalgae (Schiel et al. 2004) or more commonly in scleractinian corals found on tropical coral reefs. Mass coral bleaching events due to warming have caused widespread mortality of corals and in some cases even complete collapse of coral reef ecosystems (Pandolfi et al. 2011). Therefore, ocean warming associated with climate change could provide benefits to organisms so long as temperatures remain within species-specific thermal tolerances, but could also have dire consequences to organisms with narrow thermal tolerances.

Coralline red algae (Corallinales, Rhodophyta) are calcifying macroalgae which secrete high Mg-calcite skeletons within their intracellular spaces (Borowitzka et al. 1974). They are ubiquitous members of coastal marine ecosystems around the world and provide structural support by acting as "cement" to bind reef substrate, refugia by providing habitat (articulated or branching forms), recruitment facilitation by producing settlement cues (e.g., Price 2010), and substrate for both intertidal and subtidal marine communities 
(Steneck 1986). Furthermore, calcification plays an important role in growth and herbivore deterrence (Büdenbender et al. 2011), preventing overgrowth and fouling by tissue sloughing (Littler and Littler 1995), and protection from UV radiation (Gao and Zheng 2009).

Due to their ecological importance on reefs and their sensitivity to environmental conditions, many studies have investigated the impacts of OA and/or warming on coralline red algae. As predicted, responses of corallines to global change stressors have largely been negative. These responses have included reduced recruitment (Kuffner et al. 2007), decreased calcification or increased dissolution (Anthony et al. 2008; Jokiel et al. 2008; Martin et al. 2008; Gao and Zheng 2009; Martin and Gattuso 2009; Ries et al. 2009; Büdenbender et al. 2011; Hofmann et al. 2011; Diaz-pulido et al. 2012; Johnson and Carpenter 2012; Ragazzola et al. 2012; Johnson et al. 2014; Kram et al. 2015), decreased photosynthetic efficiency (Anthony et al. 2008; Gao and Zheng 2009; Hofmann et al. 2011), bleaching (Anthony et al. 2008), and weakening of the skeletal structure (Ragazzola et al. 2012).

Despite a convincing body of literature showing negative responses of coralline red algae to $\mathrm{OA}$, a few studies have also found that some corallines may be more resilient than previously thought. Egilsdottir et al. (2012) found that respiration, gross primary production, and calcification were not significantly affected by elevated $p \mathrm{CO}_{2}$ (up to $1000 \mu \mathrm{atm}$ ) in the intertidal alga, Corallina elongata. The authors suggest that this may be due, in part, to the dynamic 
intertidal environment in which the alga has evolved to survive. Non-linear physiological responses to OA have also been found in some coralline red algae (Ries et al. 2009; Johnson and Carpenter, 2012). In these studies, growth and calcification increased in moderately elevated $p \mathrm{CO}_{2}$ but declined at higher $p \mathrm{CO}_{2}$ levels. These findings are consistent with work by Borowitzka (1981) who found that calcification rates in coralline algae are greatly influenced by external carbonate ion concentration and photosynthetic rates. At higher $p \mathrm{CO}_{2}$, algae are able to increase photosynthetic rates due to the increased abundance of $\mathrm{CO}_{2}$ and $\mathrm{HCO}_{3}{ }^{-}$ions. However, a threshold exists where the benefits of increased $\mathrm{CO}_{2}$ for photosynthesis do not outweigh the decrease in carbonate ion availability for calcification. It's likely that species inhabiting naturally elevated or more variable $p \mathrm{CO}_{2}$ seawater conditions may optimize photosynthesis and calcification at higher $p \mathrm{CO}_{2}$.

Climate change stressors will likely have numerous effects on coralline red algal growth, calcification and mineralogy. Some species of corallines have also been documented to change the mineral composition of their skeletons, by reducing the mole $\% \mathrm{Mg}$ incorporated into their $\mathrm{Mg}$-calcite skeletons, under elevated $p \mathrm{CO}_{2}$ (Ries 2011; Egilsdottir et al. 2012). Since the solubility of Mgcalcite is positively correlated with increasing mole \% Mg (Andersson et al. 2008), species that exhibit mineralogical plasticity may be more resilient to OA. However, until we understand how this process affects overall growth and 
survivorship, it is unclear whether it functions as a short-term coping mechanism or a longer-term solution to OA.

Positive correlations have been found between the Mg content of biominerals and temperature (Stanley and Hardie 1998; Andersson et al. 2008). Since some crustose coralline algae (CCA) produce annual banding patterns, analogous to rings on a tree (dendrochronology); variation with respect to the elemental composition of the skeletal material can be correlated with differences in the abiotic environment during the time of precipitation. Biomineral heterogeneity within long-living CCA has therefore been used to reconstruct paleoclimates using mole $\% \mathrm{MgCO}_{3}$ and $\mathrm{SrCO}_{3}$ as proxies for sea surface temperatures (Kamenos et al. 2008; Kamenos and Law 2010). Far less is known about the interactive effects of warming and OA on mineral composition. Importantly, increased temperature may further stress organisms trying to maintain Mg-calcite skeletons under OA due to increased incorporation of $\mathrm{Mg}$ into the calcite lattice.

Additionally, recent work on tropical coralline red algae by Nash et al. (2011) discovered the presence of Mg-rich biogenic carbonates (protodolomite, magnesite), previously thought to form only during diagenetic processes (e.g., high heat and pressure). These mineral forms are more stable than calcite and therefore may make the skeletons of these organisms more resistant to dissolution (Nash et al. 2012). However, these minerals are yet to be found in any temperate algal species. It is uncertain whether this is due to the scarcity of 
work using newly developed techniques, which offer higher resolution, or due to some other environmental or physiological mechanism preventing their precipitation. In general, little is known about fine scale variability in biominerals throughout the algal thallus, however, this variation may be critical for the survival of coralline red algae in a changing ocean.

Although many climate change stressors will occur simultaneously, fewer studies have measured their interactive effects on marine organisms compared with those that have measured the effects of a single variable alone. Since multiple stressors can act additively, synergistically and antagonistically, in order to accurately forecast the impacts of climate change on marine organisms it is important for future studies to incorporate a multi-stressor framework (Harley et al. 2012; Harvey et al. 2013; Kroeker et al. 2013). Given that OA and warming will most certainly affect basic physiological and biological processes, these two abiotic changes are an obvious starting point in testing the interactive effects of multiple climate change stressors on coastal marine organisms.

Studies that have measured the interactive effects of increasing temperature and OA suggest that the effects of both stressors may be multiplicative and therefore studies that focus on OA or warming alone may underestimate the impacts of future environmental conditions on organismal physiology and ecology (Hoegh-Guldberg et al. 2007; Anthony et al. 2008; DiazPulido et al. 2012; Johnson and Carpenter 2012). A recent meta-analysis concluded that the combined effects of $\mathrm{OA}$ and warming had a significant 
negative effect on calcification, survival and reproduction across a wide range of taxa with the magnitude of response greater than that observed for the stressors in isolation (Harvey et al. 2013). Furthermore, concurrent OA and warming had no effect on growth, but a significant positive effect on photosynthesis in autotrophs (Harvey et al. 2013).

The aim of this chapter is to address the following questions: 1) How will $\mathrm{OA}$ and warming affect the growth, calcification and mineralogy of the abundant coralline red alga, Calliarthron cheilosporioides, inhabiting California's temperate rocky reefs? I hypothesized that 1) high $p \mathrm{CO}_{2}$ and warming would decrease growth and calcification rates with their interaction being multiplicative; 2) high $\mathrm{pCO}_{2}$ will decrease the $\mathrm{mol} \% \mathrm{Mg}$ incorporated into biominerals, but high temperature will increase the $\mathrm{mol} \% \mathrm{Mg}$, with an unknown interaction; 3) high $p \mathrm{CO}_{2}$ and warming will increase photosynthetic efficiency, with their interaction being multiplicative.

\section{Materials and Methods}

\section{Study Site and Collections}

The articulated coralline red alga, Calliarthron cheilosporioides, was collected subtidally ( $\sim 13 \mathrm{~m}$ depth) using SCUBA at Mia's Reef in San Diego, CA ( $\left.\mathrm{N} 32^{\circ} 51^{\prime} 14.8^{\prime \prime}, \mathrm{W} 117^{\circ} 16^{\prime} 52.4^{\prime \prime}\right)$ due to proximity of the experimental rearing facilities at Scripps Institution of Oceanography (SIO). C. cheilosporioides individuals were gently dislodged from the substrate with holdfasts intact. This 
articulated coralline, abundant on subtidal reefs from southern to central California, has been found to release chemical cues for the settlement of invertebrate larvae and create habitat for juvenile purple sea urchins (Harrold et al. 1991). Unlike slower growing coralline crusts, C. cheilosporioides, has been shown to have fast growth rates up to $1.8 \mathrm{~cm}^{2}$ per month (Martone 2010). C. cheilosporioides was chosen for this study due to its importance for temperate reefs, wide spatial distribution, and fast growth rates which provided adequate new growth over the duration of our experiment.

An autonomous pH and temperature logger, SeaFET (Martz et al. 2010), was deployed at Mia's Reef to record continuous high-resolution (every $15 \mathrm{~min}$ ) $\mathrm{pH}$ and temperature measurements to improve understanding of natural fluctuations at my site and aid in the interpretation of experimental results. Photosynthetically active radiation (PAR) was also measured in situ (every half hour) within the kelp forest at $\sim 13 \mathrm{~m}$ depth using a LICOR 4-T quantum sensor (Biospherical, Inc.).

\section{Seawater Bubbling System}

Ocean acidification studies to date have mostly been conducted using preequilibrated seawater to simulate stable changes in $\mathrm{pH}$ and carbonate chemistry predicted to occur by the end of the century. However, relatively recent technological advances have made it possible to better understand fluctuations in $\mathrm{pH}$ in nearshore coastal environments. Unlike open-ocean environments, which 
have been used to model predicted future ocean conditions, near-shore environments show much more variable $\mathrm{pH}$ conditions due to biological activity (i.e., photosynthesis, respiration, calcification) and terrestrial influences (Frieder et al. 2012; Hofmann et al. 2011; Price et al. 2012). These studies have shown that some organisms in nearshore regions are already periodically exposed to $\mathrm{pH}$ conditions predicted by the year 2100 in the global ocean surface waters. Therefore, predictions made on open-ocean conditions may not be indicative of future conditions that will occur in nearshore environments. In order to better simulate the possible impacts of OA on nearshore ecosystems, I used a state-ofthe-art seawater bubbling system that manipulates $p \mathrm{CO}_{2}$ and temperature on top of natural coastal variability. By maintaining a constant bubbling rate and seawater flow, $p \mathrm{CO}_{2}$ was increased by predicted magnitudes on top of naturally fluctuating seawater chemistry. This method more accurately mimics the potential effects of $\mathrm{OA}$ in the coastal environment by altering $\mathrm{pH}$ and carbonate chemistry on top of natural variability occurring over diel, semi-diurnal, and event (day-week) time scales.

The seawater bubbling system bubbles $\mathrm{CO}_{2}$ into individual mesocosms supplied with flow-through seawater pumped directly from the SIO pier. Individual specimens of $C$. cheilosporioides $(\sim 1 \mathrm{~g})$ were placed in 1-liter glass mason jars (mesocosms). Specimens ( $n=7$ per treatment) were randomly allocated to one of four treatment levels. Treatment $p \mathrm{CO}_{2}$ conditions were created by continuously bubbling a $\mathrm{CO}_{2}$-air gas blend into each individual 
mesocosm at a rate that lowers the $\mathrm{pH}$ by $0.4 \pm 0.05$ units. This treatment $\mathrm{pH}$ was chosen to represent future ocean conditions by the year 2100 as specified by the IPCC's A2 emission scenario (IPCC 2007). Ambient mesocosms were also supplied with air originating from the same source as the $\mathrm{CO}_{2}$-air gas blend used in the treatment conditions. Half of the aquaria were maintained at ambient temperature $\left(\sim 13^{\circ} \mathrm{C}\right)$ and half at $3^{\circ} \mathrm{C}$ above ambient $\left(\sim 16^{\circ} \mathrm{C}\right)$ for the duration of the experiment. Experimentally elevated temperatures were maintained in 3 replicate water baths, wherein mesocosms were immersed in seawater with submersible aquarium heaters. Ambient temperature mesocosms were placed in water baths $(n=3)$ of ambient temperature water to control for the effects of the water bath. Photoperiod was set to $12: 12$ day:night cycle for the entirety of the experiment.

Temperature and $\mathrm{pH}$ data were collected daily at midday (13:00 PST \pm 2 hours) in all aquaria using a $\mathrm{HACH} H Q 40 d$ handheld glass electrode $\mathrm{pH}$ probe calibrated each day with certified Tris buffer from the lab of Dr. Andrew Dickson at SIO. Minor adjustments were made to bubbling rates in individual aquaria if the experimental $\mathrm{pH}$ drifted above or below the desired $0.4 \pm 0.05$ units below ambient. Honeywell's Durafet non-glass $\mathrm{pH}$ probe logged $\mathrm{pH}$ and temperature every 15 minutes in one control mesocosm (i.e., no algal sample) at each treatment level for the duration of the experiment. Honeywell's Durafet lon Sensitive Field Effect Transistor (ISFET) technology has been shown to remain stable for long periods of time (Martz et al. 2010), and therefore was not 
calibrated daily. These $\mathrm{pH}$ sensors logged treatment conditions continuously in order to observe diurnal cycles in flow-through seawater conditions that may otherwise be missed from single point observations. To monitor carbonate chemistry parameters in the experiments (i.e., dissolved inorganic carbon, total alkalinity, and salinity), discrete water samples were collected in $500 \mathrm{~mL}$ Corning brand pyrex sample bottles at the beginning, middle and end of each experiment and immediately spiked with $120 \mu \mathrm{L}$ of saturated $\mathrm{HgCl}_{2}$ solution (1\% headspace); these samples also served as calibration standards for the Durafet sensors. In order to assure that algal samples did not alter seawater chemistry within mesocosms, discrete water samples were taken from three control jars (without samples) and two randomly assigned specimen jars from each treatment at the beginning, middle, and end of the experiment. Total dissolved inorganic carbon $\left(\mathrm{DIC}_{\mathrm{T}}\right)$ was measured using a Single Operator Multi-parameter Metabolic Analyzer (SOMMA) in the laboratory of Dr. Andrew Dickson (SIO). Total alkalinity $\left(A_{T}\right)$ was measured via open cell acid titration using a Metrohm Dosimat Model 665 and Thermo Scientific Ross potentiometric $\mathrm{pH}$ probe and meter. Carbon species were calculated based on measured $\mathrm{DIC}_{T}$ and $\mathrm{A}_{T}$ using CO2SYS and stoichiometric dissociation constants defined by Mehrbach et al. (1973) and refit by Dickson and Millero (1987). 


\section{Physiological and Mineralogical Responses of Coralline Algae}

To assess changes in physiology and mineralogy of coralline algae due to climate change, specimens were reared in the laboratory under two different $p \mathrm{CO}_{2}$ levels (ambient $=\sim 450 \mu \mathrm{atm}$, high $\left.=\sim 1800 \mu \mathrm{atm}\right)$ and two different temperature levels (ambient $=\sim 13^{\circ} \mathrm{C}$, high $\left.=\sim 16^{\circ} \mathrm{C}\right)$ in a multifactorial design resulting in four different treatment conditions: (1) ambient temperature, ambient $p \mathrm{CO} 2$, (2) high temperature, ambient $p \mathrm{CO}_{2}$, (3) ambient temperature, high $p \mathrm{CO}_{2}$, and (4) high temperature, high $p \mathrm{CO}_{2}$, simulating a suite of possible future ocean conditions.

\section{Growth}

All laboratory experiments manipulating temperature and $\mathrm{pH}$ were conducted in the state-of-the-art flow-through seawater system described above. Samples were placed into holding tanks with flow-through seawater where they were acclimated to ambient laboratory conditions for two weeks. 24 hours before the start of the experiment, samples were placed in a $1 \mathrm{~L}$ beaker with $0.02 \%$ Calcofluor white (Fluorescent Brightener 28, Sigma-Aldrich) in seawater for 5 minutes in order to stain initial tips before skeletal material is deposited in response to treatment conditions. This method has been used by Martone (2010) to permanently incorporate the fluorescent dye into the calcium carbonate of growing tips and allow for future measurements of new growth. 
To measure growth, linear extension and surface area were also calculated for each individual. Samples were visualized using a dissecting scope and illuminated with an ultraviolet lamp $(315-400 \mathrm{~nm})$ to visualize calcofluor stain. Calcofluor stained tips were randomly selected and removed at the closest genicula behind the leading edge of the stain using forceps. Photographs were taken of three replicate growing tips in Image Pro Plus Software (Media Cybernetics, Inc.) using a Leica microsystems camera fitted to a Leica MZ 125 dissecting scope. The field of view was calibrated using an objective micrometer $(0-1 \mathrm{~mm} / 100)$ and the length from the apex of the stained region to the tip of the branch was measured to obtain linear extension (Fig. 1). From these same photographs, planar area was also calculated as the surface area of new growth after the calcofluor arch (Fig. 2). All three tip measurements per individual were for pooled for subsequent statistical analyses. 


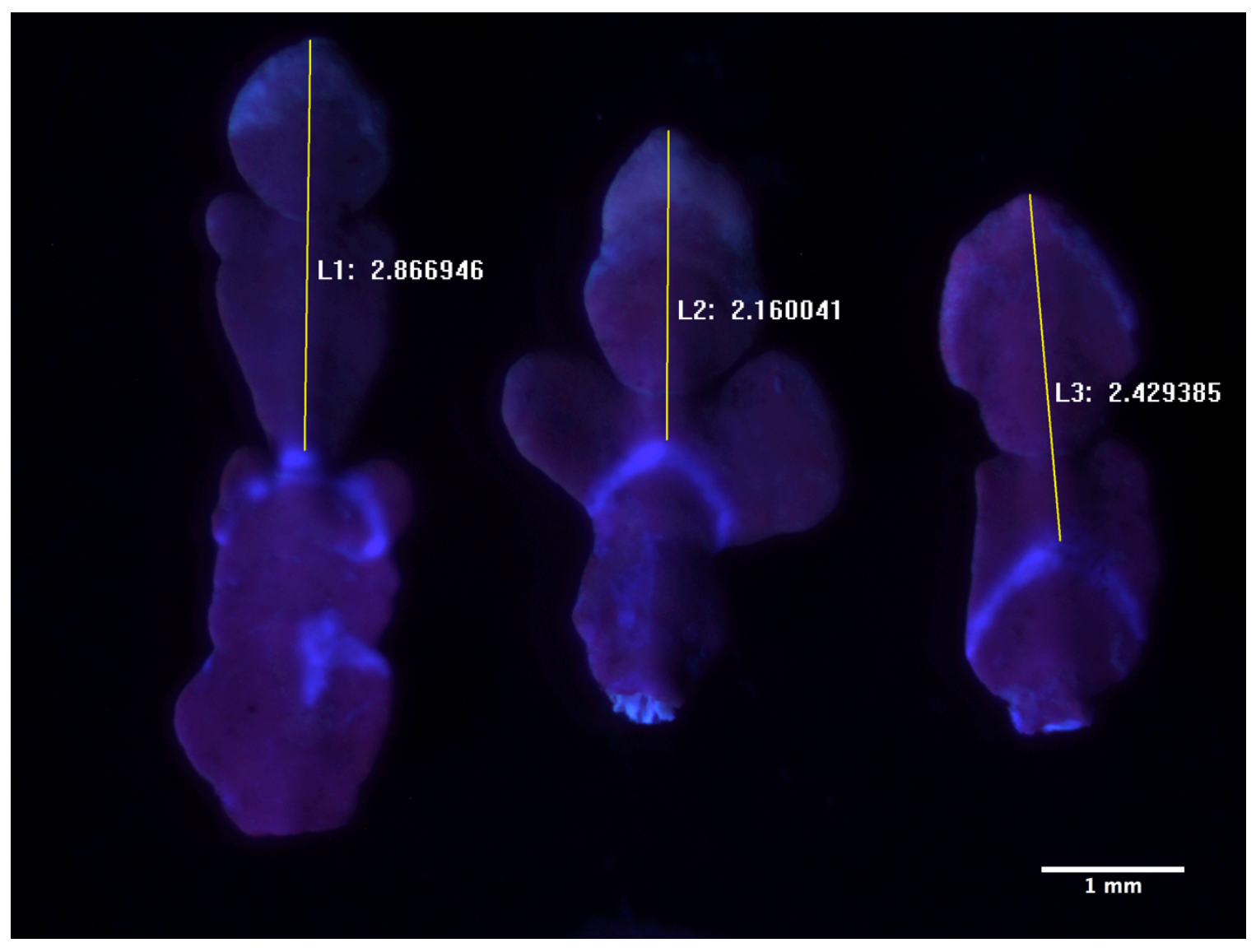

Figure 1. Calcofluor stained region is depicted as fluorescent blue arch on three growing tips from $C$. cheilosporioides. Yellow lines show linear extension measurements of new growth material during experimental rearing $(\mathrm{L} 1, \mathrm{~L} 2, \mathrm{~L} 3=$ linear extension in $\mathrm{mm}$ ). 


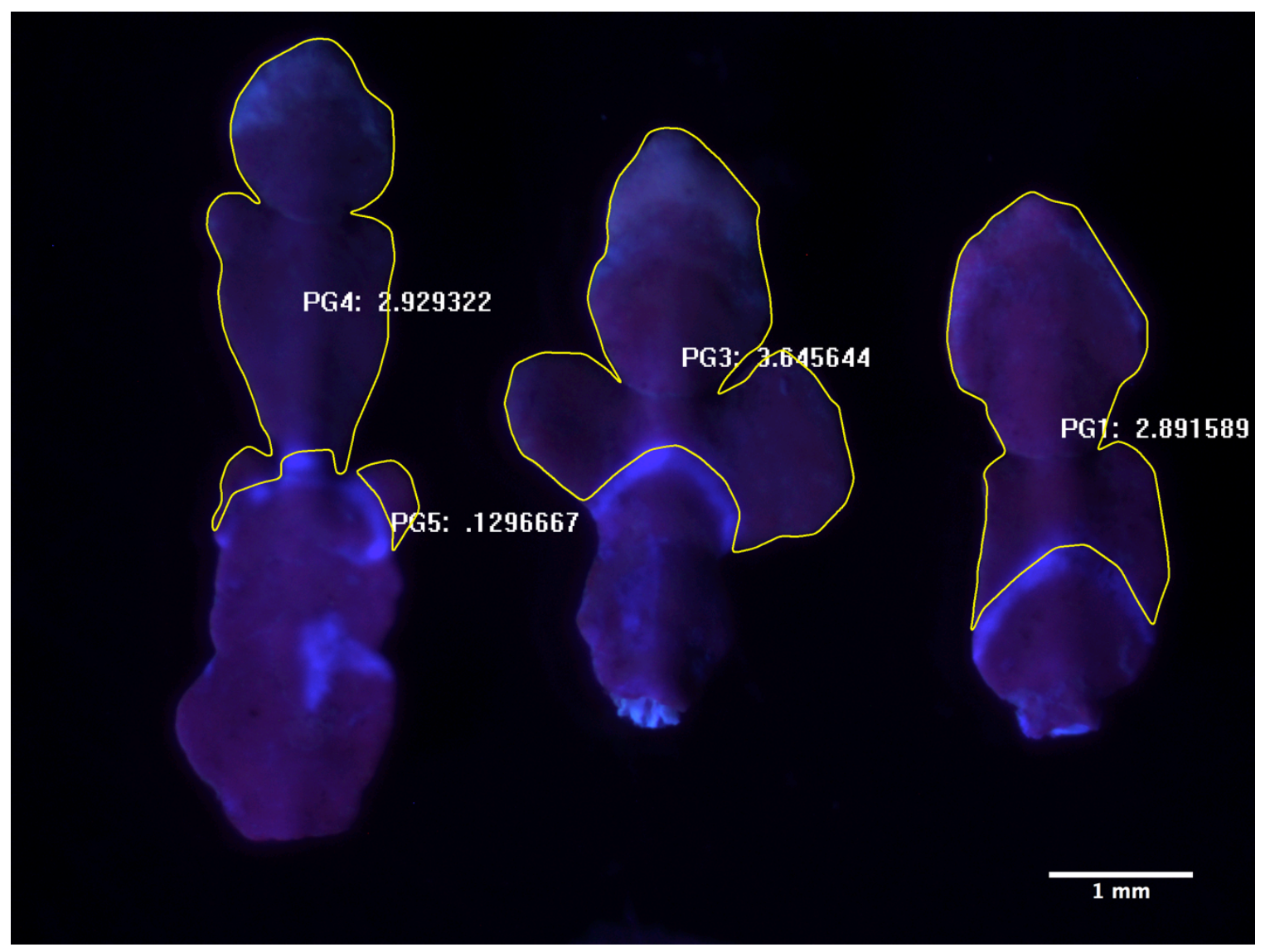

Figure 2. Surface area measurements of new growth material during experimental rearing. Yellow lines show planar surface area beyond the calcofluor white staining marker (PG1, PG3, and PG4+PG5 = surface area of new growth in $\mathrm{mm}^{2}$ ).

To measure calcification rates, all specimens were first cleaned of epiphytes by gentle removal using forceps and a soft-bristled brush and then were weighed using the buoyant weight method at the beginning and end of each experiment. Samples were placed in a metal basket completely submerged in seawater. The metal basket was attached to monofilament line and suspended from a weigh-below balance. The buoyant weight method was used since it has been found to be more accurate at measuring the weight of calcified algae than 
other methods since it does not take into account the weight of fleshy material that are less dense than water (Davies 1989). Percent change in weight was calculated as, $\frac{W_{f}-W_{i}}{W_{i}}$, where $W_{i}$ is the initial weight and $W_{f}$ is the final weight.

\section{Photophysiology}

In order to compare differences in photosynthetic efficiency, photophysiological parameters were calculated experimentally. Samples from each treatment level $(n=3)$ were randomly selected and placed in individual 1.5 $\mathrm{L}$ polycarbonate containers and covered with a polycarbonate lid with an airtight rubber seal. One container with no sample (control) was also covered to control for changes in dissolved oxygen concentrations due to water column processes. $p \mathrm{CO}_{2}$ conditions at the beginning of the incubations were obtained by bubbling either air or the same $\mathrm{CO}_{2}$-air gas blend used during the experiment into a $20 \mathrm{~L}$ carboy until the desired $\mathrm{pH}$ was obtained. Containers were incubated in the light (irradiances: 19, 36, 60, 103, 178, 198, 344, 392 and $500 \mu \mathrm{mol} \mathrm{m}^{-2} \mathrm{~s}^{-1}$ ) and dark $\left(0 \mu \mathrm{mol} \mathrm{m} \mathrm{m}^{-2}\right)$ for 45 minutes. In between each light step, containers were opened and seawater was fully replenished. Temperature was held constant and similar to treatment conditions (i.e., ambient and high [ambient $\left.+3^{\circ} \mathrm{C}\right]$ ) for the duration of each incubation by submerging containers in a water bath maintained with flow-through seawater held at the desired temperature. Magnetic stir bars continuously stirred seawater within each container to disrupt diffusive boundary 
layers. Dissolved oxygen was measured at the beginning and end of each incubation using a HACH 40D dissolved oxygen (DO) probe. Net production or respiration ( $N P$ (or $R$ ), $\mu \mathrm{mol} \mathrm{O}_{2} \mathrm{~g}^{-1} \mathrm{~h}^{-1}$ ) was calculated by plotting DO versus time at time $t_{0+10}$ to $t_{0+20}$, where $t_{0}$ indicates the sealing of the incubation chamber and each time step is one minute in duration. $N P($ or $R$ ) is the slope of the linear regression fit at each light level. To calculate photophysiological parameters NP vs Irradiance data were fit to the equation:

$$
N P=P_{\text {max }} *\left(1-\mathrm{e}^{\frac{-\alpha * I}{P_{\text {max }}}} * \mathrm{e}^{\frac{-\beta * x}{P_{\text {max }}}}\right)
$$

where $P_{\max }$ is the maximum photosynthetic rate, $\alpha$ is the photosynthetic efficiency, and $\beta$ is the irradiance at which photoinhibition begins.

\section{Mineralogy}

A Hitachi 3400n Scanning Electron Microscope (SEM) with attached INCA Energy 250 Energy Dispersive X-ray Spectrometer (EDS) was used to examine the spatial and structural variability in biomineralization, and changes to the mol $\% \mathrm{Mg}$ incorporated into biominerals. Using EDS, $\mathrm{Mg}^{2+}$ and $\mathrm{Ca}^{2+}$ concentrations were measured in the calcified cell walls surrounding both medullary and cortical cells (Fig. 3). Immediately following final calcification measurements (buoyant weighing), samples were placed in a drying oven at $60^{\circ} \mathrm{C}$ for 48 hours. Each sample was visualized under a dissecting microscope with UV light projected onto the sample to visual the calcofluor white stain. Using forceps and a razor blade, thallus material deposited after the fluorescent dye marker was removed 
from tips of two different branches and placed aside for subsequent SEM and EDS analysis. Each subsample was secured to an individual SEM stub with Epotek resin, polished and gold coated. Differences in the composition of $\mathrm{Mg}^{2+}$ and $\mathrm{Ca}^{2+}$ incorporated into biogenic carbonates was quantified by conducting spot analysis at nine points underlying a $3 \times 3$ grid matrix. At each spot the identity of the cell type (cortical versus medullary) was recorded. These analyses were conducted on two separate branch tips for each individual. To reduce error in measurements of $\mathrm{Mg}^{2+}$ and $\mathrm{Ca}^{2+}$ only spot analyses with a Wt \% equal to $80-$ 120 were considered. The mol \% Mg at each spot analysis was calculated as $\frac{A t \% M g}{A t \% M g+A t \% C a} \times 100$, where $A t \% M g$ and $A t \% C a$ are determined from EDS. For each individual, mol \% Mg from 3 spot analyses for each cell type, corresponding to those closest to a $\mathrm{Wt} \%=100$, were pooled for subsequent statistical analyses. 


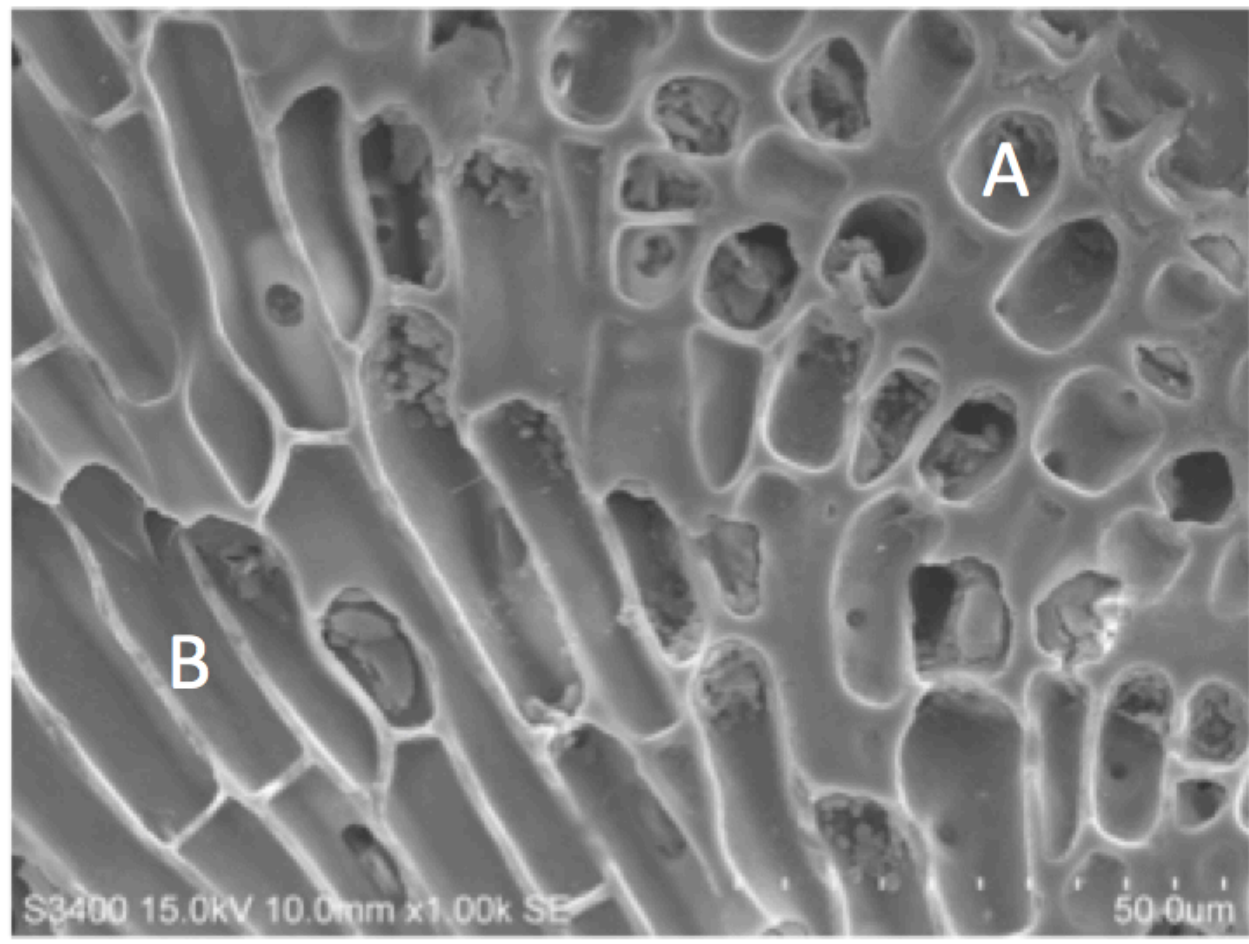

Figure 3. Scanning electron microscopy (SEM) image at 1000x. Image depicts more circular cortical cells (A) and more elongate internal medullary cells (B).

\section{Statistical Methods for Coralline Algae Experiments}

Experimental results from coralline rearing experiments were analyzed using two-way ANOVAs with fixed factors of $\mathrm{pCO}_{2}$ and temperature. The response variables tested were: calcification rate; linear extension; surface area; and mol \% Mg. Shaprio-Wilkes (W) was calculated on the residuals to test for normality and homogeneity of variances (Shapiro and Wilk 1965). In the case where a response variable did not meet the assumptions of normality, it was square root transformed and analyses were rerun on transformed data. A twosample t-test was used to compare differences between mol \% Mg of cortical and 
medullary cells pooled across treatments. A two-way ANOVA, with fixed factors of $p \mathrm{CO}_{2}$ and temperature, was run on photophysiological parameters $P_{\max }$ and $\alpha$.

\section{Results}

\section{Experimental Conditions}

Four distinct $p \mathrm{CO}_{2} \times$ temperature treatments were maintained for the duration of the 28-day experiment (Table 1-2; Fig. 4). Ambient $p \mathrm{CO}_{2}$ treatments were approximately $0.40 \mathrm{pH}$ units higher and $\sim 1200 \mu$ atm lower than the high $p \mathrm{CO}_{2}$ treatments. Ambient temperature treatments were roughly $3^{\circ} \mathrm{C}$ lower than the high temperature treatments. In situ measurements of $\mathrm{pH}$ and temperature from autonomous SeaFET loggers at Mia's reef recorded a mean $\mathrm{pH}=8.02$ and mean temperature $=15.28^{\circ} \mathrm{C}$ from October 23, $2013-$ April 12, 2014 (Table 1; Fig. 5).

Mean peak irradiance levels in treatment conditions were approximately $23 \mu \mathrm{mol} \mathrm{m} \mathrm{sec}^{-1}$, while in situ measurements of peak irradiance recorded at Mia's reef were $\sim 65 \mu \mathrm{mol} \mathrm{m}{ }^{-2} \mathrm{sec}^{-1}$ from October 6, 2013 to October 25, 2013 (Table 1; Fig. 6). 


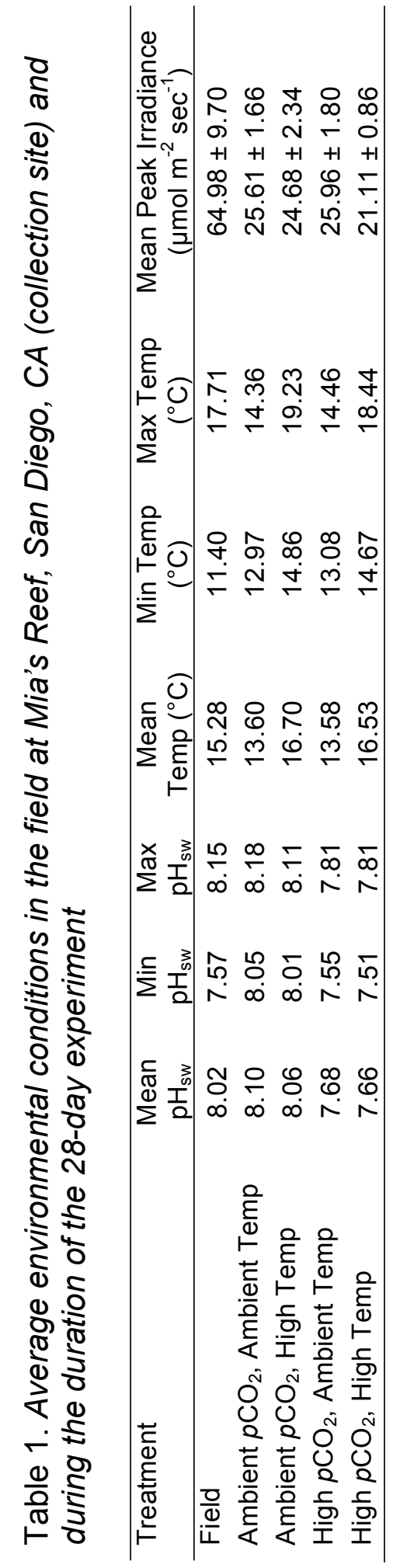




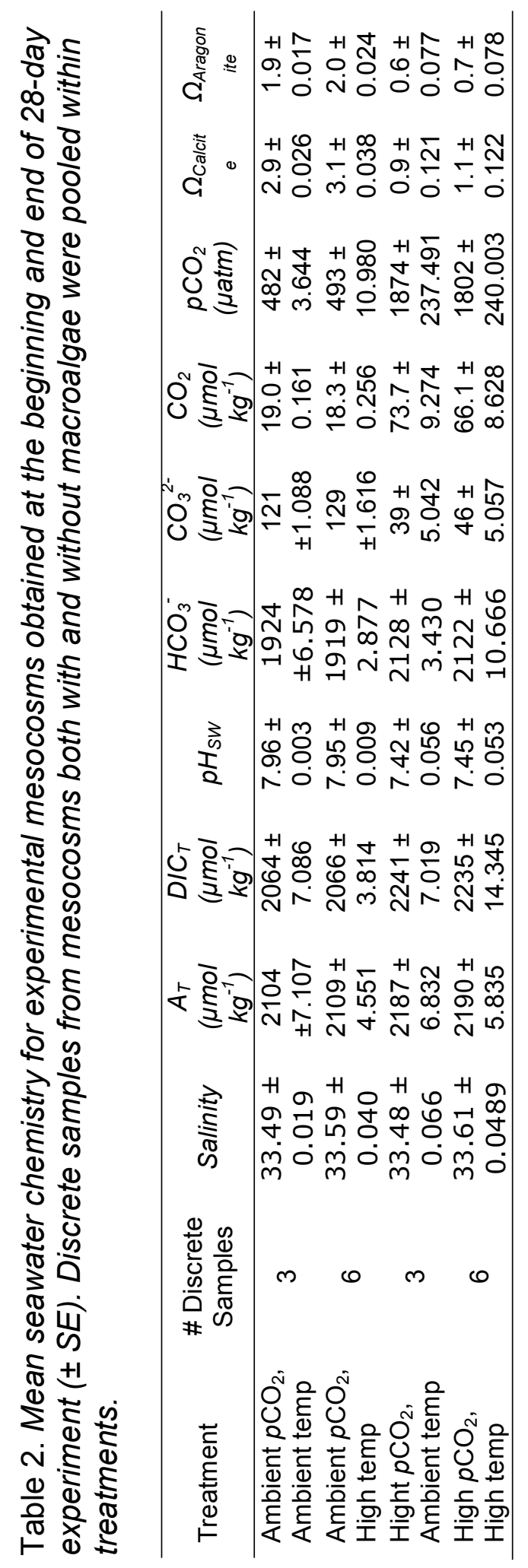



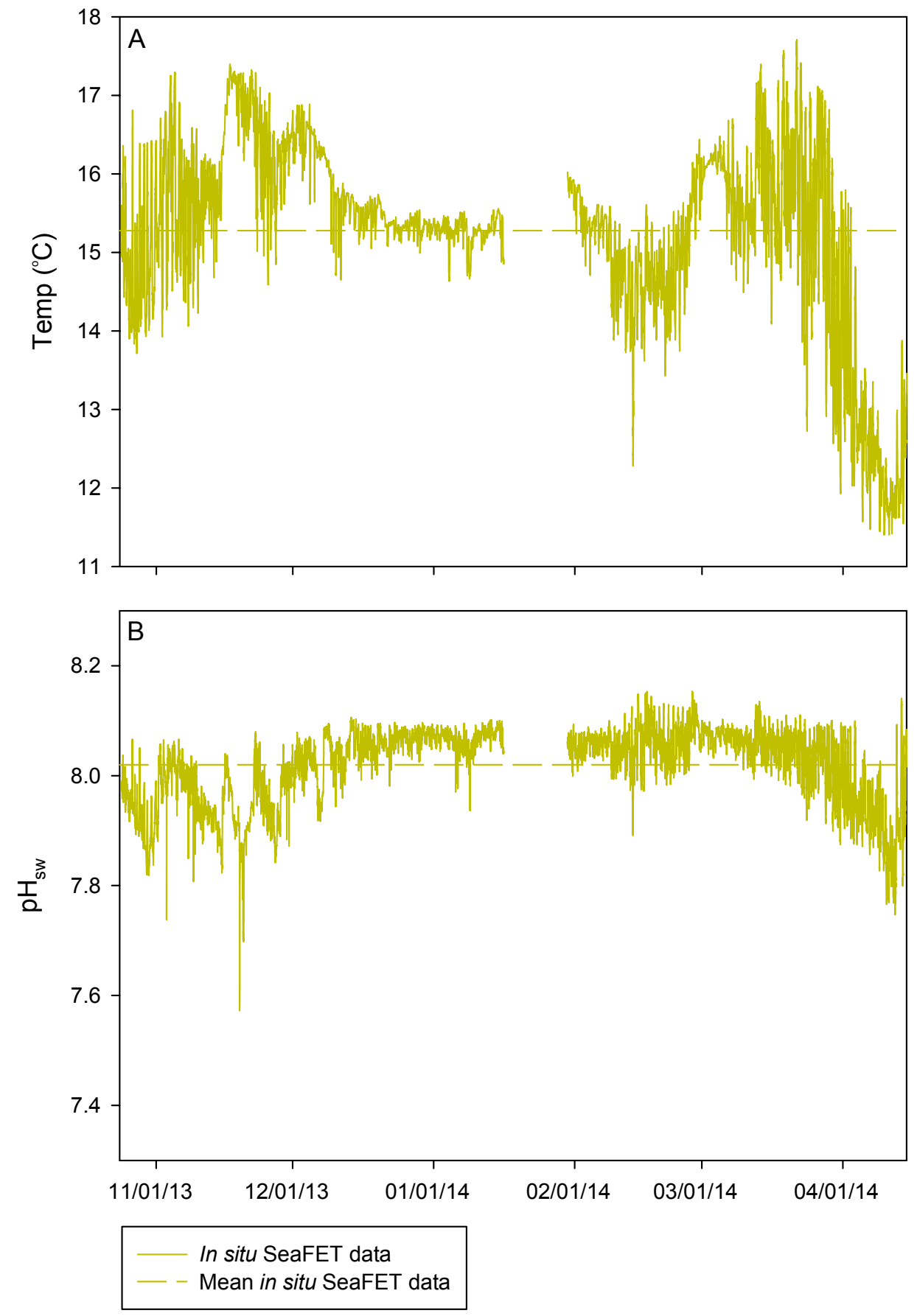

Figure 4. In situ $\mathrm{pH}$ and temperature data collected from autonomous SeaFET sensor deployed at Mia's Reef, San Diego, CA. Instrument was deployed at $15 \mathrm{~m}$ and data were collected every $15 \mathrm{~min}$. Panel A shows temperature $\left({ }^{\circ} \mathrm{C}\right)$. Panel B shows $\mathrm{pH}_{\mathrm{sw}}$. 


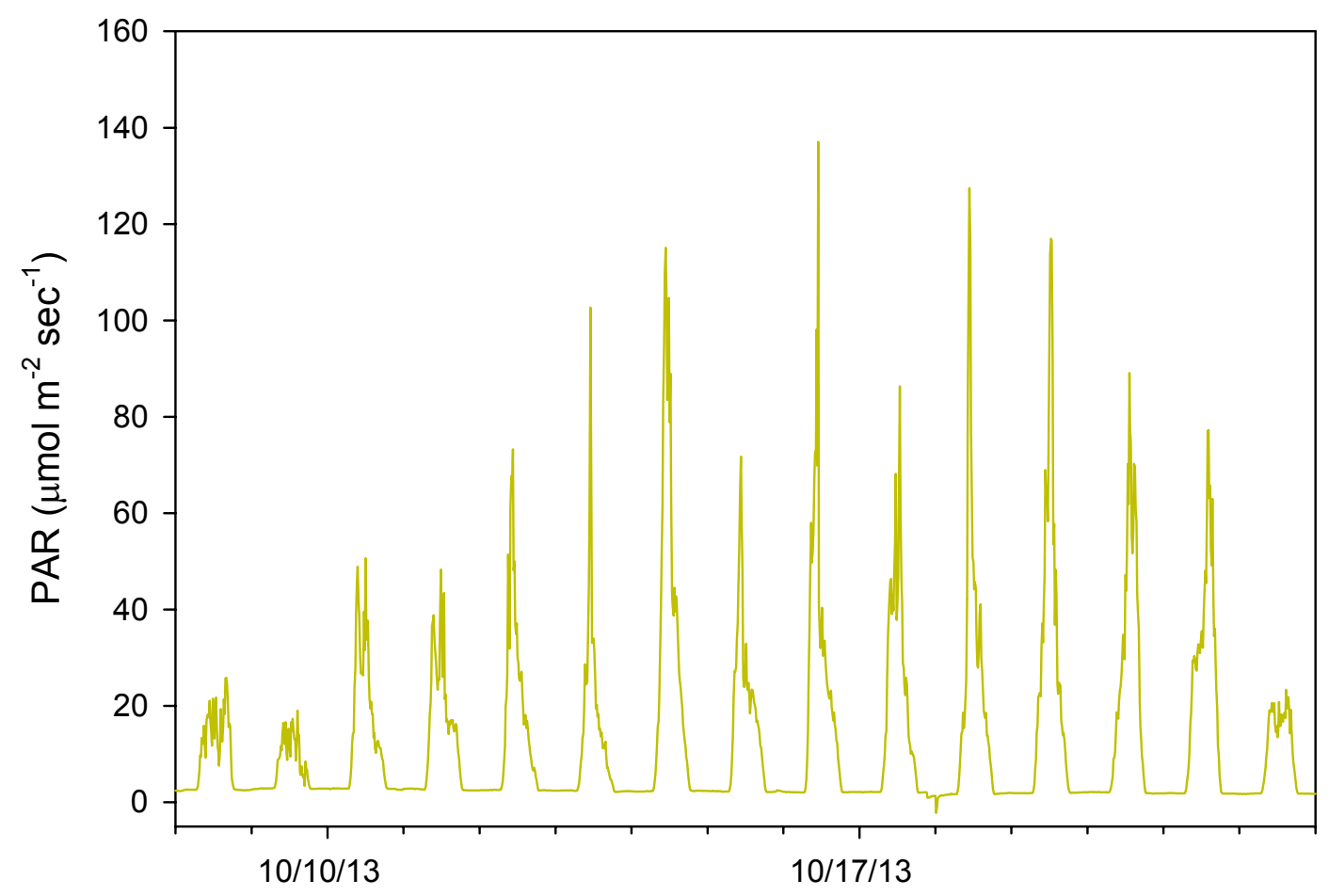

$$
\text { __ In situ PAR at Mia's Reef, San Diego, CA }
$$

Figure 5. In situ irradiance measurements (PAR) at Mia's Reef, San Diego, CA from October 6, 2013 to October 25, 2013. 

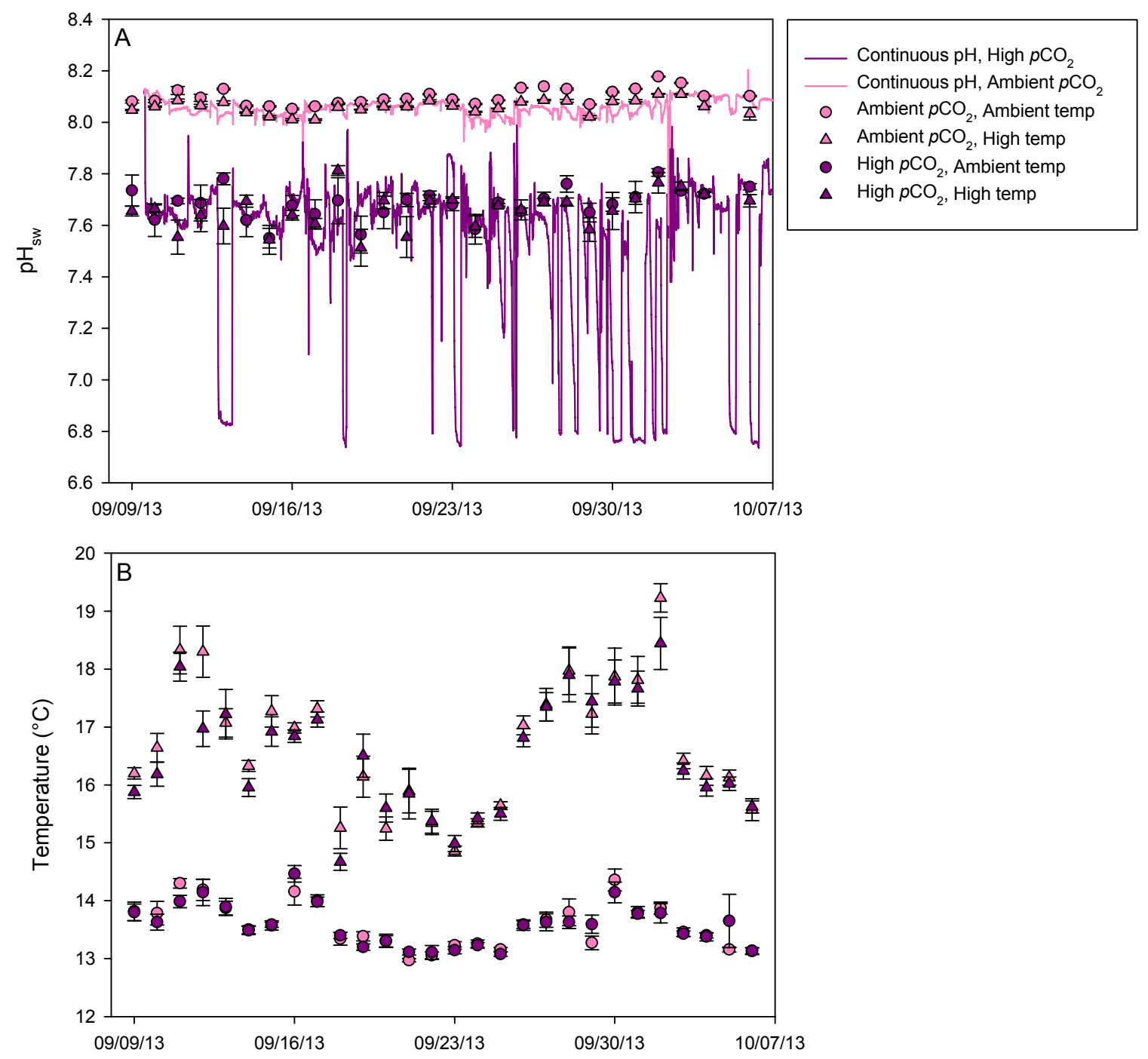

Figure 6. Daily experimental $\mathrm{pH}$ and temperature conditions in mesocosms for the duration of the 28-day experiment. Panel $\mathrm{A}$ shows $\mathrm{pH}_{\mathrm{sw}}$, with symbols representing average daily $\mathrm{HACH} \mathrm{pH}$ glass electrode measurements \pm s.e.m. Solid lines represent continuous $\mathrm{pH}$ measurements from Honeywell Durafet. Panel $\mathrm{B}$ shows average daily $\mathrm{HACH}$ temperature measurements \pm s.e.m. 


\section{Growth}

I observed a substantial reduction in buoyant weight of $C$. cheilosporioides in the high $p \mathrm{CO}_{2}$ treatments over the course of the experiment, regardless of temperature (Fig. 7). Buoyant weight was also negatively affected by increasing temperature in the ambient $\mathrm{CO}_{2}$ treatment (Table 3; Fig. 7), but the interaction was not significant (Table 3; Fig. 7). Under ambient $p \mathrm{CO}_{2}$ conditions, increased temperature reduced calcification rates (i.e., change in buoyant weight) by roughly $70 \%$, but still resulted in net positive growth of individuals. In contrast, high $p \mathrm{CO}_{2}$ treatments resulted in net dissolution of $\mathrm{CaCO}_{3}$ over the 28-day experiment, with no difference in dissolution rates between individuals reared in high $p \mathrm{CO}_{2}$ and either temperature treatment (i.e. there was no additive effect on calcification). This corresponds to a $\sim 150 \%$ reduction in $\mathrm{CaCO}_{3}$ in high $p \mathrm{CO}_{2}$ conditions in either temperature treatment compared to ambient $p \mathrm{CO}_{2}$, ambient temperature conditions.

Table 3. ANOVA results for the effects of $\mathrm{pCO}_{2}$ (ambient and high) and temperature (ambient and high) on the change in buoyant weight of $\mathrm{C}$. cheilosporioides

\begin{tabular}{lcccc}
\hline Source of variation & $d f$ & Sum of squares & $F$-statistic & $P$-value \\
\hline$p \mathrm{CO}_{2}$ & 1 & 8.643 & 76.128 & $<0.0001$ \\
$\mathrm{Temp}$ & 1 & 0.803 & 7.074 & $\mathbf{0 . 0 1 4}$ \\
$p \mathrm{CO}_{2} \times$ Temp & 1 & 0.209 & 1.840 & 0.188 \\
Error & 24 & 2.725 & & \\
\hline
\end{tabular}




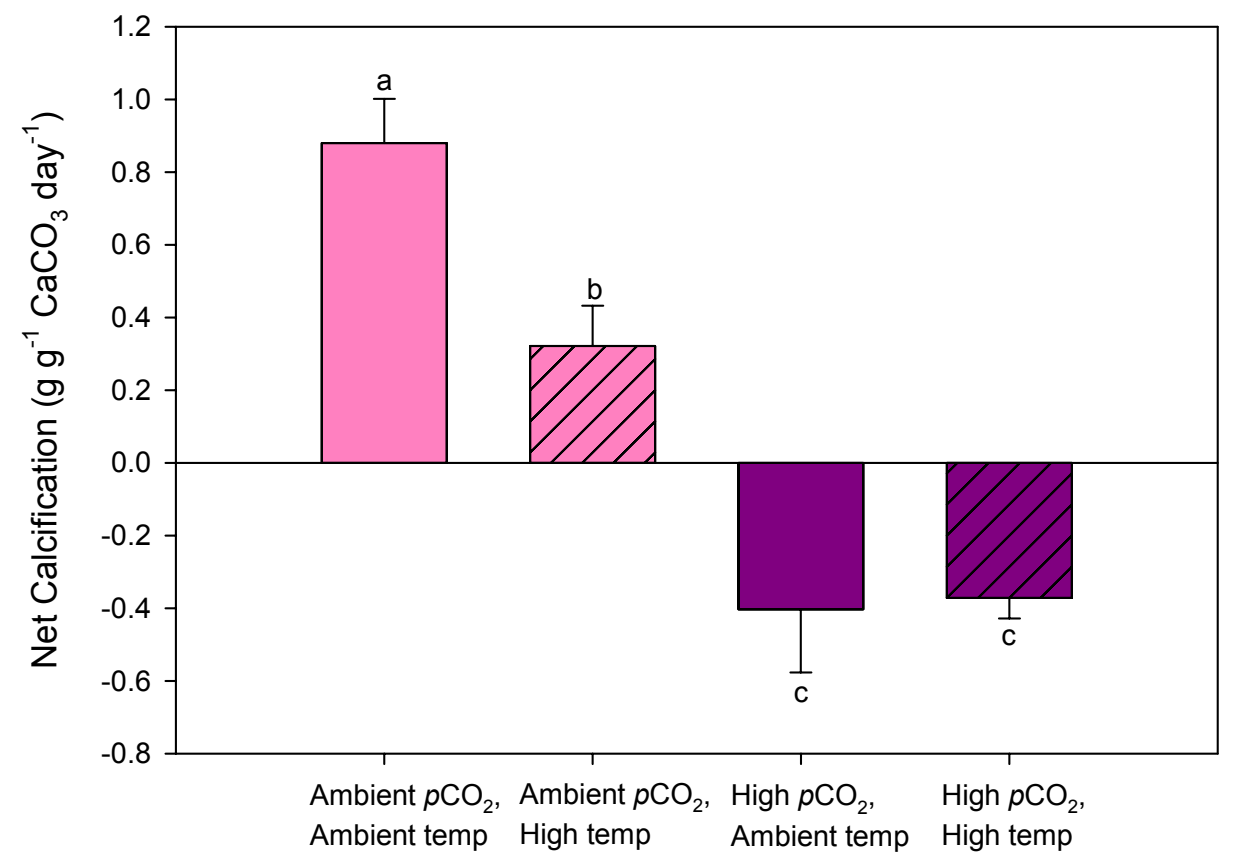

Figure 7. Percent change in buoyant weight of $C$. cheilosporioides in the four factorial $p \mathrm{CO}_{2}$ and temperature treatments. Shared letters below error bars indicate mean change in buoyant weight did not differ between treatments. Error bars denote \pm SE.

Significant decreases in linear extension of $C$. cheilosporioides branches were found in the elevated temperature and the high $p \mathrm{CO}_{2}$ treatments, but there was no $p \mathrm{CO}_{2} \times$ temperature interaction (Table 4; Fig. 8A). Elevated temperature decreased linear extension by roughly $40 \%$ in ambient $p \mathrm{CO}_{2}$ conditions. Under high temperature and high $\mathrm{pCO}_{2}$, linear extension was further reduced by $50 \%$. However, under ambient temperature and high $p \mathrm{CO}_{2}$, linear extension was only reduced by $20 \%$ compared to ambient temperature and ambient $p \mathrm{CO}_{2}$. I also found significant decreases in the surface area of new growth of branch tips in the increased temperature and the high $p \mathrm{CO}_{2}$ treatments (Table 4; Fig. 8B). 
Increased temperature decreased surface area by $\sim 50 \%$ in ambient $p \mathrm{CO}_{2}$ conditions compared with the controls. Under high temperature and high $p \mathrm{CO}_{2}$, surface area was further reduced by $75 \%$. Under ambient temperature and high $p \mathrm{CO}_{2}$, linear extension declined by $40 \%$. However, I did not find evidence for significant interactions between temperature and $p \mathrm{CO}_{2}$ on either linear extension or surface area.

Table 4. ANOVA results for the effects of $\mathrm{pCO}_{2}$ (ambient and high) and temperature (ambient and high) on the growth of $\mathrm{C}$. cheilosporioides

\begin{tabular}{lcccc}
\hline Source of variation & $d f$ & Sum of squares & F-statistic & $P$-value \\
\hline Linear extension & & & & \\
$\mathrm{CCO}_{2}$ & 1 & 0.003 & 4.335 & $\mathbf{0 . 0 4 8}$ \\
Temp & 1 & 0.017 & 24.463 & $<\mathbf{0 . 0 0 0 1}$ \\
$p \mathrm{CO}_{2} \times$ Temp & 1 & 0.001 & 0.932 & 0.344 \\
Error & 24 & 0.017 & & \\
& & & & \\
Surface area & & & & \\
$\mathrm{CCO}_{2}$ & 1 & 0.090 & 10.964 & $\mathbf{0 . 0 0 3}$ \\
$\mathrm{Temp}$ & 1 & 0.160 & 19.590 & $\mathbf{0 . 0 0 0}$ \\
$\mathrm{CCO}_{2} \times$ Temp & 1 & 0.001 & 0.081 & 0.778 \\
Error & 24 & 0.197 & & \\
\hline
\end{tabular}



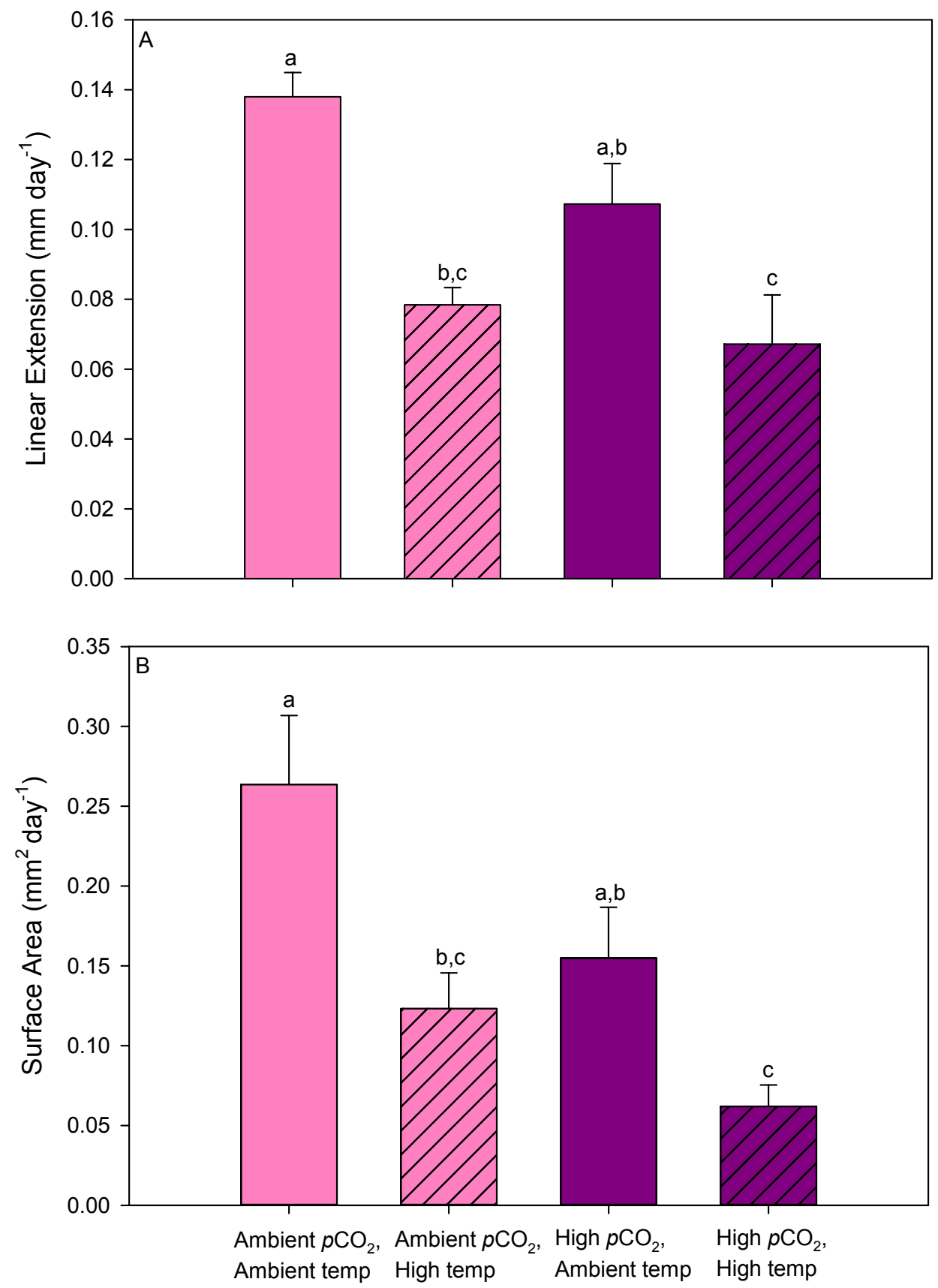

Figure 8. Growth rates as linear extension $(A)$ and new growth surface area $(B)$ for $C$. cheilosporioides in the four factorial $p \mathrm{CO}_{2}$ and temperature treatments. Shared letters below error bars indicate mean change in buoyant weight did not differ between treatments. Error bars denote \pm SE. 


\section{Photophysiology}

Three individuals from each treatment were randomly selected for measurements of photosynthetic rates and calculation of photophysiological parameters. Photosynthesis-irradiance curves were fit to truncated data $(I=0$, $19,36,60,103,178$ and $198 \mu \mathrm{mol}$ photons $\mathrm{m}^{-2} \mathrm{~s}^{-1}$ ) from one individual in the high $p \mathrm{CO}_{2}$, ambient temperature treatment and two individuals from the high $p \mathrm{CO}_{2}$, high temperature due to unequal mixing at higher light levels during incubations. Photoinhibition $(\beta)$ was only detected in the high $p \mathrm{CO}_{2}$, high temperature treatment, and was therefore excluded from analysis of treatment effects. There were no significant effects of $p \mathrm{CO}_{2}$, temperature, or the $p \mathrm{CO}_{2} \mathrm{x}$ temperature interaction on the photosynthetic efficiency, $\alpha$ (Table 5). However, I did find a significant effect of $p \mathrm{CO}_{2}$ on $\mathrm{P}_{\max }$, with a roughly $100 \%$ increase in this parameter under high $p \mathrm{CO}_{2}$ conditions (Table 5). There were no significant effects of temperature or the $p \mathrm{CO}_{2} \mathrm{x}$ temperature interaction on $\mathrm{P}_{\max }$ (Table 5). High $p \mathrm{CO}_{2}$ may increase the maximum photosynthetic rate $\left(\mathrm{P}_{\max }\right.$; Table 6; Fig. 9), while the non-significant trends (potentially due to low statistical power) suggest that under ambient $p \mathrm{CO}_{2}$ conditions, increased temperature may decrease $\alpha$ and $\mathrm{P}_{\max }$. Conversely, under high $p \mathrm{CO}_{2}$ conditions, increased temperature may increase $\alpha$ and decrease $P_{\max }$ (Table 6; Fig. 9). 
Table 5. ANOVA results for the effects of $\mathrm{pCO}_{2}$ (ambient and high) and temperature (ambient and high) on the photophysiology of C.cheilosporioides

\begin{tabular}{lcccc}
\hline Source of variation & $d f$ & Sum of squares & F-statistic & $P$-value \\
\hline$\alpha$ & & & & \\
$p \mathrm{CO}_{2}$ & 1 & 0.036 & 2.204 & 0.176 \\
$\mathrm{Temp}$ & 1 & 0.000 & 0.025 & 0.877 \\
$p \mathrm{CO}_{2} \times \mathrm{Temp}$ & 1 & 0.045 & 2.734 & 0.137 \\
Error & 8 & 0.130 & & \\
& & & & \\
$P_{\max }$ & & & & \\
$p \mathrm{CO}_{2}$ & 1 & 1001.850 & 5.447 & 0.048 \\
$\mathrm{Temp}$ & 1 & 67.624 & 0.368 & 0.561 \\
$\mathrm{COO}_{2} \times$ Temp & 1 & 7.010 & 0.038 & 0.850 \\
Error & 8 & 1471.369 & & \\
\hline
\end{tabular}

Table 6. Mean photophysiological parameters of C. cheilosporioides reared under different treatments of $\mathrm{pCO}_{2}$ (ambient and high) and temperature (ambient and high)

\begin{tabular}{lcc}
\hline Treatment & $\alpha( \pm \mathrm{SE})$ & $P_{\max }( \pm \mathrm{SE})$ \\
\hline Ambient $p \mathrm{CO}_{2}$, Ambient temp & $0.248 \pm 0.080$ & $17.737 \pm 5.328$ \\
Ambient $p \mathrm{CO}_{2}$, High temp & $0.138 \pm 0.059$ & $14.517 \pm 3.292$ \\
High $p \mathrm{CO}_{2}$, Ambient temp & $0.246 \pm 0.035$ & $37.539 \pm 12.504$ \\
High $p \mathrm{CO}_{2}$, High temp & $0.369 \pm 0.103$ & $31.263 \pm 7.047$ \\
\hline
\end{tabular}




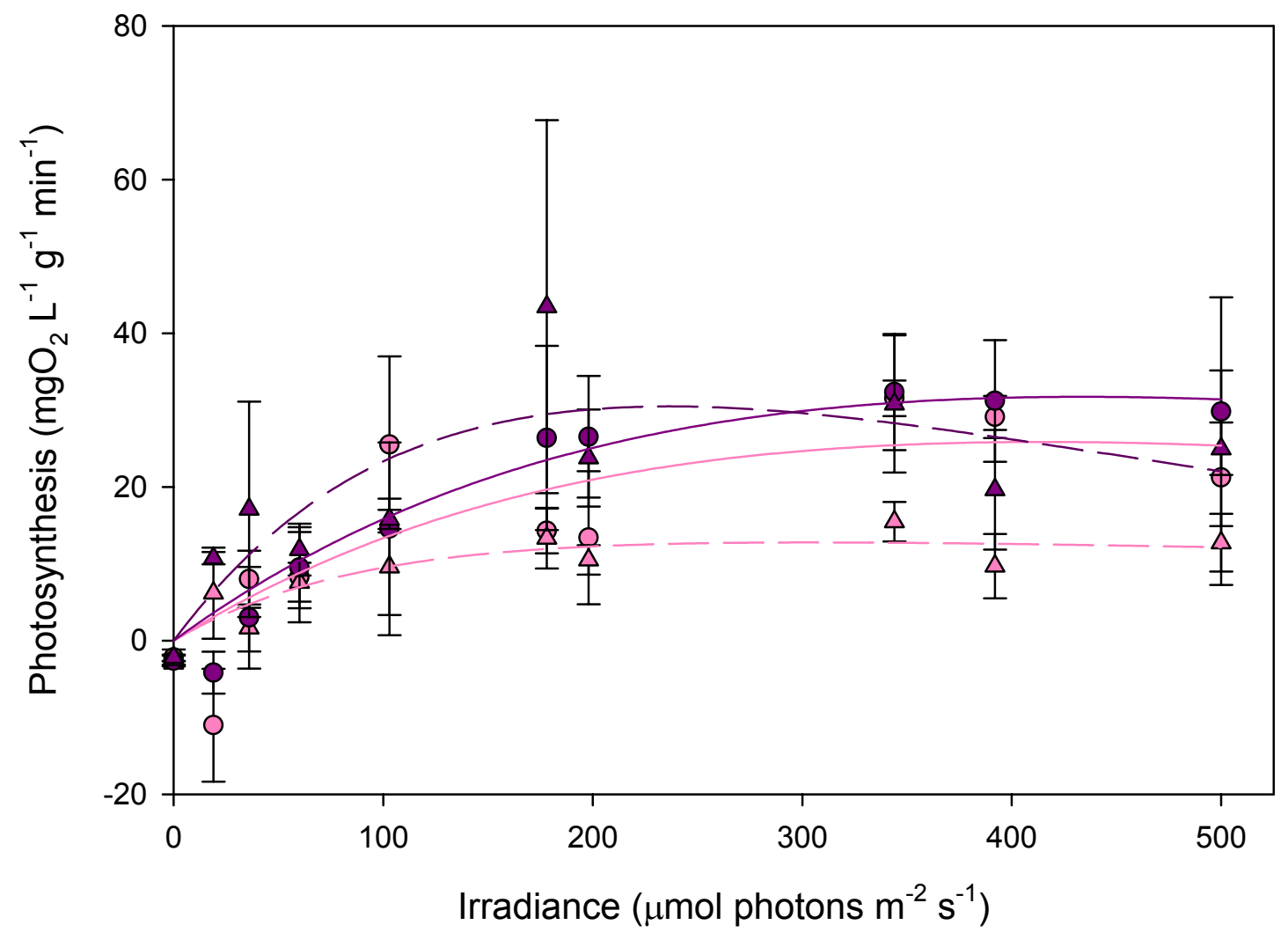

- Ambient $p \mathrm{CO}_{2}$, Ambient temp

$\triangle$ Ambient $p \mathrm{CO}_{2}$, High temp

- High $p \mathrm{CO}_{2}$, Ambient temp

$\Delta \quad$ High $p \mathrm{CO}_{2}$, High temp

Ambient $p \mathrm{CO}_{2}$, Ambient temp

Ambient $p \mathrm{CO}_{2}$, High temp

High $p \mathrm{CO}_{2}$, Ambient temp

- _ - High $p \mathrm{CO}_{2}$, High temp

Figure 9. Net photosynthesis versus irradiance curves for $C$. cheilosporioides after rearing in four factorial $p \mathrm{CO}_{2}$ and temperature treatments for 28 days. Net photosynthesis was expressed in terms of oxygen production. 


\section{Mineralogy}

There were no significant effects of $p \mathrm{CO}_{2}$, temperature or their interaction on the mol\% Mg incorporation into either cortical cells or medullary cells (Table 7; Fig. 10). Further analysis comparing differences between cell types did show a significantly higher mol \% Mg in medullary cells (mean \pm SE $=18.5 \pm 0.39$ ) versus cortical cells (mean $\pm \mathrm{SE}=14.81 \pm 0.33$; $t$-test: $t_{54}=7.2788, P=$ $<0.0001)$.

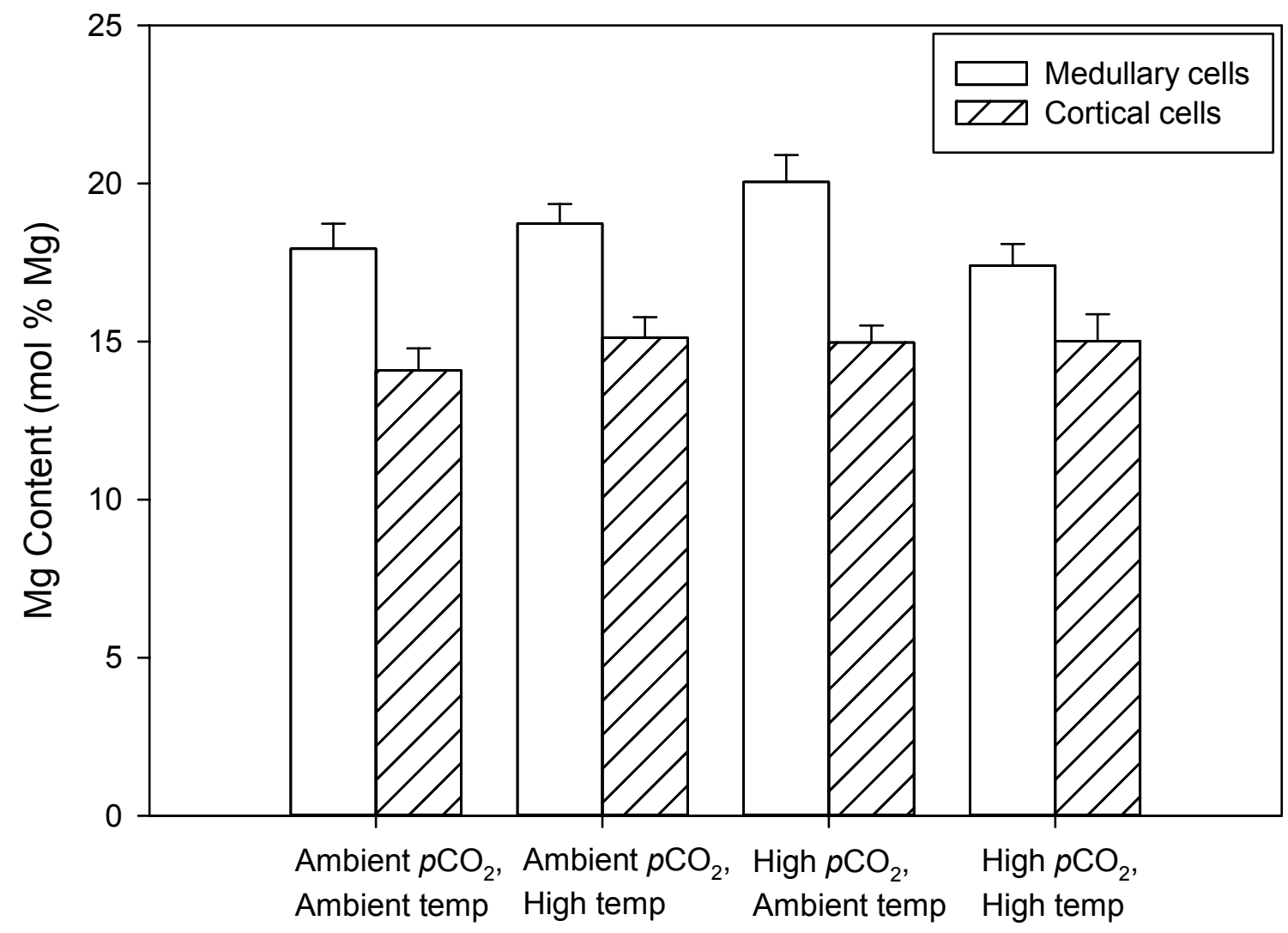

Figure $10 . \mathrm{Mol} \% \mathrm{Mg}$ found in cortical and medullary cell walls for $C$. cheilosporioides in four factorial $p \mathrm{CO}_{2}$ and temperature treatments. Error bars denote \pm SE. 
Table 7. ANOVA results for the effects of $\mathrm{pCO}_{2}$ (ambient and high) and temperature (ambient and high) on the mineralogy of $\mathrm{C}$. cheilosporioides cortical and medullary cells

\begin{tabular}{lcccc}
\hline Source of variation & $d f$ & Sum of squares & F-statistic & $P$-value \\
\hline Cortical & & & & \\
$p \mathrm{CO}_{2}$ & 1 & 1.010 & 0.306 & 0.586 \\
$\mathrm{Temp}$ & 1 & 2.051 & 0.621 & 0.439 \\
$\mathrm{pCO}_{2} \times \mathrm{Temp}$ & 1 & 1.708 & 0.517 & 0.479 \\
Error & 24 & 79.313 & & \\
& & & & \\
Medullary & & & & \\
$\mathrm{pCO}_{2}$ & 1 & 1.098 & 0.285 & 0.599 \\
$\mathrm{Temp}^{\mathrm{N}}$ & 1 & 6.059 & 1.572 & 0.222 \\
$\mathrm{CO}_{2} \times \mathrm{Temp}$ & 1 & 20.680 & 5.366 & $\mathbf{0 . 0 2 9}$ \\
Error & 24 & 92.489 & & \\
\hline
\end{tabular}

\section{Discussion}

Economically and ecologically important calcifying marine organisms have the potential to be negatively affected by global change. Recent work on temperate, tropical, and subtropical reefs has shown detrimental impacts on numerous physiological traits (e.g.; photosynthesis/respiration, calcification) in calcareous biota exposed to high $p \mathrm{CO}_{2}$ and elevated temperature conditions (Kroeker et al. 2013). Despite the tight coupling of climate change stressors, such as OA and warming (IPCC 2007), far less is known about their combined or interactive effects compared to the effects of either in isolation. This study assessed the physiological responses of an ecologically important calcified red alga, C. cheilosporioides, to climate change within a multi-stressor framework. 


\section{Growth}

In calcifying marine algae, calcification is necessary for growth and survival. The ability of an organism to calcify has been correlated with the saturation state $(\Omega)$ of seawater (Gattuso et al. 1998; Ries et al. 2009).

Calcification is favored when $\Omega>1$, whereas dissolution is favored $\Omega<1$ (Morse et al. 2007). However, these properties describe carbonate mineral precipitation and dissolution kinetics in the absence of biology. In reality, biogenic carbonate precipitation (i.e.; calcification) slows substantially as $\Omega$ approaches 1 , but can continue when $\Omega<1$ ( Ries et al. 2009; Büdenbender et al. 2011). Growing evidence suggests that species-specific controls on carbonate chemistry at the site of calcification may drive the calcification response to saturation state (e.g.; negative, parabolic; Holcomb et al. 2009; Ries et al. 2009) and could explain how some organisms continue to calcify in undersaturated conditions.

On temperate reefs, changes to $\Omega$ are driven mainly by changes in $p \mathrm{CO}_{2}$ due to natural processes (e.g. benthic metabolism, upwelling) and increased anthropogenic carbon emissions. Undersaturation (i.e.; $\Omega<1$ ) has been known to occur within the California Current System due to the upwelling of cold low $\mathrm{pH}$ seawater (Gruber et al. 2012). The frequency and intensity of upwelling events are predicted to increase in the future due to greenhouse-associated intensification of thermal low-pressure cells over coastal landmasses within upwelling regions (Bakun et al. 2010; Gruber et al. 2012; Hauri et al. 2013; Bakun et al. 2015). Therefore the extent to which saturation state affects growth 
and calcification is important to our understanding of how these organisms will respond to future ocean conditions. In our experiment, ambient $p \mathrm{CO}_{2} \Omega_{\mathrm{Ca}}=3.0 \pm$ $0.032(\mu \pm \mathrm{SE})$, whereas, $\Omega_{\mathrm{Ca}}$ in high $p \mathrm{CO}_{2}$ treatments $=1.0 \pm 0.12(\mu \pm \mathrm{SE}) . \quad$ I observed a reduction of calcification rates by up to $150 \%$ with a reduction in $\Omega_{\mathrm{Ca}}$ of 2 units. Past studies have reported net reductions in calcification of tropical coralline algae under high $p \mathrm{CO}_{2}$. For example, Johnson and Carpenter (2012) demonstrated a $24 \%$ reduction in calcification of Hydrolithon onkodes when $\Omega_{\mathrm{Ca}}$ declined from 4.6-3.21 units, while Anthony et al. (2008) reported a 190\% reduction in calcification of Hydrolithon onkodes when $\Omega_{\mathrm{Ca}}$ declined from 3.3-1.7 units. In my system, natural dissolution of $\mathrm{CaCO}_{3}$ due to seasonal undersaturation may be a common occurrence within kelp forests during the upwelling season; however, a reduction in baseline saturation states due to $\mathrm{OA}$ could tip the balance of net accretion to net dissolution within kelp forest communities.

Few studies have assessed how growth rates such as linear extension and surface area will be impacted in coralline algae due to climate change (but see: Ragazzola et al. 2012; McCoy et al. 2013; Mccoy and Ragazzola 2014). However, this information is important to better understand how changes to physiology will alter growth and morphology. McCoy et al. (2014) found that thick-crusted crustose species decreased in thickness, but did not change their internal carbonate material in response to acidification. Conversely, thin-crusted species did not change their thickness, but did change the density of internal 
carbonate material. Crustose coralline algal species exhibit both vertical and lateral growth potentially enabling them to be more plastic in response to acidification, whereas articulated species, such as $C$. cheilosporioides, grow primarily vertically. I observed a significantly greater reduction in linear extension and surface area due to increased temperature alone than elevated acidification alone, with no evidence of synergistic effects in response to the two stressors in combination. Negative relationships between temperature and calcite density have been documented previously in the artic rhodolith, Lithothamnion glaciale (Kamenos and Law 2010). Higher temperatures affect stoichiometry and create higher saturation states; therefore the calcification process should be more favorable to species inhabiting warmer waters. However, if this is the case, current research suggests that corallines may allocate additional resources to linear extension instead of vertical accretion. Taken with my finding that high $p \mathrm{CO}_{2}$ reduces calcification rates in $\mathrm{C}$. cheilosporioides, this suggests that at ambient temperature, coralline algae may compensate for reductions in calcification due to increased $p \mathrm{CO}_{2}$ by reducing the density of carbonate in skeletal materials while still maintaining growth. However, this reduction in carbonate material could have implications for structural integrity (Ragazzola et al. 2012). As storm frequency and intensity increase due to climate change, a reduction in standing kelp biomass may also reduce the wave buffering capacity within kelp beds (Byrnes et al. 2011). Reduced skeletal density (and decreased 
structural integrity) coupled with increased physical disturbance could lead to reductions in articulated coralline biomass on rocky reefs.

Past studies suggest that increased temperature may modulate the $p \mathrm{CO}_{2}$ response in coralline algae. Johnson and Carpenter (2012) found interactive effects of warming and $p \mathrm{CO}_{2}$ on the tropical coralline alga Hydrolithon onkodes during a 21 day experiment. At low $(420 \mu$ atm $)$ and high (830 $\mu$ atm) $p \mathrm{CO}_{2}$ warming resulted in an increase in calcification rates relative to ambient temperatures, however, at moderate $p \mathrm{CO}_{2}(530 \mu \mathrm{atm})$ this response was reversed. Diaz-Pulido et al. (2012) found that increased temperature also exacerbated the $\mathrm{pCO}_{2}$ response (ambient $=400 \mu$ atm; elevated $=1100 \mu$ atm $)$ on Hydrolithon onkodes by increasing partial mortality from $9 \%$ (relative to ambient $1 \%$ mortality at ambient $p \mathrm{CO}_{2}$ and temperature) to $15 \%$ over an 8 -week experimental period. In this study, I did not find evidence for interactive effects of temperature and $p \mathrm{CO}_{2}$ as predicted. This may be due in part to the length of our study (28 days) or due to local adaptation of the individuals in this study. On Mia's Reef, temperatures as high as $17^{\circ} \mathrm{C}$ were recorded during my deployments of SeaFET temperature and $\mathrm{pH}$ sensors (Fig. 4). During certain times of the year in San Diego, CA, depression of the thermocline can result in temperatures as high as $20^{\circ} \mathrm{C}$ at this site (personal observation). The frequency and duration of these warming events are unknown at this site. However, it is important to incorporate climate change stressors on top of the maximum range of 
temperatures (and $p \mathrm{CO}_{2}$ ) currently experienced by an organism in order to fully understand the potential threat they may impose.

\section{Photophysiology}

Changes in photophysiological performance in marine macrophytes can alter production on reefs. Researchers have suggested that the increase in $\mathrm{CO}_{2}$ due to climate change could actually be beneficial for marine algae (Wu et al. 2008; Harley et al. 2012; Koch et al. 2013). Since $\mathrm{CO}_{2}$ concentrations in seawater are low relative to other carbon species, most marine algae have evolved energetically costly carbon concentrating mechanisms to convert the more readily available bicarbonate ion, $\mathrm{HCO}^{-}$, to $\mathrm{CO}_{2}$ for use in photosynthetic pathways (Raven et al. 2011). If algal species are able to downregulate the use of carbon concentrating mechanisms in the presence of higher concentrations of $\mathrm{CO}_{2}$, it's possible that they may be able to utilize this extra energy for growth and reproduction (Cornwall et al. 2012). Although my study was preliminary in its efforts to assess photosynthetic performance, results suggest that the maximum photosynthetic rate could as much as double under high $\mathrm{pCO}_{2}$ conditions. Johnson et al. (2014) also found that the maximum relative electron transport rate $\left(\mathrm{rETR} \mathrm{R}_{\max }\right)$, a proxy for photosynthesis, increased under high $p \mathrm{CO}_{2}$ conditions in the weakly calcified tropical red alga Galaxaura rugosa. Although metabolic theory predicts that increases in temperature should also increase physiological

processes (Brown et al. 2004), my study lacked the power to detect a 
temperature effect on photosynthetic performance. Coralline red algae are calcifying macroalgae and my study suggests that the potential benefits of increased photophysiological performance may not outweigh the costs of decreased calcification.

\section{Mineralogy}

The number of studies on biomineralization in coralline red algae has escalated in recent years due to increased concerns about the susceptibility of their high-Mg calcite skeletons to ocean acidification (Ries 2011; Fragoso et al. 2010; Nash et al. 2011, Nash et al. 2012; Nash et al. 2015). Numerous studies have assessed whether corallines are able to change the $\mathrm{mol} \% \mathrm{Mg}$ at reduced $\mathrm{pH}$ and saturation states using techniques which measure mol \% $\mathrm{Mg}$ in bulk samples taken from whole thallus material (Ries 2011; Egilsdottir et al. 2012). One study by Ries (2011) found that the tropical crustose coralline alga, Neogoniolithon sp., reduced $\mathrm{Mg} / \mathrm{Ca}$ ratios in calcite with decreasing $\mathrm{pH}$ after 60 days in experimental conditions. Conversely, the temperate intertidal articulated alga, Corallina elongata, did not change its mineralogy in response to acidification during a 3-week rearing experiment (Egilsdottir et al. 2012). My study did not find significant effects of $p \mathrm{CO}_{2}$ or temperature on mineralogy. This could be because this species (and perhaps other articulated species) does not exhibit mineralogical plasticity in response to acidification or temperature or because of the relatively short experimental duration (28 days). 
Techniques utilizing bulk tissue samples may mask important fine-scale variability, which could be crucial to how these organisms persist in dynamic ecosystems, such as tidepools and upwelling regions. Studies that have looked at higher resolution within the algal thallus have focused on either underlying skeletal material (i.e.; not containing living cells) or lack an understanding of the biology and ecology of the study species (Nash et al. 2011, 2012, 2015). My study found significantly higher mol \% Mg in medullary cells than cortical cells. Medullary cells form the central core of filaments which run from geniculum to geniculum (Borowitzka and Vesk 1978). These internal cells had, on average, $\sim 125 \%$ higher $\mathrm{Mg} / \mathrm{Ca}$ ratios. The mechanism for this dramatic difference between different cell types remains unknown, but may be due to biology or abiotic conditions. For instance, relationships between growth rate and $\mathrm{Mg} / \mathrm{Ca}$ ratios have been found, however, these measurements are confounded by temperature. At elevated temperatures, $\mathrm{Mg} / \mathrm{Ca}$ ratios in $\mathrm{CCA}$ have been reported to increase, however, so do growth rates (Kamenos et al. 2008). The degree to which increased $\mathrm{Mg}$ incorporation is due to temperature versus growth rate remains unknown. It is possible that internal medullary cells simply grow faster than cortical cells, which could explain this pattern if growth rate is correlated with Mg incorporation. Medullary cells are responsible for increases in linear extension, whereas cortical cells thicken the alga. It's also possible that the reduced $\mathrm{Mg}$ incorporation in outer cortical cells may be a strategy to decrease solubility in cell types closer to the external environment. 


\section{Conclusion}

C. cheilosporioides can maintain large expanses, referred to as the Calliarthron Zone (McLean 1962), inshore of kelp forests in shallow wave exposed environments (Graham 1997). The branching structure of $C$. cheilosporioides creates a complex 3-dimensional structure that creates habitat for numerous associated species (McLean 1962). Within kelp forests, $C$. cheilosporioides can also be found in high abundances and may act as a secondary foundational species, especially during times of high disturbance.

The present study found that $C$. cheilosporioides growth and calcification were reduced under acidification and warming. Reductions in net yearly calcification and changes to growth could have consequences for both the abundance and integrity of $C$. cheilosporioides. We found variation in the mol $\%$ Mg within carbonate skeletons of different cell types. A better understanding of the mechanism by which corallines regulate $\mathrm{Mg}$ incorporation will be crucial to predicting the impacts of global change stressors. Although C. cheilosporioides may be able to increase photosynthetic rates with increased availability of $\mathrm{CO}_{2}$, the costs of increased temperature and acidification seem to counter any benefits. The changes to biology brought on by warming and acidification in this study could have cascading effects on species that rely on C. cheilosporioides for food, habitat, and other important ecological processes such as settlement cues. My study was conducted on individuals collected from one location and lasted only 28 days in duration. Future research should investigate the potential 
for acclimation over longer periods of time. Furthermore, variability in temperature and $\mathrm{pH}$ occurs spatially across the geographic range of $C$. cheilosporioides. Local adaptation may provide key insights into the mechanisms that coralline algae have evolved to persist in environments similar to those predicted to occur by the end of the century. 


\section{Literature Cited}

Andersson AJ, Mackenzie FT, Bates NR (2008) Life on the margin: implications of ocean acidification on Mg-calcite, high latitude and cold-water marine calcifiers. Mar Ecol Prog Ser 373:265-273

Anthony KRN, Kline DI, Diaz-Pulido G, Dove S, Hoegh-Guldberg O (2008) Ocean acidification causes bleaching and productivity loss in coral reef builders. Proc Natl Acad Sci USA 105:17442-17446

Bakun A, Field DB, Redondo-Rodriguez A, Weeks S (2010) Greenhouse gas, upwelling-favorable winds, and the future of coastal ocean upwelling ecosystems. Glob Change Biol 16:1213-1228

Bakun A, Black BA, Bograd SJ, García-Reyes M, Miller AJ, Rykaczewski RR, Sydeman WJ (2015) Anticipated Effects of Climate Change on Coastal Upwelling Ecosystems. Curr Clim Chang Rep 1:85-93

Borowitzka MA, Larkum AWD, Nockolds CE (1974). A scanning electron microscope study of the structure and organization of the calcium carbonate deposits of algae. Phycologia 13:195-203

Borowitzka MA, Vesk M (1978) Ultrastructure of the corallinaceae. I. The vegetative cells of Corallina officinalis and C. cuvierii. Mar Biol 46:295-304

Borowitzka MA (1981) Photosynthesis and calcification in the articulated coralline red algae. Mar Biol 62:17-23

Brown JH, Gillooly JF, Allen AP, Savage VM, West GB (2004) Toward a metabolic theory of ecology. Ecol 85:1771-1789

Büdenbender J, Riebesell U, Form A (2011) Calcification of the Arctic coralline red algae Lithothamnion glaciale in response to elevated CO2. Mar Ecol Prog Ser 441:79-87

Cornwall CE, Hepburn CD, Pritchard D, Currie KI, McGraw CM, Hunter KA, Hurd $C L$ (2012) Carbon-use strategies in macroalgae: differential responses to lowered $\mathrm{pH}$ and implications for ocean acidification. J of Phycol 48:137-144

Davies PS (1989) Short-term growth measurements of corals using an accurate buoyant weighing technique. Mar Biol 101:389-395

Diaz-Pulido G, Anthony KRN, Kline DI, Dove S, Hoegh-Guldberg O (2012) Interactions between ocean acidification and warming on the mortality and 
dissolution of coralline algae. J of Phycol 48:32-39

Dickson AG, Millero FJ (1987) A comparison of the equilibrium constants for the dissociation of carbonic acid in seawater media. Deep Sea Res 34:17331743

Egilsdottir H, Noisette F, Noël LM-LJ, Olafsson J, Martin S (2012) Effects of $\mathrm{pCO}_{2}$ on physiology and skeletal mineralogy in a tidal pool coralline alga Corallina elongata. Mar Biol 160:2103-2112

Fragoso D, Heredia A, Bucio $L$ (2010) Characterization of the $\mathrm{CaCO}_{3}$ biomineral in coralline red algae (Corallinales) from the Pacific coast of Mexico. Cien Mar, 36:41-58

Frieder CA, Nam SH, Martz TR, Levin LA (2012) High temporal and spatial variability of dissolved oxygen and $\mathrm{pH}$ in a nearshore California kelp forest. Biogeosciences Discuss 9:4099-4132

Gao K, Zheng Y (2009) Combined effects of ocean acidification and solar UV radiation on photosynthesis, growth, pigmentation and calcification of the coralline alga Corallina sessilis (Rhodophyta). Glob Change Biol 16:23882398

Gattuso J (1998) Effect of calcium carbonate saturation of seawater on coral calcification. Glob Planet Change 18:37-46

Graham MH (1997) Factors determining the upper limit of giant kelp, Macrocystis pyrifera Agardh, along the Monterey Peninsula, central California, USA. J of Exp Mar Biol Ecol 218:127-149

Gruber N, Hauri C, Lachkar Z, Loher D, Frölicher TL, Plattner G-K (2012) Rapid progression of ocean acidification in the California Current System. Science 337:220-223

Harley CDG, Anderson KM, Demes KW, Jorve JP, Kordas RL, Coyle TA, Graham MH (2012) Effects of climate change on global seaweed communities. J Phycol, 48:1064-1078

Harvey BP, Gwynn-Jones D, Moore PJ (2013) Meta-analysis reveals complex marine biological responses to the interactive effects of ocean acidification and warming. Ecol and Evolut 2013:1-15

Hauri C, Gruber N, Vogt M, Doney SC, Feely RA, Lachkar Z, Leinweber A, McDonnell AMP, Munnich M, Plattner G-K (2013) Spatiotemporal variability 
and long-term trends of ocean acidification in the California Current System. Biogeosciences 10:193-216

Hoegh-Guldberg O, Mumby PJ, Hooten AJ, Steneck RS, Greenfield P, Gomez E, Harvell CD, Sale PF, Edwards AJ, Caldeira K, Knowlton N, Eakin M, Iglesias-Prieto R, Muthiga N, Bradbury RH, Dubi A, Hatziolos ME (2007) Coral reefs under rapid climate change and ocean acidification. Science 318:1737-42

Hofmann GE, Smith JE, Johnson KS, Send U, Levin LA, Micheli F, Martz TR (2011) High-frequency dynamics of ocean $\mathrm{pH}$ : a multi-ecosystem comparison. PloS One 6:e28983

Hofmann LC, Yildiz G, Hanelt D, Bischof K (2011) Physiological responses of the calcifying rhodophyte, Corallina officinalis (L.), to future CO2 levels. Mar Biol 159:783-792

Holcomb M, Cohen AL, Gabitov RI, Hutter JL (2009) Compositional and morphological features of aragonite precipitated experimentally from seawater and biogenically by corals. Geochim Cosmochim Acta 73:41664179

IPCC (2007) Climate Change 2007: the physical science basis. contribution of working group I to the fourth assessment report of the intergovernmental panel on climate change. Cambridge University Press, Cambridge

Johnson MD, Carpenter RC (2012) Ocean acidification and warming decrease calcification in the crustose coralline alga Hydrolithon onkodes and increase susceptibility to grazing. J Exp Mar Biol Ecol 434:94-101

Johnson MD, Price NN, Smith JE (2014) Contrasting effects of ocean acidification on tropical fleshy and calcareous algae. PeerJ 2:e411

Jokiel PL, Rodgers KS, Kuffner IB, Andersson AJ, Cox EF, Mackenzie FT (2008). Ocean acidification and calcifying reef organisms: a mesocosm investigation. Coral Reefs 27:473-483

Kamenos NA, Cusack M, Moore PG (2008) Coralline algae are global palaeothermometers with bi-weekly resolution. Geochim Cosmochim Acta 72:771-779

Kamenos NA, Law A (2010) Temperature controls on coralline algal skeletal growth. J of Phycol 46:331-335 
Keser M, Swenarton JT, Foertch JF (2005) Effects of thermal input and climate change on growth of Ascophyllum nodosum (Fucales, Phaeophyceae) in eastern Long Island Sound (USA). J of Sea Res 54:211-220

Koch M, Bowes G, Ross C, Zhang X-H (2013) Climate change and ocean acidification effects on seagrasses and marine macroalgae. Glob Change Biol 19:103-132

Kroeker KJ, Kordas RL, Crim RN, Singh GG (2010) Meta-analysis reveals negative yet variable effects of ocean acidification on marine organisms. Ecol Lett, 13:1419-1434

Kroeker KJ, Kordas RL, Crim R, Hendriks IE, Ramajo L, Singh GS, Gattuso J-P (2013) Impacts of ocean acidification on marine organisms: quantifying sensitivities and interaction with warming. Glob Change Biol 19:1884-1896.

Kuffner IB, Andersson AJ, Jokiel PL, Rodgers KS, Mackenzie FT (2007) Decreased abundance of crustose coralline algae due to ocean acidification. Nature Geosci 1:114-117

Littler MM, Littler DS, Taylor PR (1995) Selective herbivore increases biomass of it's prey: a chiton-coralline reef-building association. Ecol 76:1666-1681

Martin S, Rodolfo-Metalpa R, Ransome E, Rowley S, Buia M, Gattuso J, HallSpencer J (2008) Effects of naturally acidified seawater on seagrass calcareous epibionts. Biol Lett 4:689-692

Martin S, Gattuso J-P (2009) Response of Mediterranean coralline algae to ocean acidification and elevated temperature. Glob Change Biol 15:20892100

Martone PT (2010) Quantifying growth and calcium carbonate deposition of Calliarthron Cheilosporioides (Corallinales, Rhodophyta) in the field using a persistent vital stain. J Phycol 46:13-17

Martz TR, Connery JG, Johnson KS (2010) Testing the Honeywell Durafet for seawater $\mathrm{pH}$ applications. Limnol Oceanogr Methods 8:172-184

McCoy SJ (2013) Morphology of the crustose coralline alga Pseudolithophyllum muricatum (Corallinales, Rhodophyta) responds to 30 years of ocean acidification in the Northeast Pacific. J Phycol 837

McCoy SJ, Ragazzola F (2014) Skeletal trade-offs in coralline algae in response to ocean acidification. Nat Clim Change June:1-5 
McLean JH (1962) Sublittoral ecology of kelp beds of the open coast area near Carmel, California Biol Bull 122:95-114

Mehrbach C, Culberson CH, Hawley JE, Pytkowicz RM (1973) Measurement of the apparent dissociation constants of carbonic acid in seawater at atmospheric pressure. Limnol Oceanogr 18:897-907

Morse JW, Arvidson RS, Lüttge A (2007) Calcium carbonate formation and dissolution. Chem Rev 107:342-381

Nash MC, Troitzsch U, Opdyke BN, Trafford JM, Russell BD, Kline DI (2011) First discovery of dolomite and magnesite in living coralline algae and its geobiological implications. Biogeosciences 8:3331-3340

Nash MC, Opdyke BN, Troitzsch U, Russell BD, Adey WH, Kato A, Kline DI (2012) Dolomite-rich coralline algae in reefs resist dissolution in acidified conditions. Nat Clim Change 2:1-5

Nash MC, Uthicke S, Negri AP, Cantin NE (2015) Ocean acidification does not affect magnesium composition or dolomite formation in living crustose coralline algae, Porolithon onkodes in an experimental system. Biogeosciences Discus 12:1373-1404

Pandolfi JM, Connolly SR, Marshall DJ, Cohen AL (2011) Projecting coral reef futures under global warming and ocean acidification. Science 333:418-22

Price N (2010) Habitat selection, facilitiation, and biotic settlement cues affect distribution and performance of coral recruits in French Polynesia. Oecol 163:747-758

Price N, Hamilton S, Tootell J, Smith J (2011) Species-specific consequences of ocean acidification for the calcareous tropical green algae Halimeda. Mar Ecol Prog Ser 440:67-78

Price NN, Martz TR, Brainard RE, Smith JE (2012) Diel variability in seawater $\mathrm{pH}$ relates to calcification and benthic community structure on coral reefs. PloS One $7: \mathrm{e} 43843$

Ragazzola F, Foster LC, Form A, Anderson PSL, Hansteen TH, Fietzke J (2012) Ocean acidification weakens the structural integrity of coralline algae. Glob Change Biol 2012:1-9

Raven JA (2011) Effects of marine algae on changed seawater chemistry with 
increasing atmospheric $\mathrm{CO}_{2}$. Biol Env Proc $\mathrm{R}$ Ir Acad 111:1-17

Ries JB, Cohen AL, McCorkle DC (2009) Marine calcifiers exhibit mixed responses to $\mathrm{CO}_{2}$-induced ocean acidification. Geol 37:1131-1134

Ries JB (2011) Skeletal mineralogy in a high-CO2 world. J of Exp Mar Biol Ecol 403:54-64

Schiel DR, Steinbeck JR, Foster MS (2004) Ten years of induced ocean warming causes comprehensive changes in marine benthic communities. Ecol 85:1833-1839

Shapiro SS, Wilk MB (1965) An analysis of variance test for normality (complete samples). Biometrik 52:591-611

Stanley SM, Hardie LA (1998) Secular oscillations in the carbonate mineralogy of reef-building and sediment-producing organisms driven by tectonically forced shifts in seawater chemistry. Palaeogeogr Palaeoclimatol Palaeoecol 144:3-19

Steneck RS (1986) The ecology of coralline algal crusts : convergent patterns and adaptative strategies. Annu Rev Ecol Syst 17:273-303

Wu H, Zou D, Gao K (2008) Impacts of increased atmospheric CO2 concentration on photosynthesis and growth of micro- and macro-algae. Sci China Ser C Life Sci Chin Acad Sci 51:1144-50

Yokohama Y (1973) A comparative study on photosynthesis temperature relationship and their seasonal changes in marine benthic algae. Int Rev Ges Hydrobiol 58:463-472 


\section{Chapter II}

Effects of ocean acidification and grazing on kelp forest communities from San Diego, CA and Carmel, CA 


\begin{abstract}
Increases in dissolved $\mathrm{CO}_{2}$ (i.e., $p \mathrm{CO}_{2}$ ), as a consequence of anthropogenic $\mathrm{CO}_{2}$ emissions, are altering seawater chemistry at an alarming rate. Studies have shown that increased $p \mathrm{CO}_{2}$ and associated changes to the carbonate system will differentially affect calcifying and non-calcifying marine organisms. I investigated how multispecies assemblages from kelp forests in central and southern California respond to future $\mathrm{pCO}_{2}$ conditions and sea urchin grazing in a multifactorial design. Settlement tiles were installed at each location to accrue natural mixed assemblages and $\mathrm{pH}$ sensors were used to record natural variability and estimate differences in $\mathrm{pH}$ exposure history. After one year, tiles were placed in a laboratory experiment for two months to simulate the effects of elevated $\mathrm{CO}_{2}(\sim 0.4 \mathrm{pH}$ units below ambient) and grazing on subsequent community development. Community composition, growth, and calcification on tiles from central California showed a strong effect of grazing, but no effect of $p \mathrm{CO}_{2}$. Conversely, species assemblages from southern California showed little effects of grazing, but a significant effect of $\mathrm{pCO}_{2}$ on community composition, growth and calcification. In addition, block effects were detected, such that taxa-specific responses depended upon the initial community state, which differed among tiles cultivated on the separate racks from San Diego, CA. These findings suggest that the community-level responses to climate change stressors may depend on initial community composition, species interactions, and prior $\mathrm{pH}$ exposure.
\end{abstract}




\section{Introduction}

Numerous studies have addressed how individual taxa will respond to ocean acidification. In general, results from single-species experiments suggest that calcified taxa, such as corals and calcified macroalgae, will exhibit reduced growth and calcification due to lowered $\mathrm{pH}$ and saturation states (Kroeker et al. 2010; Harvey et al. 2013; Kroeker et al. 2013). Conversely, non-calcified photoautotrophs, such as fleshy macroalgae and seagrasses, may experience increased growth due to the increased availability of $\mathrm{CO}_{2}$ and $\mathrm{HCO}_{3}{ }^{-}$for photosynthesis (Harley et al. 2012). These studies can be useful in order to understand how biological processes may be affected by climate change. However, as organisms interact on a reef, changes to biology (i.e., growth and metabolism) may alter their abilities to compete for resources and space. Since species interactions are complex, the effects of climate change on biodiversity and ecosystem functioning are challenging to predict from single-species experiments alone. Therefore, in order to better understand community level responses, it is necessary to focus on whole species assemblages.

Environmental stressors such as $\mathrm{pH}$, temperature, and nutrients have been shown to dramatically change the structure and biodiversity in benthic communities (Schiel et al. 2004; Russell et al. 2009; Hale et al. 2011; Kroeker et al. 2011; Porzio et al. 2011; Hofmann et al. 2012; Kroeker et al. 2012; Price 2012; Enochs et al. 2015). Opposing responses of closely related species within the same assemblage suggest that compensatory dynamics may occur among 
the most tolerant species (Kroeker et al. 2013). However, despite potential compensatory mechanisms, shifts from communities dominated by calcified taxa to communities dominated by fleshy taxa have been documented under OA-like conditions (Hoegh-Guldberg et al. 2007; Hall-Spencer et al. 2008; Russell et al. 2009; Fabricius et al. 2011; Porzio et al. 2011; Kroeker et al. 2012; Enochs et al. 2015) and even across natural present-day gradients in $\mathrm{pH}$ (Price et al. 2012). Taken together, these studies suggest that climate change stressors could have dramatic impacts on benthic communities and the subsequent organisms that depend on them for food, structure, and refuge.

Studies focusing on the impacts of climate change on temperate communities are lacking. Those that have been published suggest that reduced abundances of calcifying macroalgae and increased abundances of fleshy macroalgae and turfs will occur under OA (Russell et al. 2009; Hofmann et al. 2012). Although temperate communities are characteristically identified by the dominance of charismatic brown algae from the family Laminariales (i.e., kelps), they also maintain a high diversity of calcifying organisms such as crustose coralline red algae and shelled marine invertebrates. These calcified organisms are important to the structure and function of kelp forest communities as they cement reef structure and provide habitat, food, and settlement cues.

In addition to changes in numerous abiotic conditions (i.e., temperature, carbonate chemistry, etc.) in response to climate change, changes to ecological processes, such as grazing pressure, are also likely to affect benthic 
communities. Grazers have been shown to structure community composition on reefs. Since many grazers, such as chitons and sea urchins, also build protective shells or skeletons by precipitating calcium carbonate, it is likely that they will also be negatively affected by OA. In addition, metabolic depression associated with a decrease in intra or extracellular $\mathrm{pH}$ has been observed in a number of marine invertebrates under hypercapnic (low-pH, high $\mathrm{CO}_{2}$ ) conditions (Widdicombe and Spicer 2008). It is unclear how these physiological changes may affect grazing pressure; however, it is likely that numerous factors (i.e., changes to growth and survivorship, recruitment, grazing rates, etc.) will result in alterations to grazing pressure on reefs. More studies that directly measure changes to community structure across multiple ecosystems and that incorporate biotic stressors (such as grazing) are necessary to understand the emergent effects of climate change on marine systems.

\section{Spatio-temporal variation in seawater chemistry along the California coast}

The California coast is part of one of the four Eastern Boundary Current Systems (EBCS), which are highly productive and dynamic coastal environments

driven by seasonal upwelling (Gruber et al. 2012). Southerly winds prevail during the spring and summer months causing upwelling of cold, low $\mathrm{pH}$ and nutrientrich waters. During El Niño years, a depression of the thermocline results in reduced upwelling and warmer waters with decreased nutrients available to biological organisms. All of this seasonal and multi-year variation is 
superimposed upon a larger climatic phenomenon known as the Pacific Decadal Oscillation (PDO), which occurs on a decadal time scale and oscillates between periods of cold, nutrient rich waters and warm, nutrient poor waters. For these reasons, California's rocky temperate reefs (hereafter, 'reefs') are among the most dynamic and productive ecosystems on the planet.

Due to the upwelling of high $\mathrm{CO}_{2}$ (low pH) waters, the EBCS are naturally lower in $\mathrm{pH}$ and saturation states than other regions of the ocean (Feely et al. 2008). Therefore, calcifying organisms that inhabit these regions may already be near the physiological limits of what is necessary for growth and maintenance of calcium carbonate skeletons. Due to increasing anthropogenic $\mathrm{CO}_{2}$ emissions, regional model projections have shown rapid acidification within the California current system (CCS) over the next 20-30 years with much of the nearshore region of the California coast experiencing summer-long undersaturation of carbonate ion with respect to aragonite $\left(\Omega_{\mathrm{Ar}}\right)$ by 2050 (Gruber et al. 2012).

Furthermore, a large gradient in upwelling frequency and intensity exists latitudinally. North of Point Conception strong seasonal upwelling events and remineralization result in spring $\mathrm{pH}$ drops as low as 7.65 with $\Omega_{\mathrm{Ar}}$ as low as 0.8 (Feely et al. 2008; Hauri et al. 2013). Upwelling is weaker, yet more persistent south of Point Conception (Hauri et al. 2013). Due to biological drawdown of $\mathrm{CO}_{2}$ in warm subsurface waters, $\mathrm{pH}$ and saturation states reach their highest during the summer in southern California (Hauri et al. 2013). Spatial and temporal variability in $\mathrm{pH}$ and saturation states as well as the magnitude of that 
variability differ greatly between northern and southern California. By measuring the responses of kelp forest communities from multiple locations along a natural gradient in $\mathrm{pH}$, researchers may better understand how local adaptation to oceanographic conditions may alter the responses of similar taxa to ocean acidification.

The aim of this chapter is to address the following questions: 1) Will the differential responses of organisms to OA result in shifts in community composition? I hypothesize that the cover and/or biomass of calcified taxa will decrease in natural communities reared in high $p \mathrm{CO}_{2}$, but increase in the presence of grazers. The magnitude of these responses will differ between central California and southern California, with central California sites being affected less than those from southern California because organisms in central California will be acclimatized to low $\mathrm{pH}$ conditions due to development in waters characterized by high levels of upwelling and thus lower $\mathrm{pH}$. 2) How will ocean acidification alter grazer biology? I hypothesize that sea urchin growth and grazing rates will be reduced in high $p \mathrm{CO}_{2}$ conditions, due to metabolic depression - and that these altered grazing rates can explain differences in macroalgae species assemblages? 


\section{Materials and Methods}

\section{Study Sites}

In order to gain better insight into how different communities may respond to OA and warming along California's coast, two sites were chosen, one at Stillwater Cove in Monterey County (N 36 $36^{\prime} 38.4^{\prime \prime}$ W $\left.12156^{\prime} 44.9^{\prime \prime}\right)$ and one at Mia's Reef in San Diego County (N 32 $51^{\prime} 14.8^{\prime \prime}$, W $\left.117^{\circ} 16^{\prime} 52.4^{\prime \prime}\right)$, to install racks of settlement tiles (Fig. 1) for community-level experiments. Stillwater Cove is characterized by granite, sandstone and conglomerate terraces separated by cobble and sand channels (Edwards 1998). The dominant habitatforming species include a surface canopy of Macrocystis pyrifera and a subsurface canopy of Pterogophyera californica. Fleshy red and calcareous algae and numerous genera of sessile invertebrates carpet the benthos (Edwards 1998). Stillwater Cove was chosen as a representative central California kelp forest subject to intense seasonal upwelling of low $\mathrm{pH}$ seawater and naturally lower mean $\mathrm{pH}$ and saturation states. Mia's Reef, similar to other southern California kelp forests, is characterized by limestone reef which can be fragmented into large boulders (Dayton et al. 1984). At Mia's Reef, a large terrace provided continuous bathymetry in which to deploy settlement tile arrays. The habitat-forming species is also M. pyrifera with an understory community dominated by low lying fleshy red and brown macroalgae, branching bryozoans and sponges. Mia's Reef was chosen as a representative southern California kelp forest with higher mean $\mathrm{pH}$ and weak seasonal upwelling events. Each site 
was co-located with autonomous $\mathrm{pH}$ and temperature loggers, SeaFETs (Martz et al. 2010; Fig. 2). These instruments provide continuous high-resolution (every $15 \mathrm{~min}) \mathrm{pH}$ and temperature measurements to improve my understanding of natural fluctuations at each site and aid in the interpretation of experimental results. SeaFET pH and temperature loggers were deployed at Stillwater Cove, Carmel, CA on November 12, 2012 and at Mia's Reef, La Jolla, CA on November 1, 2012. Water samples for carbonate chemistry were taken as frequently as possible at the SeaFET loggers using a custom Niskin to calibrate $\mathrm{pH}$ measurements. At the surface, water samples were transferred to $500 \mathrm{~mL}$ Corning brand Pyrex sample bottles and immediately spiked with $240 \mu \mathrm{L}$ of $\mathrm{HgCl}_{2}$ solution. Carbonate chemistry and salinity were analyzed from water samples using water chemistry analysis methods outlined in chapter 1 . In addition, in situ photosynthetically active radiation (PAR) was measured for one month at each site using a LICOR $4 \pi$ quantum sensor (Biospherical, Inc.) to characterize irradiances at each location.

Grazing pressure has been shown to alter community composition and structure on reefs (Paine and Vadas 1969; Breitburg 1984; Harrold and Reed 1985; Watanabe and Harrold 1991; Byrnes et al. 2013). In order to better understand how grazers may mediate competitive interactions under climate change stressors, the purple sea urchin (Strongylocentrotus purpuratus) was used in community level experiments. Sea urchins of the genus Strongylocentrotus alter algal species composition by removing algal biomass via 
grazing (Paine and Vadas 1969). Therefore the presence of urchin grazers may reduce fleshy biomass and indirectly increase the biomass of calcified taxa. Strongylocentrotus purpuratus are abundant in both central and southern California making them an ideal grazer for comparisons between both study sites.

\section{Benthic Community Structure Responses to Ocean Acidification}

To assess changes in growth and species interactions due to climate change at the community level, mixed communities of sessile organisms were cultured on settlement tiles outplanted to the field for one year. After a year, the tiles were retrieved and reared in the laboratory under a multi-stressor design. Experiments used two different $p \mathrm{CO}_{2}$ levels (ambient $p \mathrm{CO}_{2}=\sim 450 \mu$ atm $[\mathrm{pH}=$ 8.07], high $\left.p \mathrm{CO}_{2}=\sim 1800 \mu \mathrm{atm}[\mathrm{pH}=7.69]\right)$. To determine whether benthic mesograzers may mediate interactions under OA, the presence or absence of sea urchin grazers, S. purpuratus, was cross-factored with the two $p \mathrm{CO}_{2}$ treatments to result in a total of four different factorial treatment conditions: (1) ambient $p \mathrm{CO}_{2}$, -grazer (2) ambient $p \mathrm{CO}_{2}$, grazer (3) high $p \mathrm{CO}_{2}$, -grazer and (4) high $\mathrm{pCO}_{2}$, +grazer. All laboratory experiments were conducted in a state-of-theart flow through seawater system in the lab of Dr. Jennifer Smith at SIO.

Sets of settlement tiles were deployed at $\sim 13 \mathrm{~m}$ within the two kelp forests to generate different initial communities of sessile invertebrates and algae to assess community-level responses to $\mathrm{OA}$ and grazing. Community tile racks 
$(n=3)$ with $18-100 \mathrm{~cm}^{2}$ tiles per rack were deployed at Stillwater Cove, Carmel, CA on January 16, 2013 and at Mia's Reef, La Jolla, CA on August 3, 2012 (Fig. 1). At each location, all three tile racks were installed within a $10 \times 10 \mathrm{~m}$ cell. Holes were drilled into the reef and eyebolts were secured into holes using ZSpar marine epoxy. Tile racks were secured to eyebolt attachment points via zip-ties. All settlement tiles remained on the reef for approximately 1 year to accumulate natural mixed communities of invertebrates and seaweeds, at which time $n=39$ and 40 individual tiles (Stillwater Cove and Mia's Reef respectively) were collected and transported to the laboratory for experimental rearing in the aforementioned treatment conditions for a two month period. Grazers were collected from the Point Loma kelp forest during the week of September 23, 2013. Prior to their use as experimental grazers, sea urchins were held in ambient flow-through aquaria and fed $M$. pyrifera fronds ad libitum. 

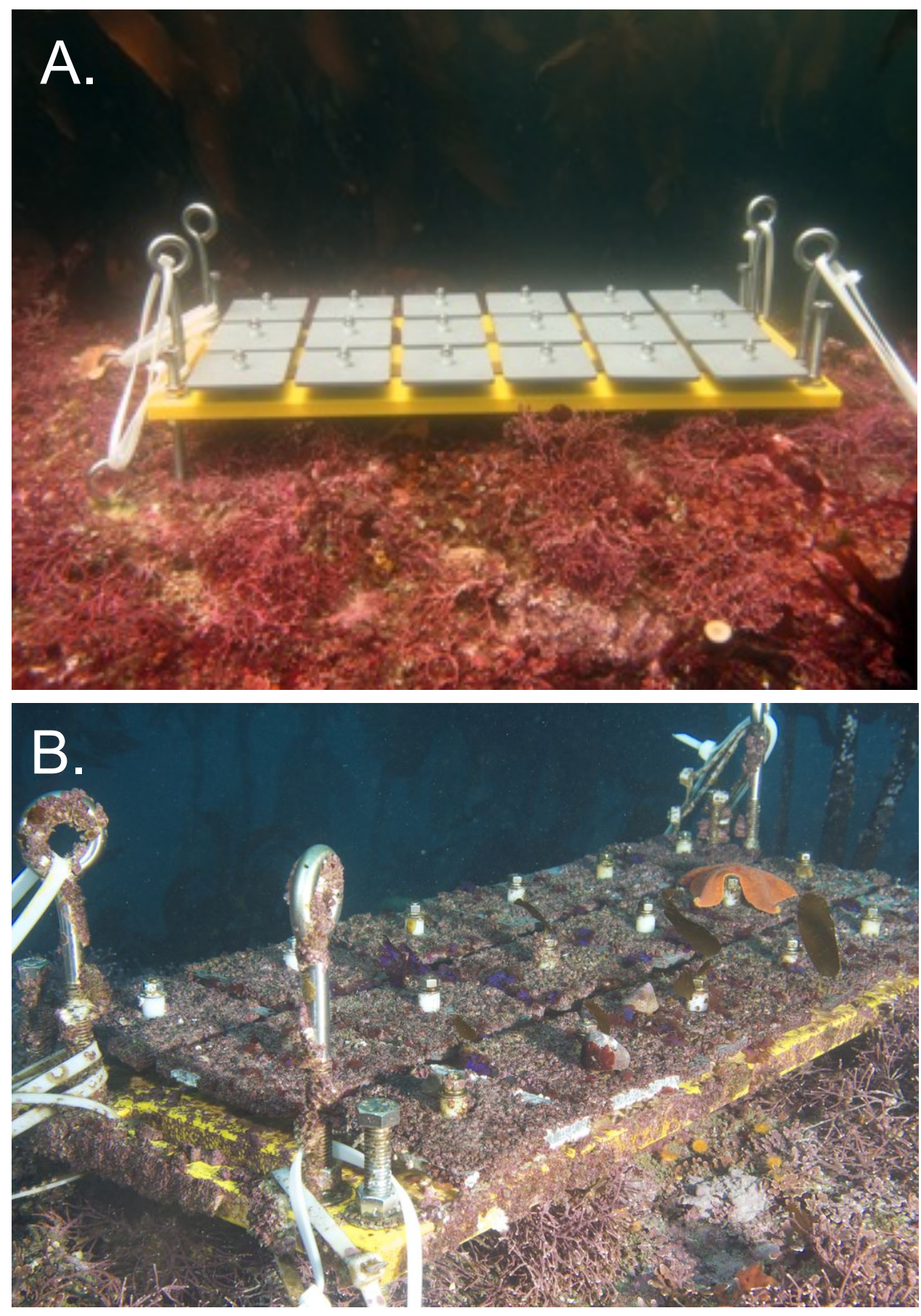

Figure 1. Settlement tile array containing $18-100 \mathrm{~cm}^{2}$ PVC settlement tiles deployed in the kelp forest at Stillwater Cove, Carmel, CA (A) upon deployment and $(B)$ after $\sim 9$ months in the field. 


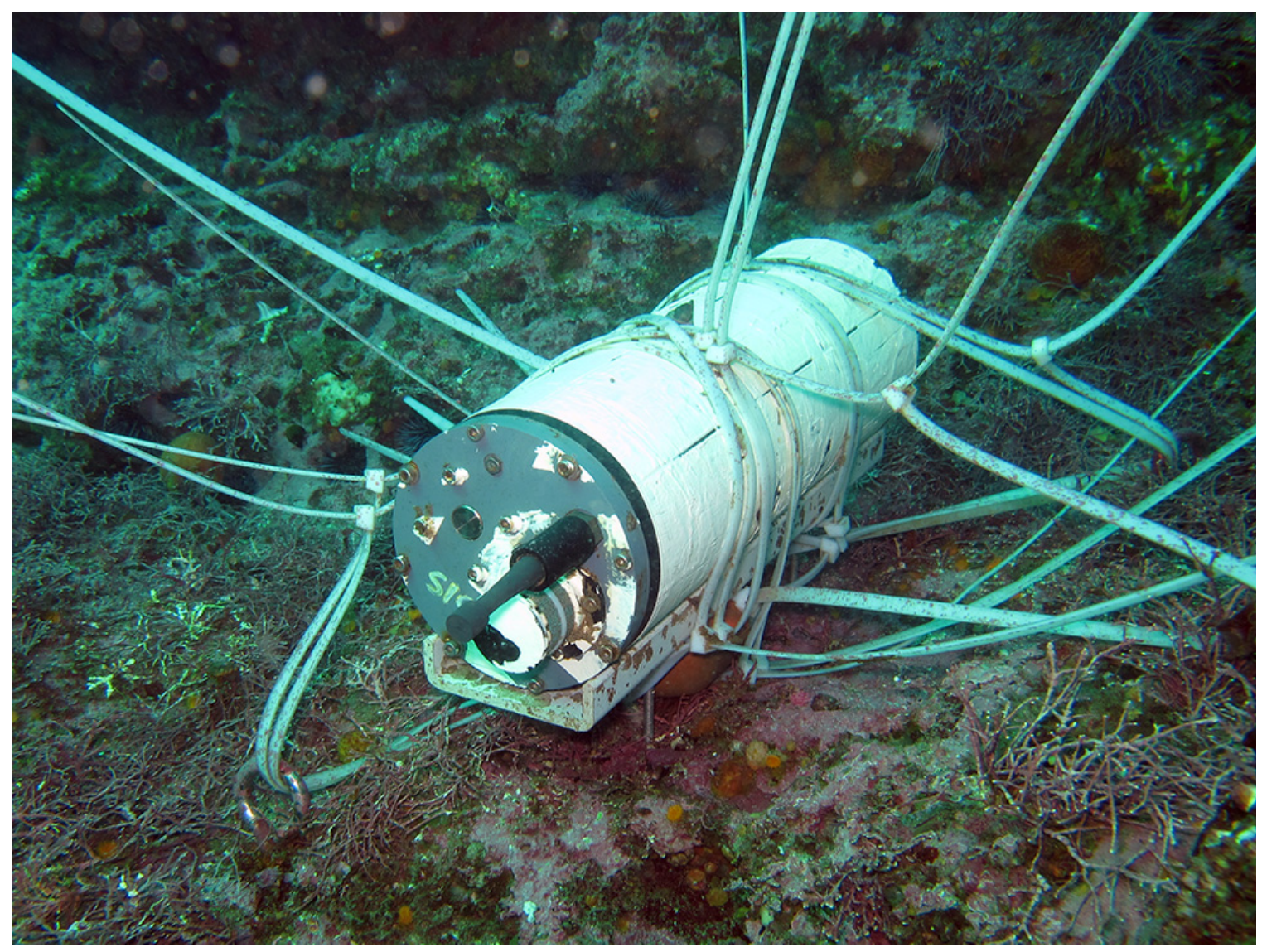

Figure 2. Autonomous SeaFET temperature and $\mathrm{pH}$ sensor deployed in a kelp forest at Stillwater Cove, Carmel, CA.

All community tile experimental rearing was carried out in the same flowthrough system as described for the coralline algae experiment explained in detail in Chapter 1 (Fig. 3). Briefly, the seawater bubbling system bubbled $\mathrm{CO}_{2}$ into individual mesocosms supplied with flow-through seawater. Treatment $p \mathrm{CO}_{2}$ conditions were created by continuously bubbling a $\mathrm{CO}_{2}$-air gas blend into each individual mesocosm at a rate that lowered the $\mathrm{pH}$ by $0.4 \pm 0.05$ units. This treatment $\mathrm{pH}$ was chosen to represent future ocean conditions by the year 2100 
as specified by the IPCC's A2 emission scenario (IPCC 2007). Ambient mesocosms were also supplied with air originating from the same source as the $\mathrm{CO}_{2}$-air gas blend used in the treatment conditions. Two distinct $p \mathrm{CO}_{2}$ treatment conditions were maintained for the entirety of the experiment $\left(\right.$ ambient $p \mathrm{CO}_{2}=$ $\sim 450 \mu$ atm and treatment $\left.p \mathrm{CO}_{2}=\sim 1800 \mu \mathrm{atm}\right)$. In addition to $p \mathrm{CO}_{2}$, grazers were added to half of the mesocosms to yield a total of four factorial treatments (ambient $p \mathrm{CO}_{2}$-grazer, ambient $p \mathrm{CO}_{2}+$ grazer, high $p \mathrm{CO}_{2}$-grazer, high $p \mathrm{CO}_{2}$ +grazer). Three or four tiles from each rack (block) were cleaned of mesograzers using forceps and placed into individual square $1.5 \mathrm{~L}$ glass containers (mesocosms) maintained at each of the four factorial treatment conditions ( $n=10$ per treatment, except in the Stillwater Cove experiment ambient $p \mathrm{CO}_{2}$, -grazer treatment where $n=9$ ). Tiles remained free of all grazers and at ambient $p \mathrm{CO}_{2}$ for one week in order to acclimatize to laboratory conditions. Following acclimatization, desired $p \mathrm{CO}_{2}$ treatments were attained by bubbling either ambient air or an ambient air- $\mathrm{CO}_{2}$ gas blend into mesocosms and individual sea urchins (one individual per mesocosm; test diameter $\sim 1.5 \mathrm{~cm}$ ) were placed on tiles specified as +grazer treatments. Tiles were exposed to experimental treatment conditions for 2 months to observe changes in space occupancy and survivorship as a result of differential growth and competitive abilities of various invertebrate and seaweed taxa in response to the experimental conditions. 


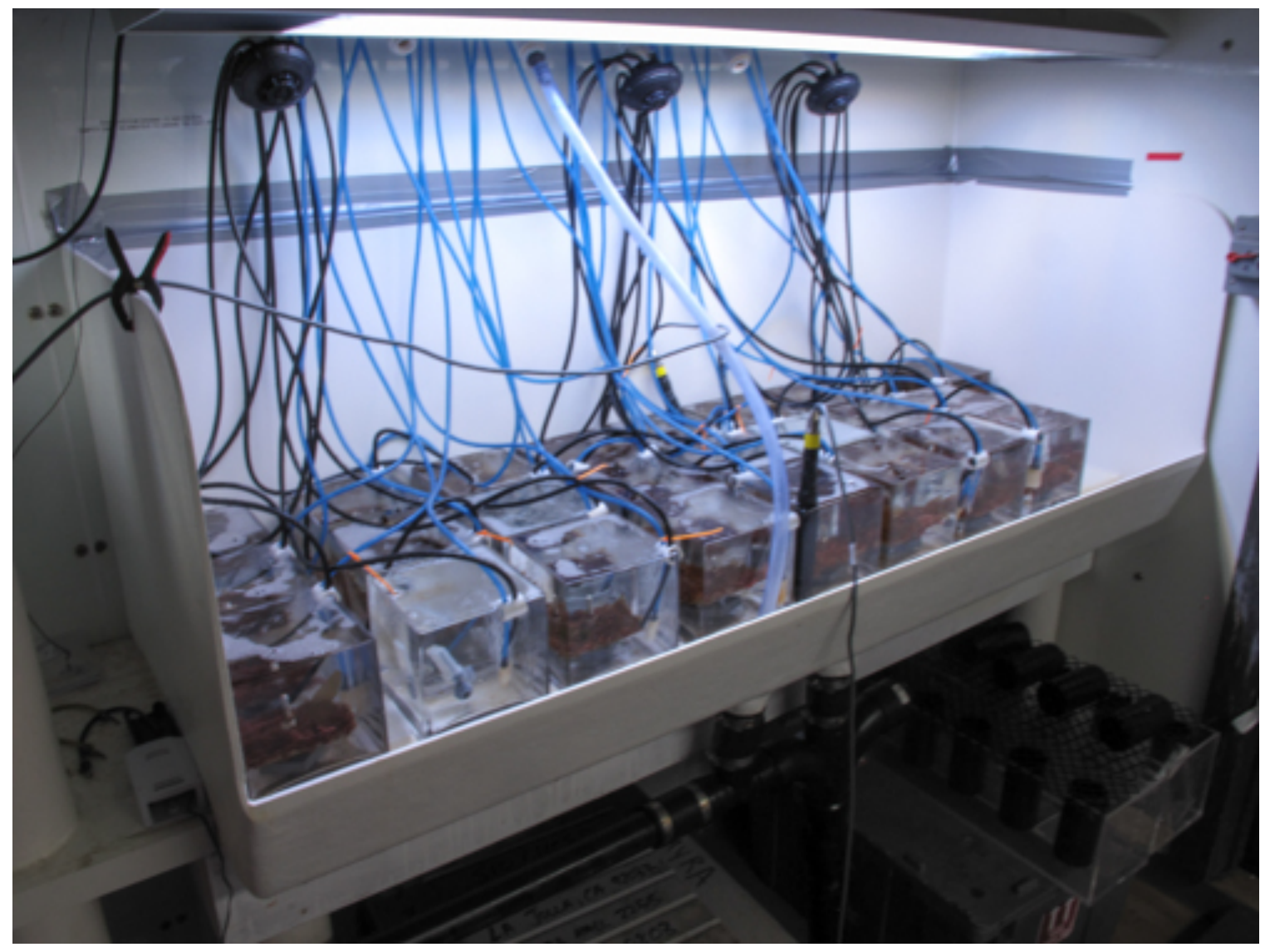

Figure 3. Experimental laboratory mesocosm setup shows individual replicate glass aquaria containing a single settlement tile. Blue lines indicate gas lines bubbling either air or air- $\mathrm{CO}_{2}$ mix. Black lines indicate flow-through seawater.

At the beginning and end of each experiment, all tiles were weighed using the buoyant weight technique to quantify calcification rates on tiles from each of the four treatments. This technique measures net community calcification, taking into account organisms inhabiting both the top and bottom of each tile. Before being placed in treatment conditions and at the end of the experiment, sea urchin grazers were also buoyant weighed and test diameter was measured to the nearest $0.01 \mathrm{~mm}$ using calipers. Percent change in buoyant weight of tiles and 
percent change in buoyant weight of sea urchins and sea urchin test diameter were calculated as, $\frac{W_{f}-W_{i}}{W_{i}}$, where $W_{i}$ is the initial weight and $W_{f}$ is the final weight.

To examine changes in percent cover and community composition of taxa on the tiles in response to the treatment conditions, the top and bottom of each tile were photographed at the start of the experiment and was carefully removed from its mesocosm biweekly and photographed for the duration of the 2-month rearing experiments (Fig. 4, 5). Images were imported into Coral Point Count with Excel extensions (CPCe V4.1, National Coral Reef Institute) and a $10 \times 10$ point grid was overlaid over each photograph. Due to issues of overgrowth making it difficult to discern the space-occupying organism, only photographs from the start of the experiment were analyzed. The space-occupying organism underlying the crosshairs at each grid intersection was identified to the highest taxonomic resolution. These data were pooled to functional group and used to look at differences between tiles and blocks at the onset of the experiment. At the end of the experiment tiles were placed in $4 \%$ formalin in seawater to preserve specimens for subsequent analysis of the emergent effects of $\mathrm{pCO}_{2}$ and grazing on community composition. Fixed tiles were visualized under a dissecting scope and a $10 \times 10$ grid was placed over each tile. The spaceoccupying organism was identified under the crosshairs at each grid intersection. These data were pooled to functional group (i.e.; calcified invertebrates, non- 
calcified invertebrates, calcified algae, fleshy algae, sediment, bare space) for subsequent statistical analyses.
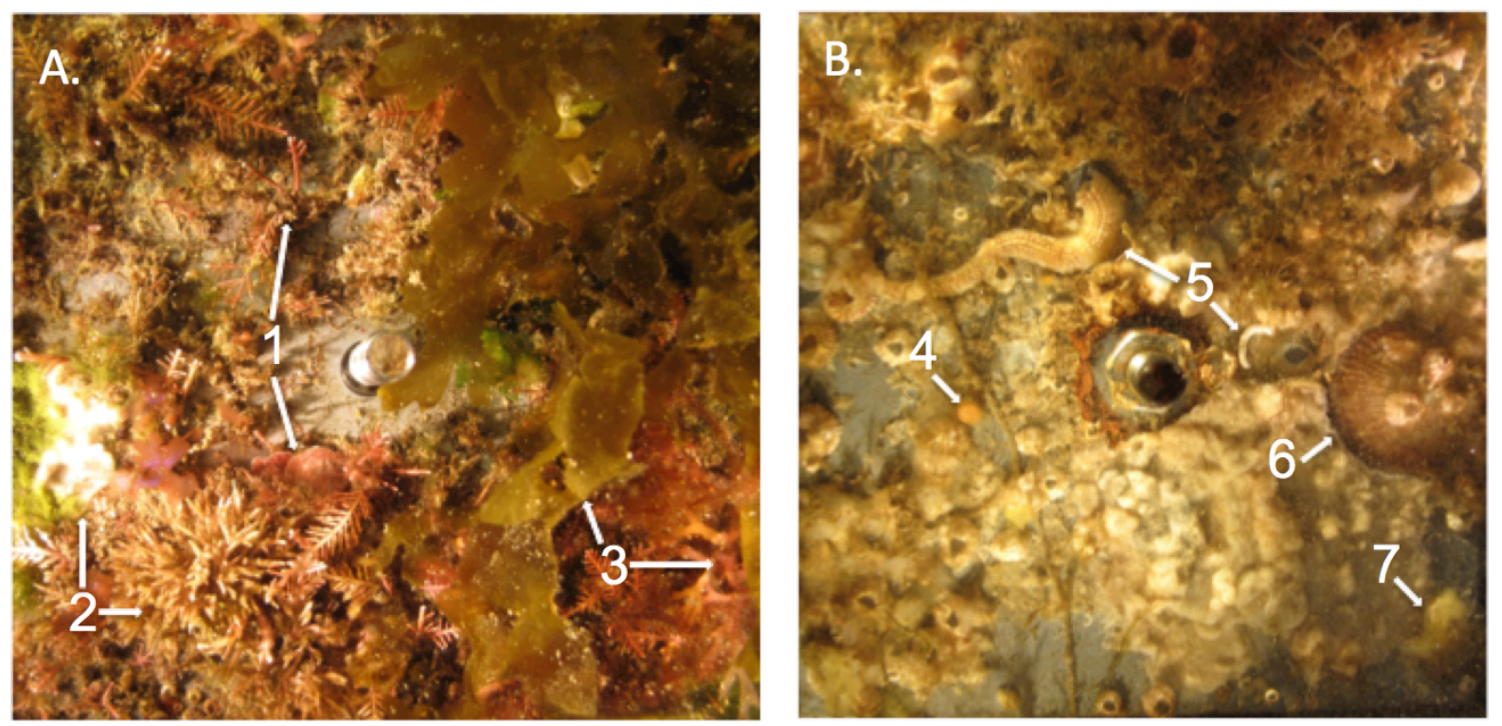

Figure 4. Settlement tile top (A) and bottom (B) from Mia's Reef after 56 days in experimental rearing conditions in the lab. Numbers indicate key taxa $(1=$ calcified algae, 2 = bryozoan, 3 = fleshy macroalgae, 4 = tunicate, $5=$ serpulid worm, 6 = bivalve, 7 = sponge). 

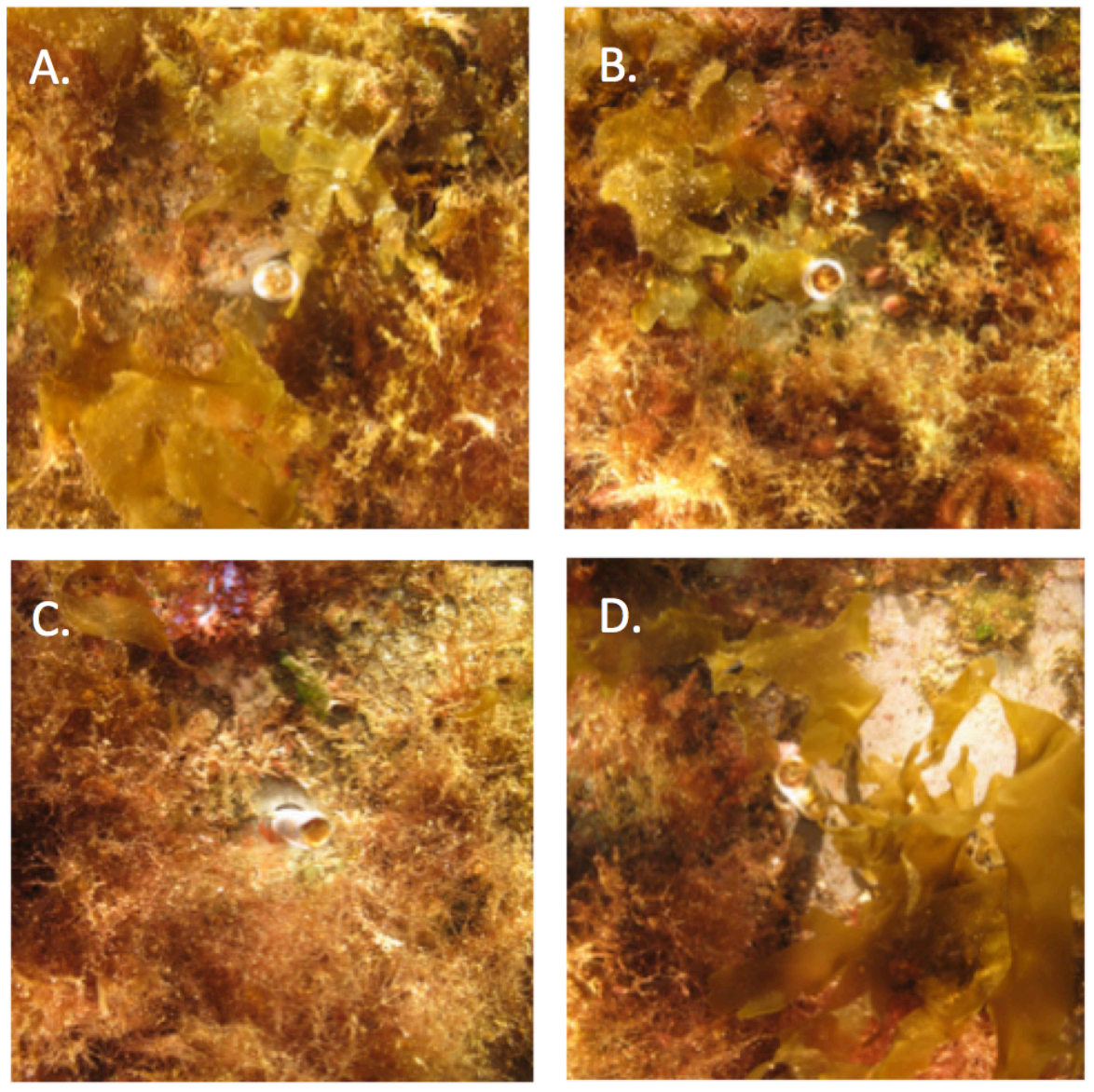

Figure 5. Images of representative settlement tile tops from San Diego, CA after 56 days in experimental conditions. A) ambient $p \mathrm{CO}_{2}$, -grazer; B) ambient $p \mathrm{CO}_{2}$, +grazer; C) high $p \mathrm{CO}_{2}$, -grazer; and D) high $p \mathrm{CO}_{2}$, +grazer.

Because our analysis of community composition only took into account the space-occupying organism on the tile, the abundances of some macroalgae, such as the giant kelp M. pyrifera, may be underrepresented. Therefore, juvenile kelp were removed at the end of the experiment to quantify their density and biomass on community tiles. All kelp were gently removed using forceps, laid flat on waterproof paper, and photographed. After being photographed, juvenile sporophytes were placed in a drying oven at $60^{\circ} \mathrm{C}$ for 48 hours before being 
weighed to calculate biomass as dry weight. Photographs were visualized using Image J software and all kelp sporophytes were counted to obtain a density as individuals per tile.

Sea urchin grazing responses to elevated $p \mathrm{CO}_{2}$ were tested at the end of experiment. All sea urchins were removed from settlement tiles and held under treatment conditions (i.e., high or ambient $p \mathrm{CO}_{2}$ ) in the same mesocosms used during the experiment. Sea urchins were starved for three days before being presented with a single pre-weighed (wet weight) kelp frond collected from the field the same day as the beginning of the grazing trial. Sea urchins were allowed to graze on kelp for 24 hours before the kelp were removed and reweighed (wet weight). The percent change in weight of kelp was calculated as,

$\frac{W_{f}-W_{i}}{W_{i}}$, where $W_{i}$ was the initial weight and $W_{f}$ was the final weight. Urchin grazing rates were calculated as the percent change in wet weight of kelp per day.

\section{Statistical Methods}

Final percent cover of functional group taxa data were normalized and square-root transformed. Analysis of community structure was conducted separately for the top and bottom of the tiles. Bray-Curtis resemblance matrices were calculated from transformed community data. Multidimensional scaling (MDS) plots were constructed from resemblance matrices to visualize the 
similarities between treatments in multidimensional space. Three-factor Permutational Multivariate Analysis of Variance's (PERMANOVA) were run on resemblance matrices using 9999 permutations with fixed factors $p \mathrm{CO}_{2}$, sea urchin, and block. A factor of block was used to test for differences in the initial communities that developed on each settlement tile rack $(n=3)$ and their subsequent composition, which could have resulted from micro-scale variability in environmental conditions (i.e., light and temperature), settlement behavior, or ecological processes (competition and mortality). Where a significant block effect was found in the PERMANOVA results $\left(P_{\text {perm }}<0.05\right)$, two-way PERMANOVA's were run on community structure data with fixed factors of $p \mathrm{CO}_{2}$ and sea urchin grazing as separate blocks. Highly non-significant interactions $(P>0.25)$ were removed from statistical models.

Three-factor PERMANOA's were conducted on univariate variables (functional groups) with fixed factors of $p \mathrm{CO}_{2}$, sea urchin, and block to ascertain which group or groups explained the differences in community composition seen between treatments. In the case where a significant block effect was found in three-way PERMANOVA results, two-way PERMANOVA's were run on univariate variables with fixed factors of $p \mathrm{CO}_{2}$ and urchin as separate blocks. Highly non-significant interactions $(P>0.25)$ were removed from statistical models.

Permutation-based approaches were run with 9999 permutations of square-root transformed data. A dummy variable $=1$ was added to functional 
groups in which two or more samples contained a value of zero thus precluding the calculation of Bray-Curtis dissimilarities. All permutation-based analyses were carried out in PRIMER v6 (PRIMER-E Ltd, Plymouth, UK). General linear models with fixed factors $p \mathrm{CO}_{2}$, sea urchin, and block were conducted on square-root transformed variables of kelp biomass (dry weight) and kelp density on the tiles.

t-tests were used to compare differences between initial mean sea urchin buoyant weight and sea urchin test diameter between the ambient and high $p \mathrm{CO}_{2}$ grazing assays. Sea urchin grazing rates, percent change in buoyant weight day ${ }^{-1}$ and percent change in sea urchin diameter day ${ }^{-1}$ were also compared using t-tests. Kruskal-Wallis tests were used when variables violated assumptions of normality. All tests were carried out in JMP Pro 12 v12.0.0.

Mean SeaFET pH and temperature were calculated at each site. By better understanding the natural variability in $\mathrm{pH}$ and temperature at each site I was able to better interpret the results of community tile experiments. Organisms that inhabit more variable or low $\mathrm{pH}$ environments may be more resilient to $\mathrm{OA}$ and warming and therefore may be less likely to show shifts in abundance and diversity. 


\section{Results}

\section{Mia's Reef, San Diego, CA \\ Experimental Conditions}

Two distinct $p \mathrm{CO}_{2}$ treatments were maintained for the duration of the 56day experiment (Table 1; Fig. 6). Ambient $p \mathrm{CO}_{2}$ treatments were $0.39 \mathrm{pH}$ units higher than high $p \mathrm{CO}_{2}$ treatments. Ambient mesocosm temperatures were approximately $13^{\circ} \mathrm{C}$ for the duration of the experiment. In situ measurements of $\mathrm{pH}$ and temperature from autonomous SeaFET loggers recorded a mean $\mathrm{pH}=$

8.02 and mean temperature $\sim 15^{\circ} \mathrm{C}$ from October 23, 2013 - April 12, 2014 (Table 1; Fig. 7). 


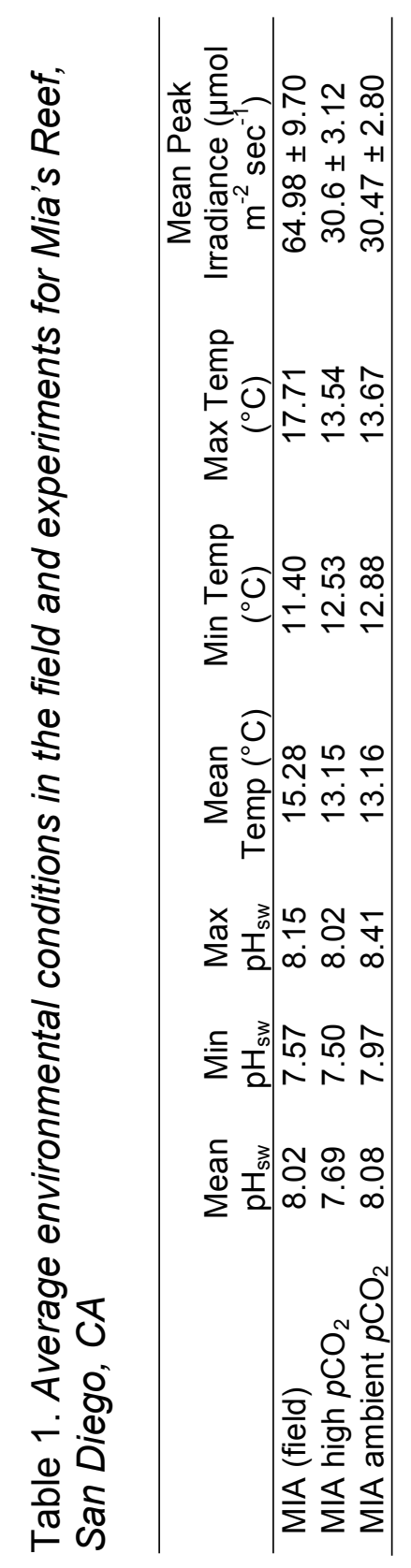




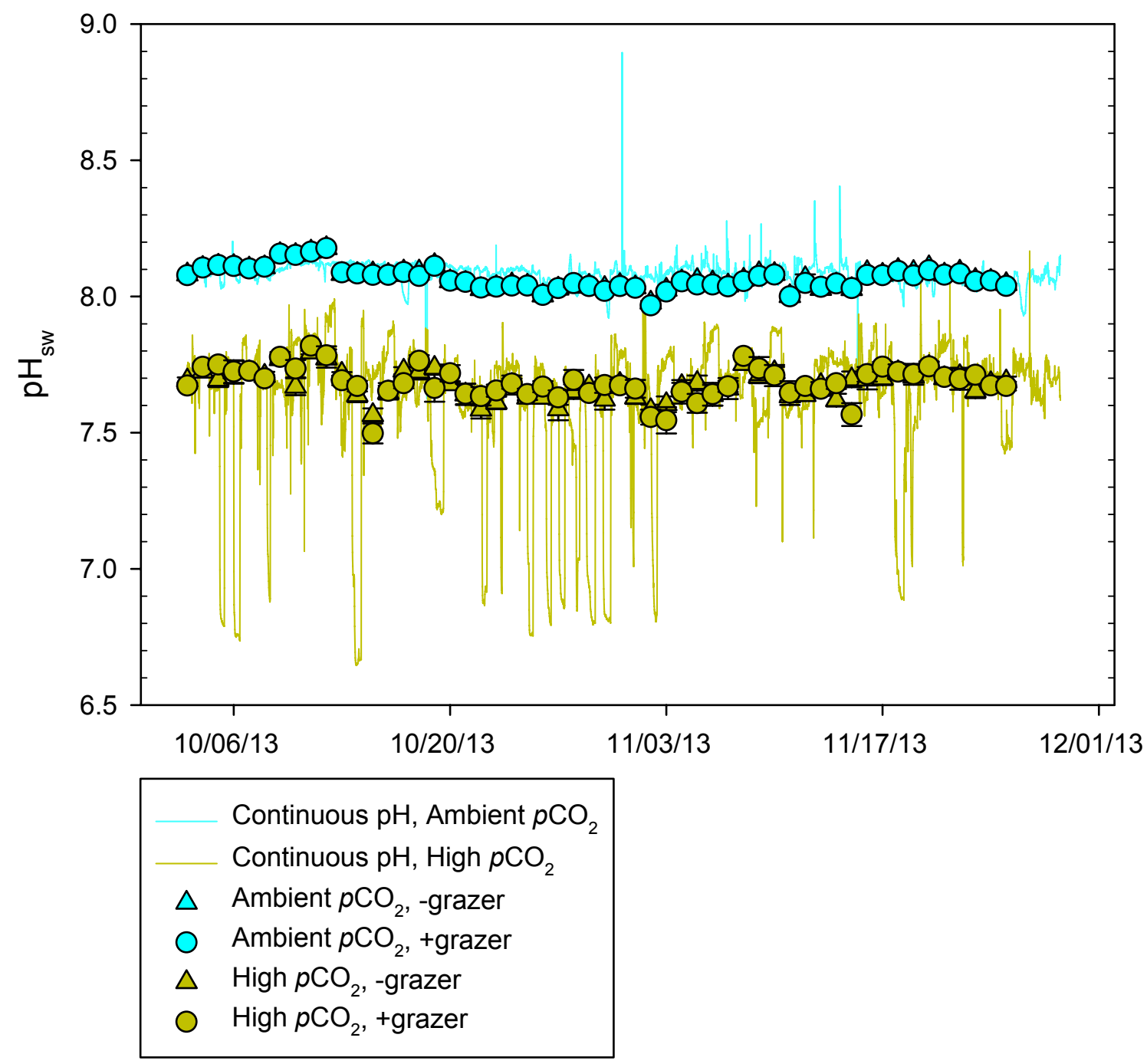

Figure 6. Daily experimental $\mathrm{pH}$ and temperature conditions in mesocosms for the duration of the 56-day experiment with tiles from Mia's Reef. $\mathrm{pH}_{\mathrm{sw}}$, with symbols representing average daily $\mathrm{HACH}$ pH glass electrode measurements \pm $\mathrm{SE}$. Solid lines represent continuous pH measurements from Honeywell Durafet. 

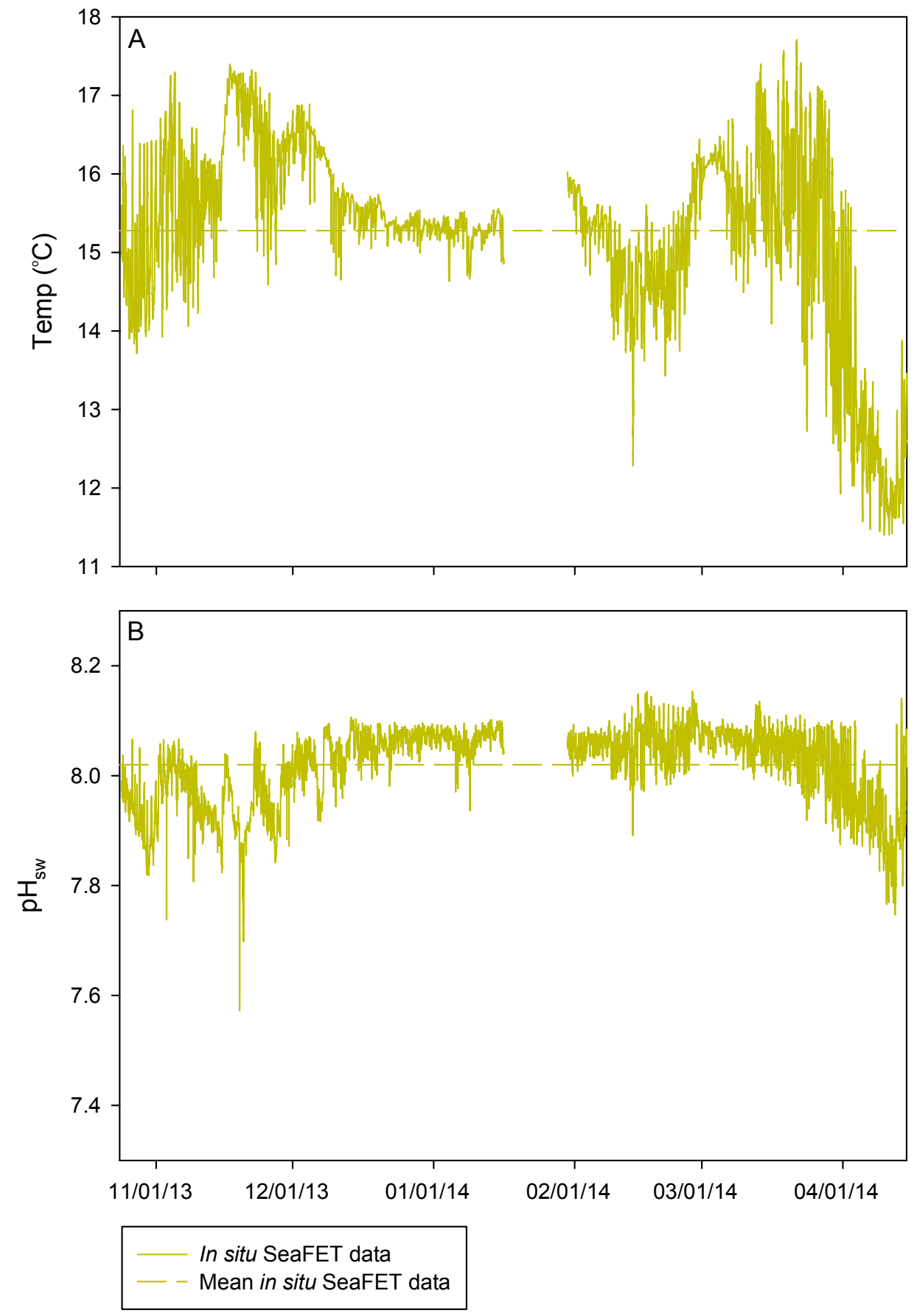

Figure 7. In situ $\mathrm{pH}$ and temperature data collected from autonomous SeaFET sensor deployed at Mia's Reef, San Diego, CA. Instrument was deployed at $15 \mathrm{~m}$ and data were collected every $15 \mathrm{~min}$. Panel A shows temperature $\left({ }^{\circ} \mathrm{C}\right)$. Panel B shows $\mathrm{pH}_{\mathrm{sw}}$. 
Mean irradiance levels in treatment conditions were approximately 30 $\mu \mathrm{mol} \mathrm{m} \mathrm{mec}^{-1}$. In situ measurements of irradiance were higher at $\sim 65 \mu \mathrm{mol} \mathrm{m}{ }^{-2}$ $\sec ^{-1}$ from October 6, 2013 to October 25, 2013 (Table 1; Fig. 8).

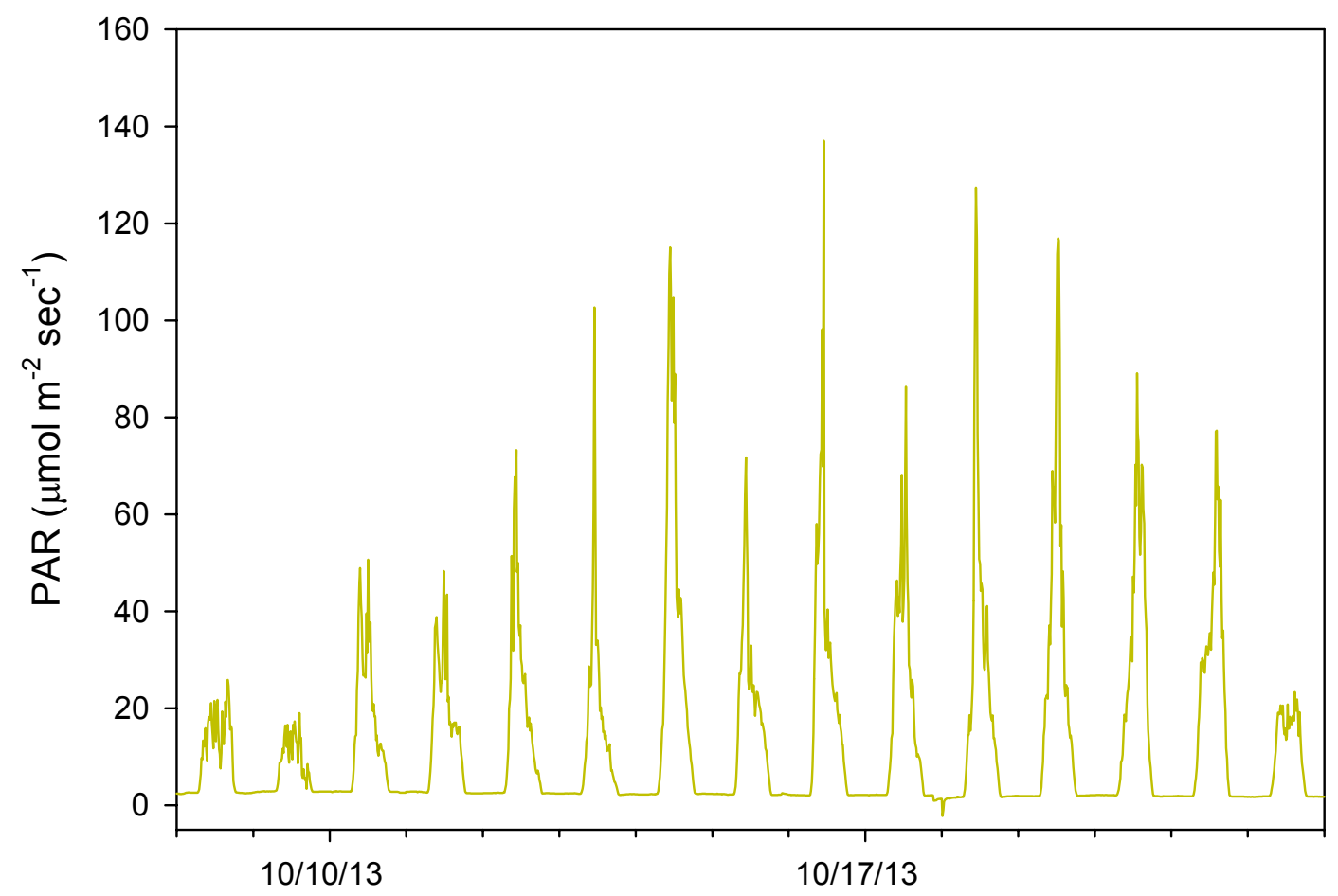

In situ PAR at Mia's Reef, San Diego, CA

Figure 8. In situ irradiance measurements (PAR) at Mia's Reef, San Diego, CA from October 6, 2013 to October 25, 2013.

\section{Buoyant Weight}

Final buoyant weights of tiles from Mia's Reef, after 56 days in treatment conditions, were almost always lower than initial buoyant weights (i.e., a net loss of calcium carbonate) across all treatments during the duration of the experiment 
(Fig. 9). I observed a significant reduction in the buoyant weight of organisms living on the tiles in high $p \mathrm{CO}_{2}$ treatments and treatments that included urchin grazers, relative to the control $p \mathrm{CO}_{2}$ tiles and those without grazers. High $p \mathrm{CO}_{2}$ increased the loss in buoyant weight relative to the control (ambient $p \mathrm{CO}_{2}$, urchin) by $58 \%$ in the absence of grazers and and $68 \%$ in the presence of grazers. Under ambient $p \mathrm{CO}_{2}$, the presence of urchins increased the loss in buoyant weight by $24 \%$ relative to the control treatment. There was also a significant effect of block, with block A having a higher percent change in buoyant weight than blocks $\mathrm{B}$ and $\mathrm{C}$. There was no effect of the interaction between $p \mathrm{CO}_{2}$ and sea urchin grazing on buoyant weight (three-way ANOVA $F_{5,34}=$ 13.868, $P=<0.0001$; Table 2: Fig. 9).

Table 2. ANOVA results for the effects of $\mathrm{pCO}_{2}$ (ambient and high), urchins (presence and absence), and block ( $A, B$ and $C$ ) on the change in buoyant weight of tile communities from Mia's Reef.

\begin{tabular}{|c|c|c|c|c|}
\hline Source of variation & $d f$ & Sum of squares & F-statistic & $P$-value \\
\hline $\mathrm{pCO}_{2}$ & 1 & 0.0217 & 40.7229 & $<0.0001^{*}$ \\
\hline Urchin & 1 & 0.0033 & 6.1688 & $0.0181^{*}$ \\
\hline$p \mathrm{CO}_{2} \times$ Urchin & 1 & 0.0002 & 0.4262 & 0.5183 \\
\hline Block & 2 & 0.0109 & 10.2083 & $0.0003^{*}$ \\
\hline Error & 34 & 0.0181 & & \\
\hline
\end{tabular}




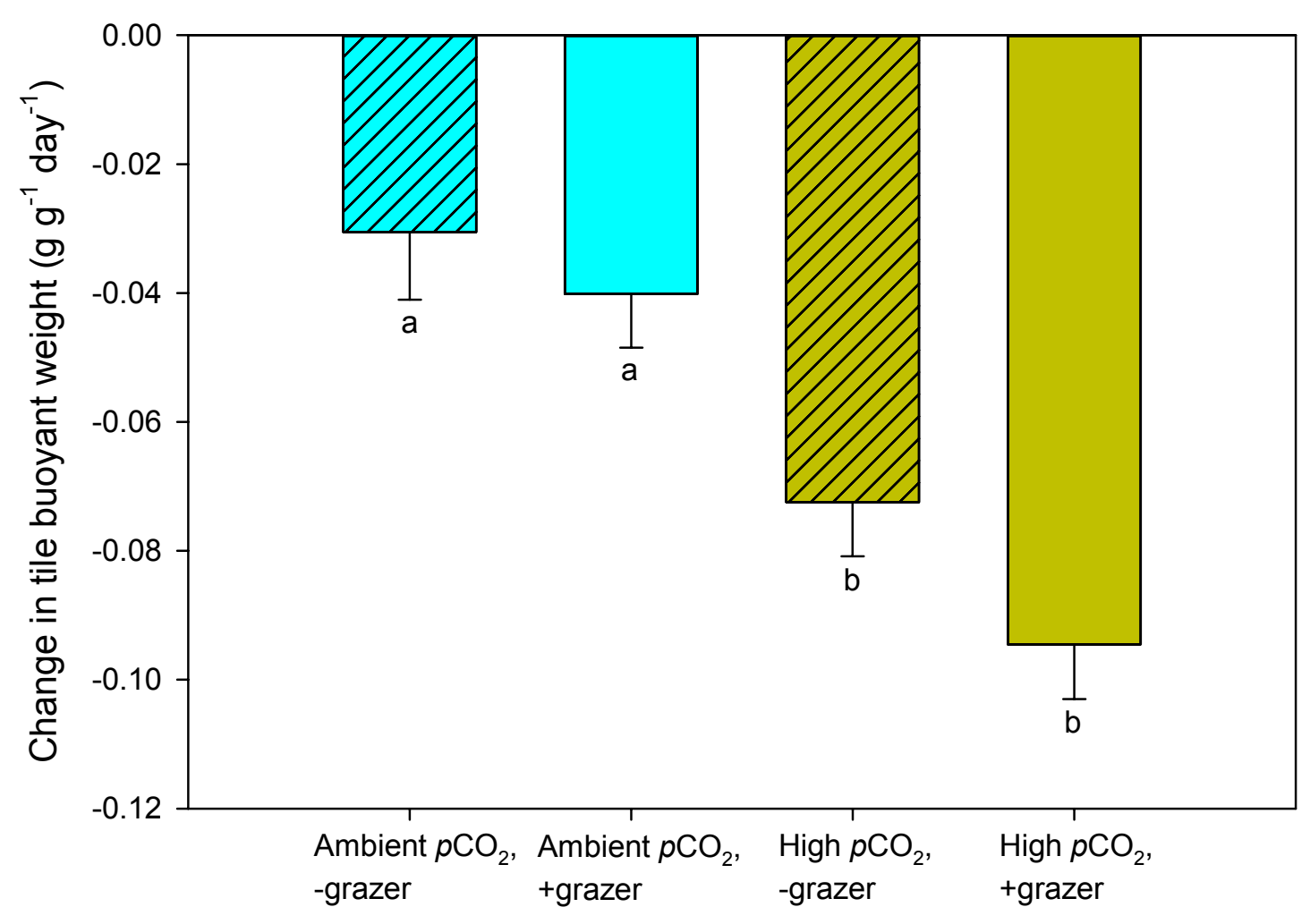

Figure 9. Percent change in buoyant weight of settlement tiles from Mia's Reef. Shared letters below error bars indicate mean change in buoyant weight did not differ between treatments. Error bars denote $\pm \mathrm{SE}$.

\section{Community Composition}

Six functional groups were identified on the tops and bottoms of tiles.

These groups included calcified invertebrates (bryozoans, barnacles and serpulid worms), non-calcified invertebrates (sponges, anemones and tunicates), calcified algae, fleshy algae, sediment, and bare space (Figs. 4, 5). Following two months exposure to the experimental treatments, I found a marginally significant effect of $p \mathrm{CO}_{2}$ on community composition $(P=0.059)$, but no effect of sea urchin grazing or the interaction of $p \mathrm{CO}_{2} \times$ grazing (Table 3; Fig. 10D). However, there was also 
a highly significant effect of block on community composition on the top of tiles (Table 3), indicating that the final community composition depended on the structure of the initial assemblage. Due to the significant block effect and marginally non-significant $p \mathrm{CO}_{2}$ effect, separate PERMANOVAs were run on all three blocks. I found significant main effects of $p \mathrm{CO}_{2}$ and sea urchin grazing on community structure in Block A (Table 3; Fig. 10A), but a highly non-significant interaction term that was dropped from the model. The species assemblages tended to cluster together in multivariate space as a function of the individual treatment they occurred in. There was a significant effect of $p \mathrm{CO}_{2}$ on community composition in Block B (Table 3; Fig. 10B). Tiles from the high $\mathrm{pCO}_{2}$ treatments clustered together in multivariate space, while tiles from the ambient $p \mathrm{CO}_{2}$ treatments grouped separately. There were no significant differences in community structure in Block $\mathrm{C}$ when the interaction of $p \mathrm{CO}_{2} \times$ grazer was included in our model. Without the interaction, I found significant $p \mathrm{CO}_{2}$ effects on community structure (Table 3; Fig. 10C), such that tiles from the ambient $p \mathrm{CO}_{2}$ treatments clustered separately from the tiles in the high $\mathrm{pCO}_{2}$ treatments. 
Table 3. PERMANOVA results of the effects of $\mathrm{pCO}_{2}$ (ambient and high), sea urchins (presence and absence), and block ( $A, B$ and $C$ ) on community composition on the tops of settlement tiles from Mia's Reef.

\begin{tabular}{|c|c|c|c|c|}
\hline Source of variation & $d f$ & Mean squares & Pseudo- $F$ & $P($ perm $)$ \\
\hline \multicolumn{5}{|l|}{ All } \\
\hline$p \mathrm{CO}_{2}$ & 1 & 286.310 & 2.258 & 0.059 \\
\hline Grazer & 1 & 118.150 & 0.932 & 0.460 \\
\hline$p \mathrm{CO}_{2} \times$ grazer & 1 & 123.780 & 0.976 & 0.430 \\
\hline Block & 2 & 1049.400 & 8.276 & 0.001 \\
\hline Residuals & 34 & 126.790 & & \\
\hline \multicolumn{5}{|l|}{ Block $A$} \\
\hline$p \mathrm{CO}_{2}$ & 1 & 311.120 & 2.493 & 0.041 \\
\hline Grazer & 1 & 337.250 & 2.703 & 0.043 \\
\hline Residuals & 10 & 124.790 & & \\
\hline \multicolumn{5}{|l|}{ Block B } \\
\hline$p \mathrm{CO}_{2}$ & 1 & 306.120 & 3.265 & 0.021 \\
\hline Grazer & 1 & 25.150 & 0.268 & 0.911 \\
\hline$p \mathrm{CO}_{2} \times$ grazer & 1 & 81.582 & 0.870 & 0.499 \\
\hline Residuals & 10 & 93.759 & & \\
\hline \multicolumn{5}{|l|}{ Block C } \\
\hline$p \mathrm{CO}_{2}$ & 1 & 289.600 & 2.352 & 0.034 \\
\hline Grazer & 1 & 64.809 & 0.526 & 0.724 \\
\hline Residuals & 10 & 123.150 & & \\
\hline
\end{tabular}



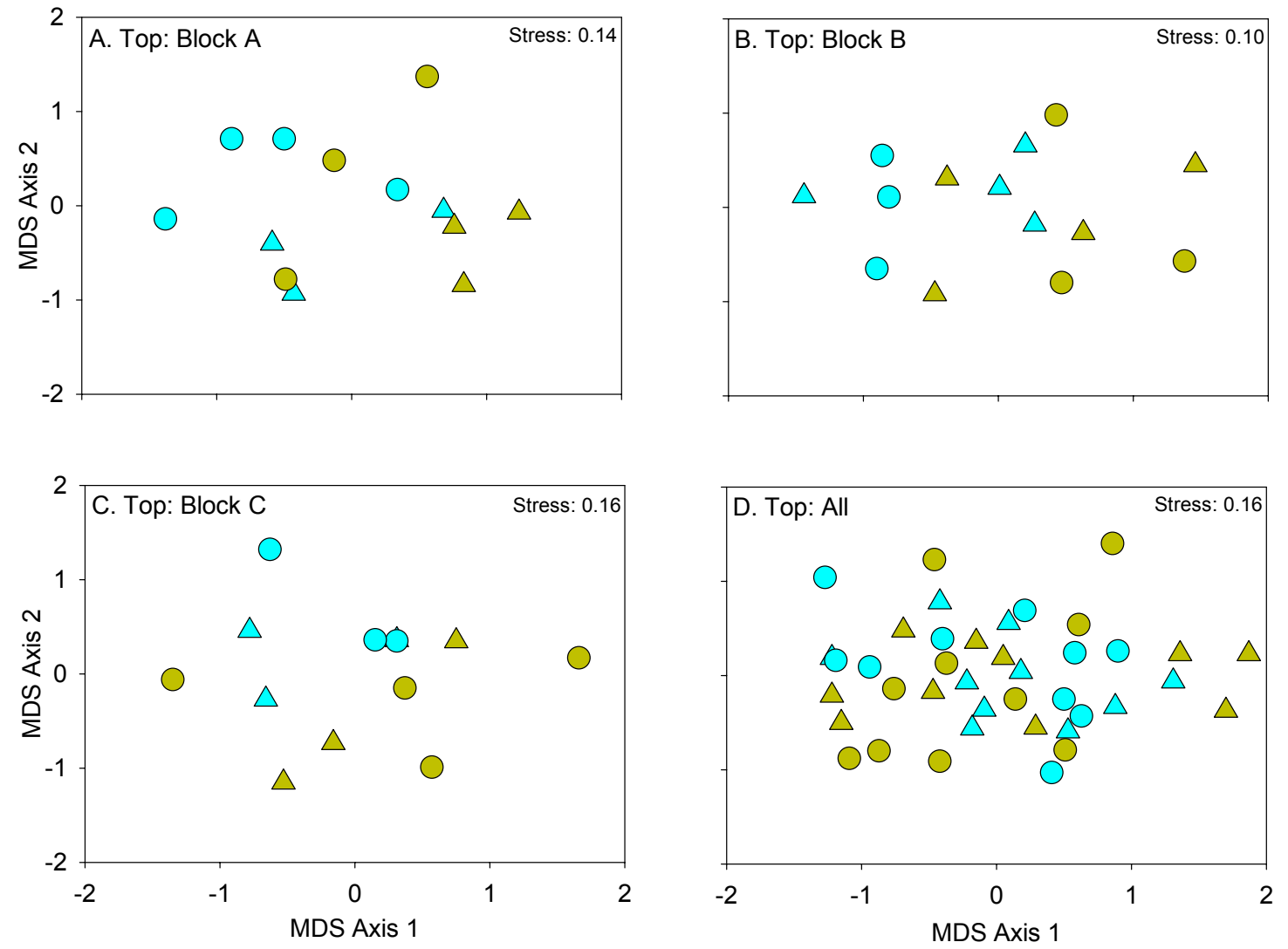

Top Tile Assemblage
$\triangle$ Ambient $p \mathrm{CO}_{2}$, -grazer
$\bigcirc \quad$ Ambient $p \mathrm{CO}_{2}$, +grazer
$\triangle$ High $\mathrm{CO}_{2}$, - grazer
$\bigcirc \quad$ High $p \mathrm{CO}_{2}$, +grazer

Figure 10. nMDS plots showing dissimilarities in community composition between settlement tile benthic assemblages from Mia's Reef reared in experimental $p \mathrm{CO}_{2}$ and urchin treatments. Points (tiles) closer together indicate communities more similar than points further apart. A-C show nMDS plots of community data from the top of tiles separated by block, $D$ shows all community data from the top of tiles together.

Further analyses conducted on the responses of individual functional groups helped to explain which group or groups contributed to differences in 
community composition observed among treatments. In Block A (top), we found significant effects of both $\mathrm{pCO}_{2}$ and grazing (Table 4; Fig. 11A). At ambient $p \mathrm{CO}_{2}$, grazing reduced fleshy algal cover by $35 \%$; however, at high $p \mathrm{CO}_{2}$, fleshy algal cover was $26 \%$ in the absence of grazing. In Block B (top), I found a $\sim 35 \%$ lower percent cover of sediment on tiles reared in high $p \mathrm{CO}_{2}$, but observed $\sim 27 \%$ higher cover of bare space in the high $p \mathrm{CO}_{2}$ conditions (Table 5; Fig. 11B). On average I found a $45 \%$ higher percent cover of calcified sessile invertebrates at ambient $p \mathrm{CO}_{2}$ than in high $p \mathrm{CO}_{2}$ treatments on Block $\mathrm{C}$ (top) (Table 6; Fig. 11C). 
Table 4. PERMANOVA results of the effects of $\mathrm{pCO}_{2}$ (ambient and high) and grazers (presence and absence) on community composition on the top of Block A tiles from Mia's Reef.

\begin{tabular}{|c|c|c|c|c|}
\hline Source of variation & $d f$ & Mean squares & Pseudo- $F$ & $P($ perm $)$ \\
\hline \multicolumn{5}{|c|}{ Calcified invertebrates } \\
\hline $\mathrm{pCO}_{2}$ & 1 & 31.513 & 0.137 & 0.839 \\
\hline Grazer & 1 & 104.610 & 0.455 & 0.563 \\
\hline$p \mathrm{CO}_{2} \times$ grazer & 1 & 62.399 & 0.271 & 0.691 \\
\hline Residuals & 9 & 230.020 & & \\
\hline \multicolumn{5}{|c|}{ Non-calcified invertebrates } \\
\hline $\mathrm{pCO}_{2}$ & 1 & 517.540 & 0.452 & 0.768 \\
\hline Grazer & 1 & 1519.500 & 1.327 & 0.285 \\
\hline$p \mathrm{CO}_{2} \times$ grazer & 1 & 493.630 & 0.431 & 0.784 \\
\hline Residuals & 9 & 1144.800 & & \\
\hline \multicolumn{5}{|l|}{ Calcified algae } \\
\hline$p \mathrm{CO}_{2}$ & 1 & 409.230 & 1.104 & 0.327 \\
\hline Grazer & 1 & 1518.200 & 4.094 & 0.069 \\
\hline$p \mathrm{CO}_{2} \times$ grazer & 1 & 416.090 & 1.122 & 0.327 \\
\hline Residuals & 9 & 370.810 & & \\
\hline \multicolumn{5}{|l|}{ Fleshy algae } \\
\hline$p \mathrm{CO}_{2}$ & 1 & 253.430 & 6.089 & 0.034 \\
\hline Grazer & 1 & 242.000 & 5.815 & 0.036 \\
\hline Residuals & 10 & 416.180 & & \\
\hline \multicolumn{5}{|l|}{ Sediment } \\
\hline$p \mathrm{CO}_{2}$ & 1 & 76.406 & 1.036 & 0.324 \\
\hline Grazer & 1 & 262.410 & 3.558 & 0.088 \\
\hline$p \mathrm{CO}_{2} \times$ grazer & 1 & 53.146 & 0.721 & 0.417 \\
\hline Residuals & 9 & 73.758 & & \\
\hline \multicolumn{5}{|l|}{ Bare space } \\
\hline $\mathrm{pCO}_{2}$ & 1 & 1123.300 & 3.699 & 0.067 \\
\hline Grazer & 1 & 458.950 & 1.511 & 0.235 \\
\hline$p \mathrm{CO}_{2} \times$ grazer & 1 & 253.240 & 0.834 & 0.408 \\
\hline Residuals & 9 & 303.680 & & \\
\hline
\end{tabular}


Table 5. PERMANOVA results of the effects of $\mathrm{pCO}_{2}$ (ambient and high) and grazers (presence and absence) on community composition on the top of Block $B$ tiles from Mia's Reef.

\begin{tabular}{|c|c|c|c|c|}
\hline Source of variation & $d f$ & Mean squares & Pseudo- $F$ & $P$ (perm) \\
\hline \multicolumn{5}{|c|}{ Calcified invertebrates } \\
\hline $\mathrm{pCO}_{2}$ & 1 & 57.743 & 0.267 & 0.695 \\
\hline Grazer & 1 & 26.032 & 0.121 & 0.848 \\
\hline $\mathrm{pCO}_{2} \times$ grazer & 1 & 467.750 & 2.166 & 0.173 \\
\hline Residuals & 10 & 215.970 & & \\
\hline \multicolumn{5}{|c|}{ Non-calcified invertebrates } \\
\hline $\mathrm{pCO}_{2}$ & 1 & 5.465 & 0.014 & 0.980 \\
\hline Grazer & 1 & 199.950 & 0.499 & 0.532 \\
\hline$p \mathrm{CO}_{2} \times$ grazer & 1 & 323.960 & 0.809 & 0.397 \\
\hline Residuals & 10 & 400.390 & & \\
\hline \multicolumn{5}{|l|}{ Calcified algae } \\
\hline $\mathrm{pCO}_{2}$ & 1 & 927.310 & 1.105 & 0.389 \\
\hline Grazer & 1 & 1031.400 & 1.229 & 0.301 \\
\hline$p \mathrm{CO}_{2} \times$ grazer & 1 & 1044.400 & 1.244 & 0.292 \\
\hline Residuals & 10 & 839.480 & & \\
\hline \multicolumn{5}{|l|}{ Fleshy algae } \\
\hline $\mathrm{pCO}_{2}$ & 1 & 0.537 & 0.011 & 0.941 \\
\hline Grazer & 1 & 2.776 & 0.056 & 0.831 \\
\hline$p \mathrm{CO}_{2} \times$ grazer & 1 & 3.246 & 0.066 & 0.817 \\
\hline Residuals & 10 & 49.464 & & \\
\hline \multicolumn{5}{|l|}{ Sediment } \\
\hline$p \mathrm{CO}_{2}$ & 1 & 852.480 & 6.919 & 0.027 \\
\hline Grazer & 1 & 31.682 & 0.257 & 0.663 \\
\hline$p \mathrm{CO}_{2} \times$ grazer & 1 & 61.068 & 0.496 & 0.510 \\
\hline Residuals & 10 & 123.200 & & \\
\hline \multicolumn{5}{|l|}{ Bare space } \\
\hline $\mathrm{pCO}_{2}$ & 1 & 390.790 & 10.870 & 0.008 \\
\hline Grazer & 1 & 38.579 & 1.073 & 0.318 \\
\hline$p \mathrm{CO}_{2} \times$ grazer & 1 & 120.390 & 3.349 & 0.098 \\
\hline Residuals & 10 & 35.950 & & \\
\hline
\end{tabular}


Table 6. PERMANOVA results of the effects of $\mathrm{pCO}_{2}$ (ambient and high) and grazers (presence and absence) on community composition on the top of Block C tiles from Mia's Reef.

\begin{tabular}{|c|c|c|c|c|}
\hline Source of variation & $d f$ & Mean squares & Pseudo- $F$ & $P($ perm $)$ \\
\hline \multicolumn{5}{|c|}{ Calcified invertebrates } \\
\hline$p \mathrm{CO}_{2}$ & 1 & 779.740 & 5.089 & 0.045 \\
\hline Grazer & 1 & 101.660 & 0.663 & 0.481 \\
\hline$p \mathrm{CO}_{2} \times$ grazer & 1 & 69.638 & 0.455 & 0.576 \\
\hline Residuals & 9 & 153.210 & & \\
\hline \multicolumn{5}{|c|}{ Non-calcified invertebrates } \\
\hline$p \mathrm{CO}_{2}$ & 1 & 1349.400 & 2.505 & 0.139 \\
\hline Grazer & 1 & 162.540 & 0.302 & 0.684 \\
\hline$p \mathrm{CO}_{2} \times$ grazer & 1 & 2.673 & 0.005 & 0.993 \\
\hline Residuals & 9 & 538.710 & & \\
\hline \multicolumn{5}{|l|}{ Calcified algae } \\
\hline $\mathrm{pCO}_{2}$ & 1 & 1322.200 & 1.529 & 0.249 \\
\hline Grazer & 1 & 957.250 & 1.107 & 0.404 \\
\hline$p \mathrm{CO}_{2} \times$ grazer & 1 & 947.300 & 1.095 & 0.412 \\
\hline Residuals & 9 & 864.860 & & \\
\hline \multicolumn{5}{|l|}{ Fleshy algae } \\
\hline$p \mathrm{CO}_{2}$ & 1 & 334.150 & 0.988 & 0.363 \\
\hline Grazer & 1 & 226.360 & 0.670 & 0.471 \\
\hline$p \mathrm{CO}_{2} \times$ grazer & 1 & 582.730 & 1.724 & 0.223 \\
\hline Residuals & 9 & 338.100 & & \\
\hline \multicolumn{5}{|l|}{ Sediment } \\
\hline$p \mathrm{CO}_{2}$ & 1 & 67.310 & 0.856 & 0.371 \\
\hline Grazer & 1 & 4.838 & 0.062 & 0.839 \\
\hline$p \mathrm{CO}_{2} \times$ grazer & 1 & 23.392 & 0.298 & 0.603 \\
\hline Residuals & 9 & 78.590 & & \\
\hline \multicolumn{5}{|l|}{ Bare space } \\
\hline $\mathrm{pCO}_{2}$ & 1 & 1.739 & 0.025 & 0.905 \\
\hline Grazer & 1 & 25.955 & 0.379 & 0.553 \\
\hline$p \mathrm{CO}_{2} \times$ grazer & 1 & 50.262 & 0.733 & 0.414 \\
\hline Residuals & 9 & 68.571 & & \\
\hline
\end{tabular}



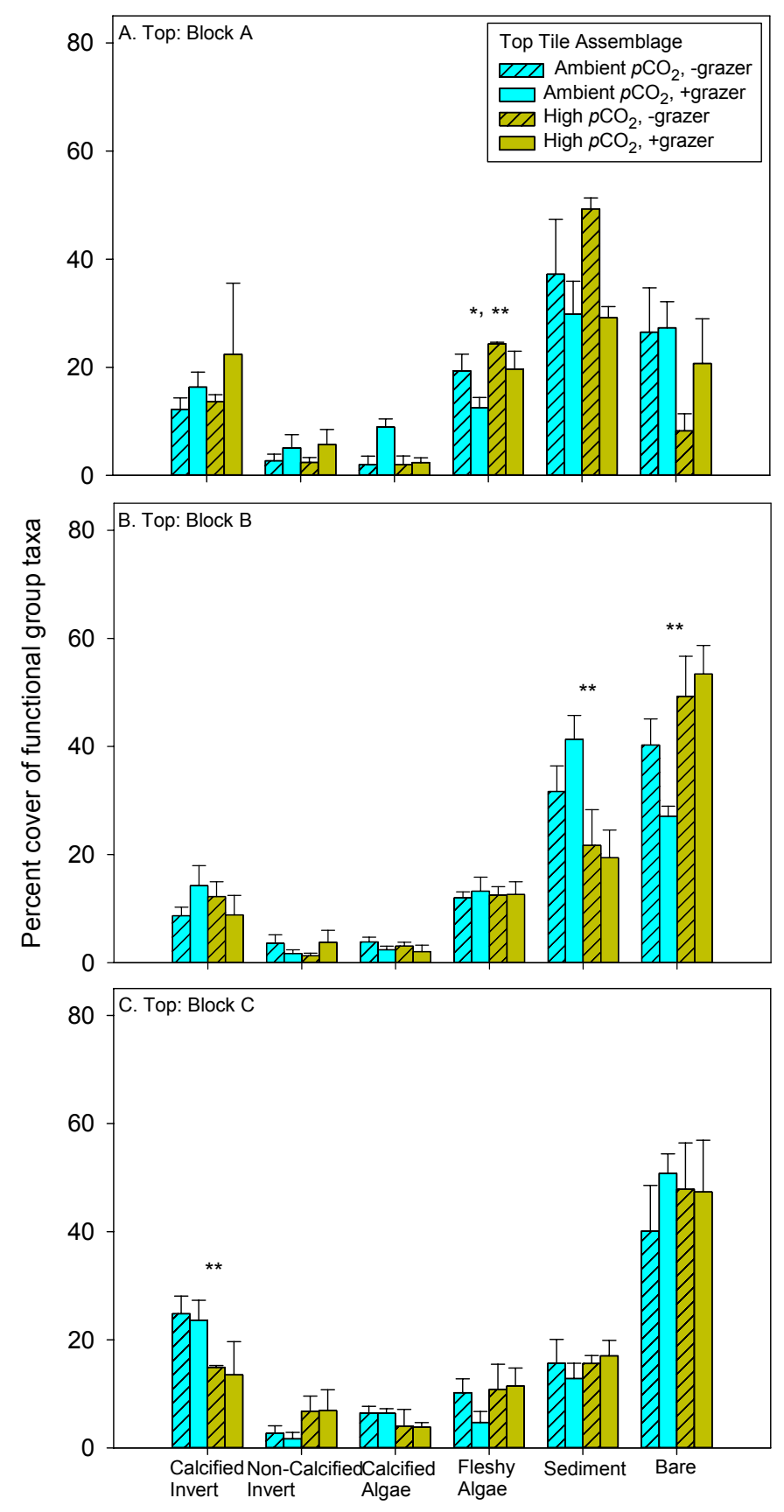

Figure 11. Percent cover of functional group taxa on the top of tiles by block from Mia's Reef. Note: *, indicates a significant difference in percent cover between factor grazer; ${ }^{* *}$, a significant difference in percent cover between $p \mathrm{CO}_{2}$ treatments; ${ }^{* * *}$, a significant difference in percent cover by block $(\alpha=0.05)$. Error bars denote \pm SE. 
I found a significant effect of block on community composition on the bottoms of tiles as well, but no effect of $p \mathrm{CO}_{2}$, sea urchin grazing, or the interaction of $p \mathrm{CO}_{2} \times$ grazing (Table 7; Fig. 12D). These results indicate that the final community assemblage on the bottom of the tiles depended on the settlement tile rack on which they were cultivated. Due to the significant block effect, separate PERMANOVAs were run on all three blocks. No significant differences in community structure were found in Block A or Block B (Table 7; Fig. 12A-B). In Block C, I found significant grazing effects on community structure (Table 7; Fig. 12C), with the tiles in the +grazer treatments clustering separately in multivariate space from the tiles in the -grazer treatments. 
Table 7. PERMANOVA results of the effects of $p \mathrm{CO}_{2}$ (ambient and high), grazers (presence and absence), and block ( $A, B$ and $C$ ) on community composition on the bottoms of settlement tiles from Mia's Reef.

\begin{tabular}{|c|c|c|c|c|}
\hline Source of variation & $d f$ & Mean squares & Pseudo- $F$ & $P($ perm $)$ \\
\hline \multicolumn{5}{|l|}{ All } \\
\hline $\mathrm{pCO}_{2}$ & 1 & 76.997 & 0.590 & 0.618 \\
\hline Grazer & 1 & 365.210 & 2.799 & 0.063 \\
\hline$p \mathrm{CO}_{2} \times$ grazer & 1 & 63.752 & 0.489 & 0.686 \\
\hline Block & 2 & 987.640 & 7.570 & 0.001 \\
\hline Residuals & 34 & 130.470 & & \\
\hline \multicolumn{5}{|l|}{ Block A } \\
\hline$p \mathrm{CO}_{2}$ & 1 & 177.950 & 1.426 & 0.274 \\
\hline Grazer & 1 & 28.154 & 0.226 & 0.828 \\
\hline$p \mathrm{CO}_{2} \times$ grazer & 1 & 248.720 & 1.993 & 0.144 \\
\hline Residuals & 9 & 124.830 & & \\
\hline \multicolumn{5}{|l|}{ Block B } \\
\hline $\mathrm{pCO}_{2}$ & 1 & 73.040 & 0.609 & 0.640 \\
\hline Grazer & 1 & 245.270 & 2.044 & 0.123 \\
\hline$p \mathrm{CO}_{2} \times$ grazer & 1 & -4.895 & Negative & \\
\hline Residuals & 10 & 120.020 & & \\
\hline \multicolumn{5}{|l|}{ Block C } \\
\hline$p \mathrm{CO}_{2}$ & 1 & 49.665 & 0.435 & 0.730 \\
\hline Grazer & 1 & 476.860 & 4.176 & 0.021 \\
\hline$p \mathrm{CO}_{2} \times$ grazer & 1 & 283.850 & 2.486 & 0.086 \\
\hline Residuals & 9 & 114.180 & & \\
\hline
\end{tabular}



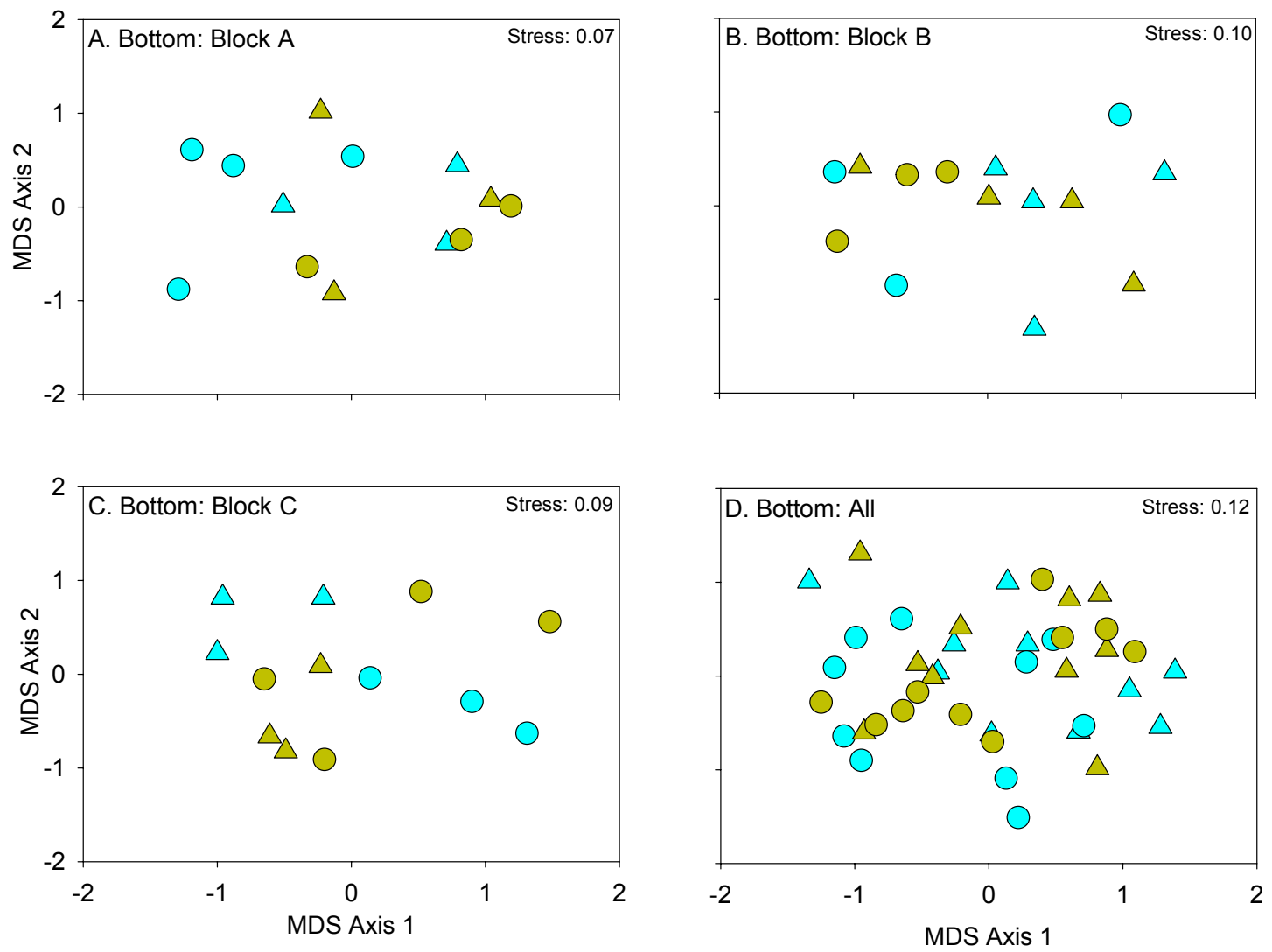

$$
\begin{aligned}
& \text { Bottom Tile Assemblage } \\
& \triangle \quad \text { Ambient } p \mathrm{CO}_{2} \text {, -grazer } \\
& \bigcirc \text { Ambient } p \mathrm{CO}_{2} \text {, +grazer } \\
& \triangle \text { High } p \mathrm{CO}_{2}, \text {-grazer } \\
& \bigcirc \quad \text { High } p \mathrm{CO}_{2} \text {, +grazer }
\end{aligned}
$$

Figure 12. nMDS plots showing dissimilarities in community composition between settlement tile benthic assemblages reared in experimental $p \mathrm{CO}_{2}$ and grazer treatments. Points (tiles) closer together indicate communities more similar than points further apart. A-C show nMDS plots of community data from the bottom of tiles separated by block, $D$ shows all community data from the bottom of tiles together. 
On the bottom of tiles, there was approximately $50 \%$ lower percent cover of non-calcified invertebrates in the presence of sea urchin grazers in Block B (Table 8-10; Figure 13A-C). There was a $60 \%$ and $15 \%$ higher percent cover of calcified invertebrates in the absence of grazing within $p \mathrm{CO}_{2}$ treatments (in ambient and high $p \mathrm{CO}_{2}$ respectively) in block $\mathrm{C}$. In addition, block $\mathrm{C}$ had $\sim 50 \%$ higher percent cover of bare space in the presence of sea urchins. I also found a significant interaction between $p \mathrm{CO}_{2}$ and grazing on non-calcified taxa in block $\mathrm{C}$, indicating that at ambient $p \mathrm{CO}_{2}$, sea urchin grazing increased the abundance of non-calcified taxa. However, at high $p \mathrm{CO}_{2}$, sea urchin grazing negatively affected the abundance of non-calcified taxa. There were no effects of $p \mathrm{CO}_{2}$, grazing, or the interaction on the bottom of block $A$. 
Table 8. PERMANOVA results of the effects of $\mathrm{pCO}_{2}$ (ambient and high) and grazers (presence and absence) on community composition on the bottom of Block A tiles from Mia's Reef.

\begin{tabular}{|c|c|c|c|c|}
\hline Source of variation & $d f$ & Mean squares & Pseudo- $F$ & $P$ (perm) \\
\hline \multicolumn{5}{|c|}{ Calcified invertebrates } \\
\hline $\mathrm{pCO}_{2}$ & 1 & 0.001 & 0.000 & 0.999 \\
\hline Grazer & 1 & 7.990 & 0.156 & 0.705 \\
\hline $\mathrm{pCO}_{2} \times$ grazer & 1 & 2.775 & 0.054 & 0.825 \\
\hline Residuals & 9 & 51.076 & & \\
\hline \multicolumn{5}{|c|}{ Non-calcified invertebrates } \\
\hline $\mathrm{pCO}_{2}$ & 1 & 897.480 & 0.731 & 0.602 \\
\hline Grazer & 1 & 447.260 & 0.364 & 0.846 \\
\hline$p \mathrm{CO}_{2} \times$ grazer & 1 & 2101.300 & 1.711 & 0.169 \\
\hline Residuals & 9 & 1228.200 & & \\
\hline \multicolumn{5}{|l|}{ Fleshy algae } \\
\hline $\mathrm{pCO}_{2}$ & 1 & 102.290 & 0.303 & 0.628 \\
\hline Grazer & 1 & 88.125 & 0.261 & 0.667 \\
\hline $\mathrm{pCO}_{2} \times$ grazer & 1 & 23.687 & 0.070 & 0.876 \\
\hline Residuals & 9 & 337.310 & & \\
\hline \multicolumn{5}{|l|}{ Sediment } \\
\hline $\mathrm{pCO}_{2}$ & 1 & 57.083 & 0.600 & 0.582 \\
\hline Grazer & 1 & 57.083 & 0.600 & 0.575 \\
\hline$p \mathrm{CO}_{2} \times$ grazer & 1 & 57.083 & 0.600 & 0.590 \\
\hline Residuals & 9 & 95.138 & & \\
\hline \multicolumn{5}{|l|}{ Bare space } \\
\hline $\mathrm{pCO}_{2}$ & 1 & 185.100 & 1.047 & 0.328 \\
\hline Grazer & 1 & 46.193 & 0.261 & 0.644 \\
\hline$p \mathrm{CO}_{2} \times$ grazer & 1 & 339.950 & 1.923 & 0.192 \\
\hline Residuals & 9 & 176.750 & & \\
\hline
\end{tabular}


Table 9. PERMANOVA results of the effects of $\mathrm{pCO}_{2}$ (ambient and high) and grazers (presence and absence) on community composition on the bottom of Block B tiles from Mia's Reef.

\begin{tabular}{|c|c|c|c|c|}
\hline Source of variation & $d f$ & Mean squares & Pseudo- $F$ & $P($ perm $)$ \\
\hline \multicolumn{5}{|c|}{ Calcified invertebrates } \\
\hline $\mathrm{pCO}_{2}$ & 1 & 25.082 & 0.338 & 0.570 \\
\hline Grazer & 1 & 56.791 & 0.764 & 0.392 \\
\hline $\mathrm{pCO}_{2} \times$ grazer & 1 & 1.538 & 0.021 & 0.926 \\
\hline Residuals & 9 & 74.307 & & \\
\hline \multicolumn{5}{|c|}{ Non-calcified invertebrates } \\
\hline $\mathrm{pCO}_{2}$ & 1 & 28.599 & 0.183 & 0.715 \\
\hline Grazer & 1 & 828.390 & 5.315 & 0.041 \\
\hline$p \mathrm{CO}_{2} \times$ grazer & 1 & 65.334 & 0.419 & 0.557 \\
\hline Residuals & 10 & 155.870 & & \\
\hline \multicolumn{5}{|l|}{ Fleshy algae } \\
\hline $\mathrm{pCO}_{2}$ & 1 & 957.250 & 2.694 & 0.132 \\
\hline Grazer & 1 & 367.970 & 1.036 & 0.340 \\
\hline $\mathrm{pCO}_{2} \times$ grazer & 1 & 239.950 & 0.675 & 0.458 \\
\hline Residuals & 10 & 355.350 & & \\
\hline \multicolumn{5}{|l|}{ Sediment } \\
\hline $\mathrm{pCO}_{2}$ & 1 & 61.427 & 0.262 & 0.646 \\
\hline Grazer & 1 & 167.590 & 0.714 & 0.416 \\
\hline $\mathrm{pCO}_{2} \times$ grazer & 1 & 59.245 & 0.253 & 0.672 \\
\hline Residuals & 10 & 234.620 & & \\
\hline \multicolumn{5}{|l|}{ Bare space } \\
\hline $\mathrm{pCO}_{2}$ & 1 & 89.883 & 0.842 & 0.398 \\
\hline Grazer & 1 & 25.863 & 0.242 & 0.640 \\
\hline$p \mathrm{CO}_{2} \times$ grazer & 1 & 2.331 & 0.022 & 0.921 \\
\hline Residuals & 10 & 106.780 & & \\
\hline
\end{tabular}


Table 10. PERMANOVA results of the effects of $\mathrm{pCO}_{2}$ (ambient and high) and grazers (presence and absence) on community composition on the bottom of Block C tiles from Mia's Reef.

\begin{tabular}{|c|c|c|c|c|}
\hline Source of variation & $d f$ & Mean squares & Pseudo- $F$ & $P($ perm $)$ \\
\hline \multicolumn{5}{|c|}{ Calcified invertebrates } \\
\hline$p \mathrm{CO}_{2}$ & 1 & 2.971 & 0.088 & 0.793 \\
\hline Grazer & 1 & 258.440 & 7.624 & 0.019 \\
\hline$p \mathrm{CO}_{2} \times$ grazer & 1 & 77.699 & 2.292 & 0.159 \\
\hline Residuals & 9 & 33.897 & & \\
\hline \multicolumn{5}{|c|}{ Non-calcified invertebrates } \\
\hline$p \mathrm{CO}_{2}$ & 1 & 461.050 & 2.633 & 0.124 \\
\hline Grazer & 1 & 115.990 & 0.662 & 0.481 \\
\hline$p \mathrm{CO}_{2} \times$ grazer & 1 & 1610.800 & 9.199 & 0.014 \\
\hline Residuals & 9 & 175.110 & & \\
\hline \multicolumn{5}{|l|}{ Fleshy algae } \\
\hline$p \mathrm{CO}_{2}$ & 1 & 164.830 & 0.272 & 0.618 \\
\hline Grazer & 1 & 109.910 & 0.181 & 0.692 \\
\hline$p \mathrm{CO}_{2} \times$ grazer & 1 & 55.437 & 0.091 & 0.772 \\
\hline Residuals & 9 & 606.270 & & \\
\hline \multicolumn{5}{|l|}{ Sediment } \\
\hline $\mathrm{pCO}_{2}$ & 1 & 504.130 & 2.365 & 0.177 \\
\hline Grazer & 1 & 7.473 & 0.035 & 0.854 \\
\hline $\mathrm{pCO}_{2} \times$ grazer & 1 & 7.473 & 0.035 & 0.847 \\
\hline Residuals & 9 & 213.170 & & \\
\hline \multicolumn{5}{|l|}{ Bare space } \\
\hline$p \mathrm{CO}_{2}$ & 1 & 113.340 & 1.023 & 0.338 \\
\hline Grazer & 1 & 874.300 & 7.889 & 0.022 \\
\hline$p \mathrm{CO}_{2} \times$ grazer & 1 & 3.570 & 0.032 & 0.924 \\
\hline Residuals & 9 & 110.830 & & \\
\hline
\end{tabular}



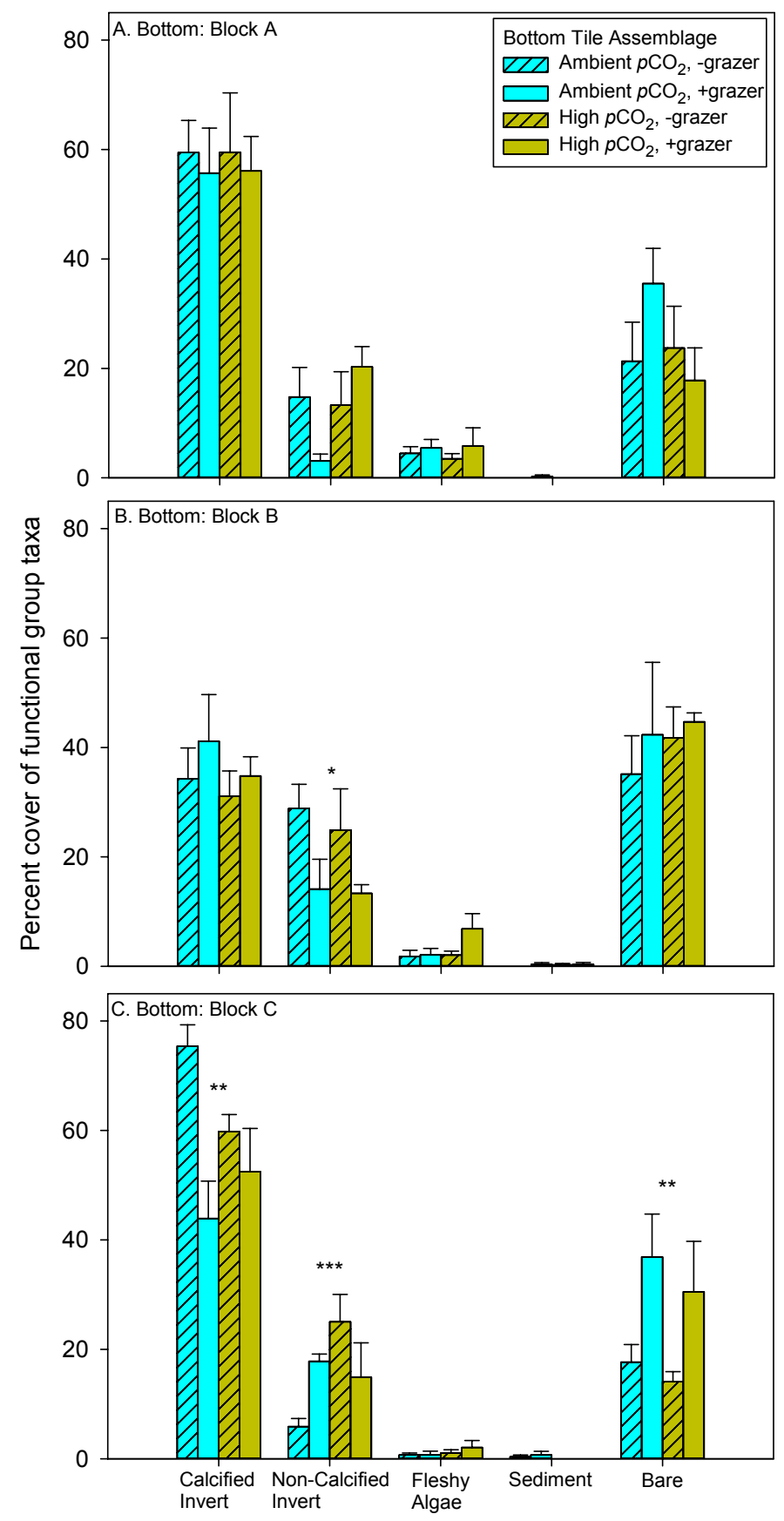

Figure 13. Percent cover of functional group taxa on the bottom of tiles by block from Mia's Reef. Note: * indicates a significant difference in percent cover between factor grazer; ${ }^{* *}$, a significant difference in percent cover between $p \mathrm{CO}_{2}$ treatments; ${ }^{* * *}$, a significant difference in percent cover by block $(\alpha=0.05)$. Error bars denote \pm SE. 
Juvenile kelp sporophytes were present on 22 of 40 tiles at the end of the experiment. Sea urchin grazing significantly reduced the density of kelp on tiles, but not the total biomass (ANOVA: kelp density $F_{5,34}=2.2967, P=0.0669$; kelp biomass $F_{5,34}=1.193, P=0.3333$; Table 11; Fig. 14). Tiles without urchin grazers present had $50 \%$ and $75 \%$ higher kelp densities on ambient and high $p \mathrm{CO}_{2}$ tiles, respectively. Although not significant, kelp biomass data did follow a similar trend with increased biomass of juvenile kelp on tiles that excluded urchin grazers.

Table 11. ANOVA results of the effects of $p \mathrm{CO}_{2}$ (ambient and high) and urchin grazers (presence and absence) on the density and biomass of juvenile kelp on settlement tiles from Mia's Reef.

\begin{tabular}{lcccc}
\hline Source of variation & $d f$ & Sum of squares & F-statistic & $P$-value \\
\hline Kelp density & & & & \\
$p \mathrm{CO}_{2}$ & 1 & 1.374 & 1.148 & 0.292 \\
Urchin & 1 & 8.182 & 6.837 & $\mathbf{0 . 0 1 3}$ \\
$p \mathrm{CO}_{2}$ x Urchin & 1 & 2.649 & 2.213 & 0.146 \\
Block & 2 & 2.192 & 0.916 & 0.410 \\
Error & 34 & 54.431 & & \\
& & & & \\
$\mathrm{Kelp} \mathrm{biomass}$ & 1 & 0.083 & 0.738 & 0.396 \\
$p \mathrm{CO}_{2}$ & 1 & 0.323 & 2.863 & 0.100 \\
Urchin & 1 & 0.203 & 1.800 & 0.189 \\
$p \mathrm{CO}_{2} \times$ Urchin & 2 & 0.058 & 0.259 & 0.774 \\
Block & 34 & 3.835 & & \\
Error & & &
\end{tabular}



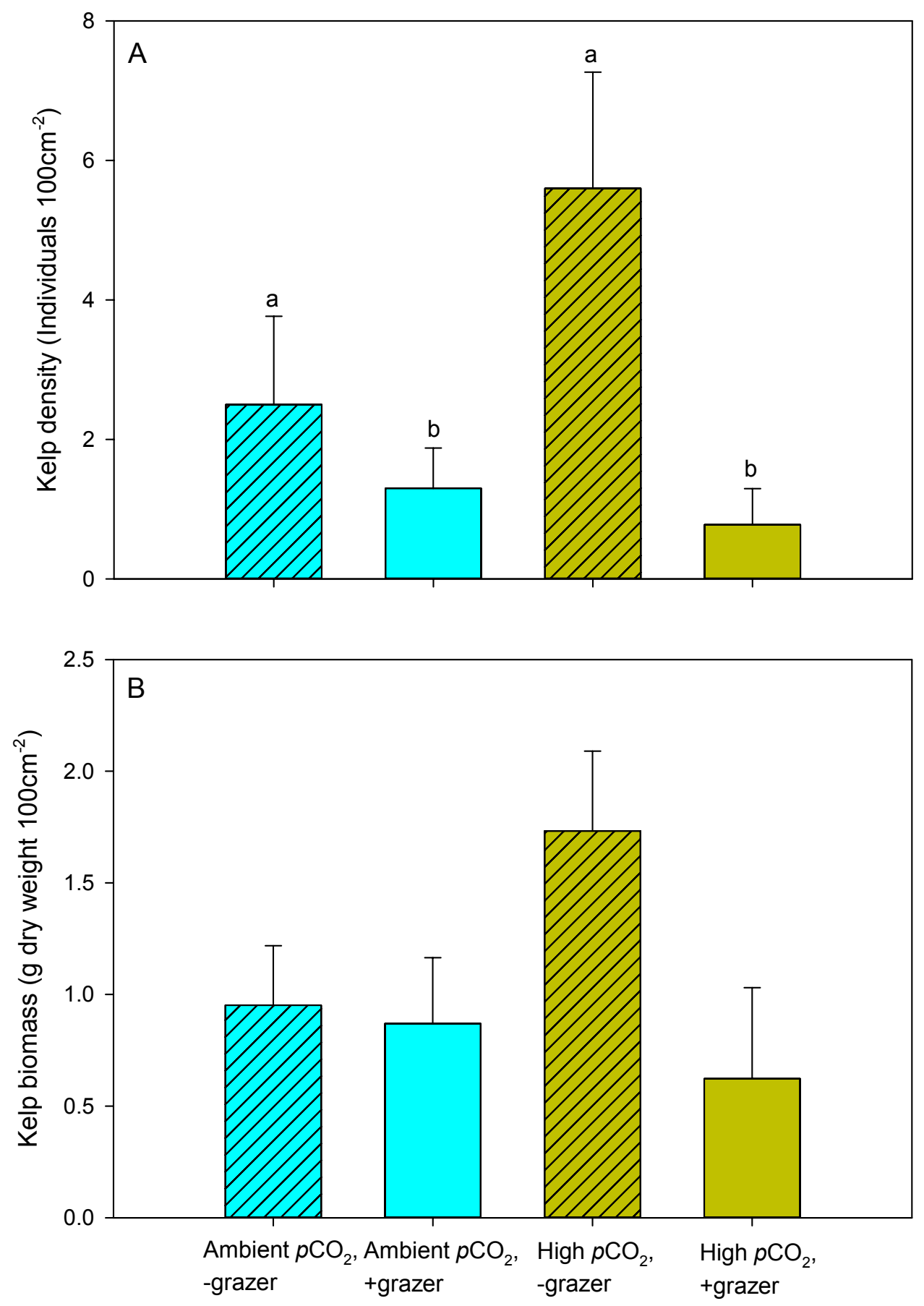

Figure 14. Density (A) and biomass (B) of juvenile kelp on settlement tiles from Mia's Reef at the end of 56 days reared under different $p \mathrm{CO}_{2}$ and urchin grazing treatments. Shared letters below error bars indicate mean density did not differ between treatments. Error bars denote \pm SE. 


\section{Sea Urchin Growth and Grazing}

Initial mean sea urchin buoyant weight and sea urchin test diameter did not differ between treatments (t-test buoyant weight, $t_{18}=0.2635, P=0.7952$; $\mathrm{t}$ test test diameter, $\left.t_{18}=0.1683, P=0.8683\right)$. However, sea urchin growth measured as buoyant weight was $60 \%$ higher in ambient $p \mathrm{CO}_{2}$ than at high $p \mathrm{CO}_{2}$, while there was no detectable difference in change in test size between treatments, suggesting that sea urchin tests became thinner under high $p \mathrm{CO}_{2}$ conditions (t-test percent change in buoyant weight, $t_{16}=-2.8562, P=0.0114$; $\mathrm{t}$ test percent change in test diameter, $t_{16}=-1.4441, P=0.1680$; Figure 15). 

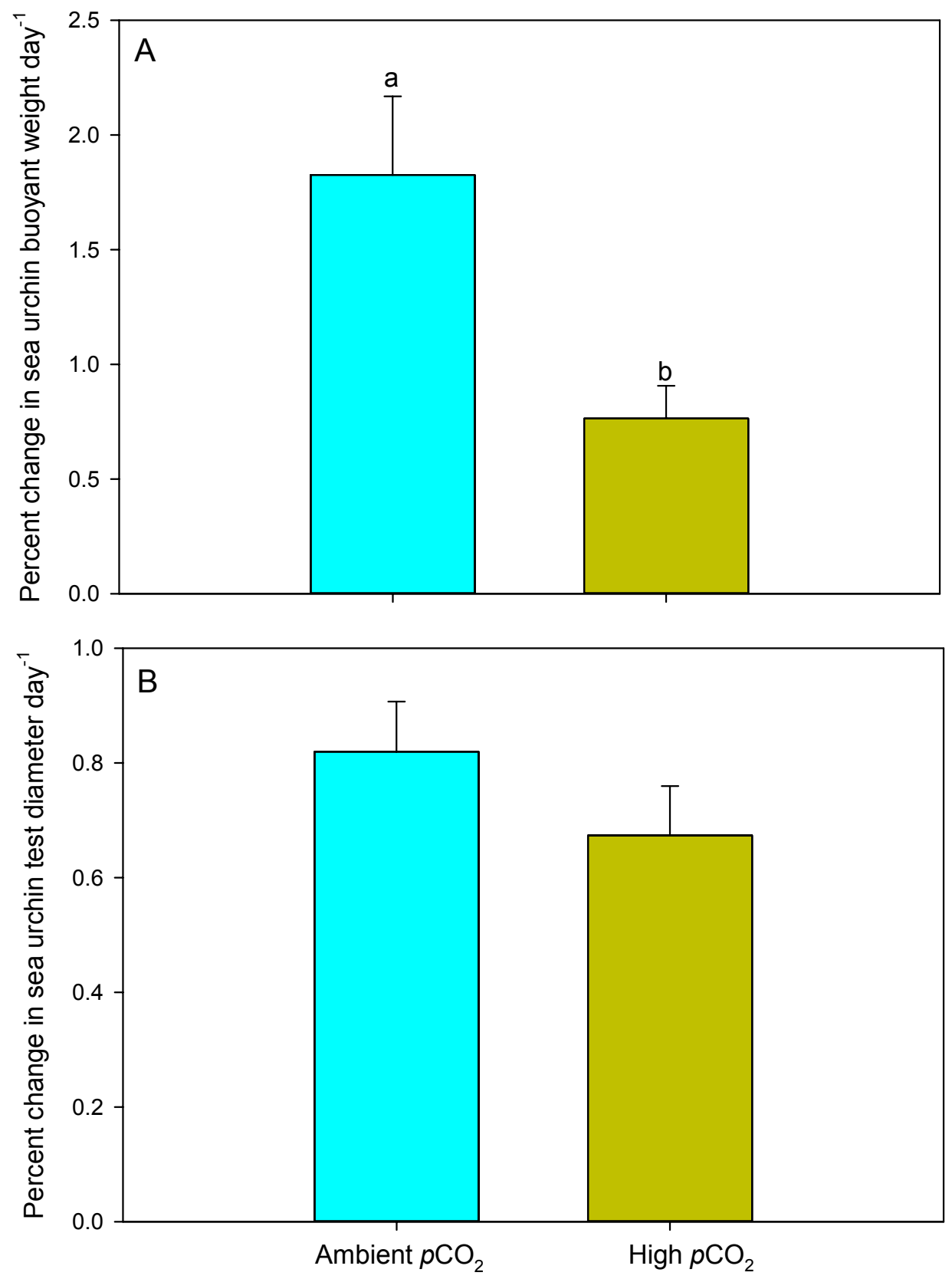

Figure 15. Growth rates of sea urchins reared on settlement tiles from Mia's Reef in ambient and high $p \mathrm{CO}_{2}$ conditions standardized to initial size after 56 days in experimental rearing. Error bars denote $\pm \mathrm{SE}$. 
Nine sea urchins from ambient and high $p \mathrm{CO}_{2}$ treatments were removed from tiles at the end of the experiment for use in a grazing assay. One replicate from my high $p \mathrm{CO}_{2}$ assay was removed from analysis due to inaccurate reweighing of kelp frond at the end of the experiment. Results from my grazing trial showed significantly higher grazing rates (lower \% change in wet weight of kelp) in sea urchins exposed to ambient $p \mathrm{CO}_{2}$ than high $p \mathrm{CO}_{2}$ treatments (t-test, $t_{15}=4.410192, P=0.0005$; Fig. 16). Kelp in the ambient $\mathrm{CO}_{2}$ treatments lost mass as a result of sea urchin grazing, whereas kelp in the high $\mathrm{CO}_{2}$ treatments gained mass, even in the presence of grazers.

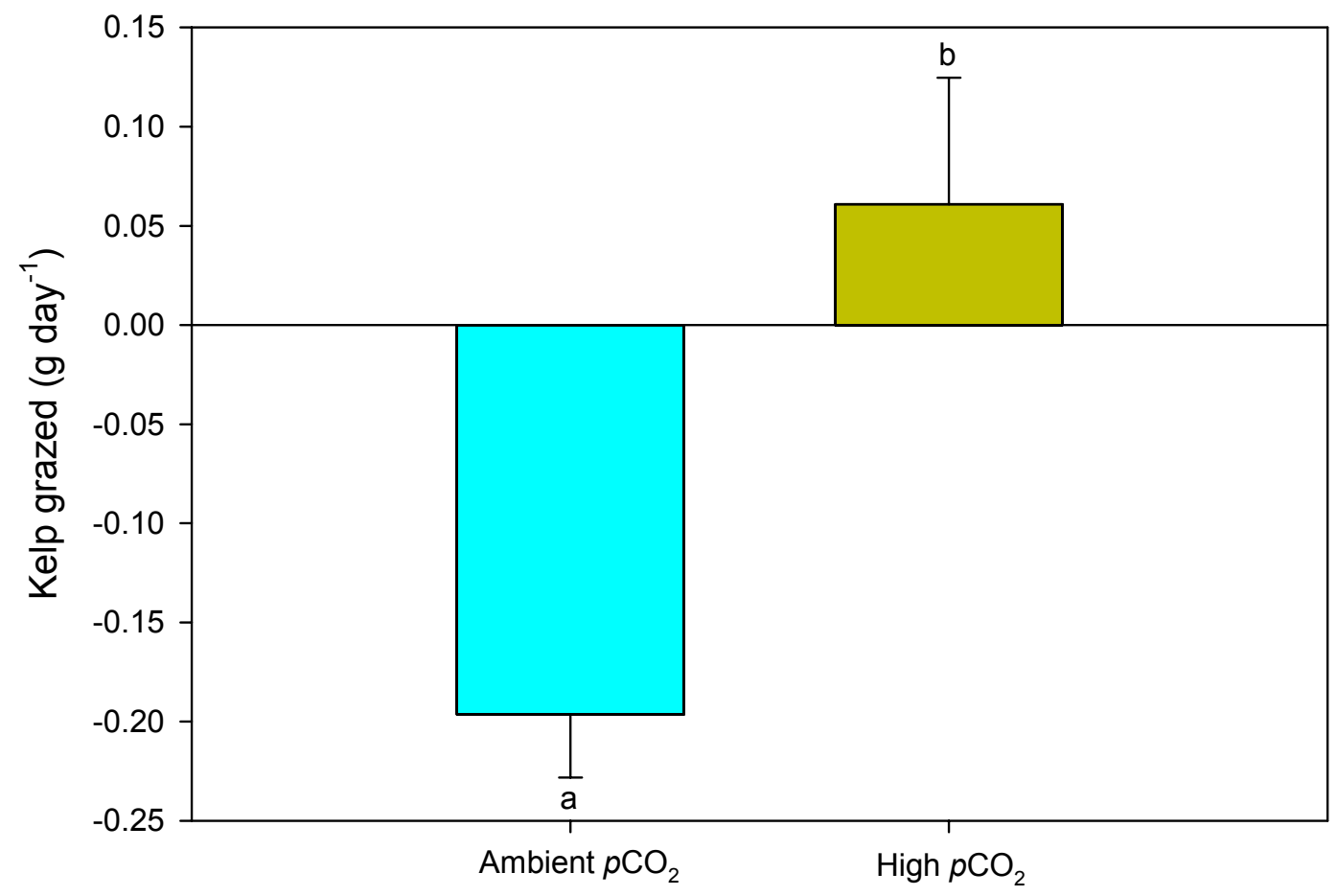

Figure 16. Results from grazing assay with sea urchins from settlement tiles accrued at Mia's reef after 56 days of rearing in ambient or high $p \mathrm{CO}_{2}$. A decrease in $\mathrm{g} \mathrm{day}^{-1}$ indicates a removal of algal biomass via grazing. Error bars denote \pm SE. 


\section{Stillwater Cove, Carmel, CA}

\section{Experimental Conditions}

Two distinct $p \mathrm{CO}_{2}$ treatments were maintained for the duration of the 56day experiment using tiles from Stillwater Cove (Table 12; Fig. 17). Ambient $p \mathrm{CO}_{2}$ treatments $(\mathrm{pH}=8.06)$ were $0.36 \mathrm{pH}$ units higher than high $p \mathrm{CO}_{2}$ treatments $(\mathrm{pH}=7.70)$, while mesocosm temperatures were roughly $13^{\circ} \mathrm{C}$ for the duration of the experiment. In situ measurements of $\mathrm{pH}$ and temperature from autonomous SeaFET loggers recorded a mean $\mathrm{pH}=7.75$ and mean temperature $\sim 12^{\circ} \mathrm{C}$ from October 23, 2013 - April 12, 2014) from Stillwater Cove, Carmel, CA (Table 12; Fig. 18). 


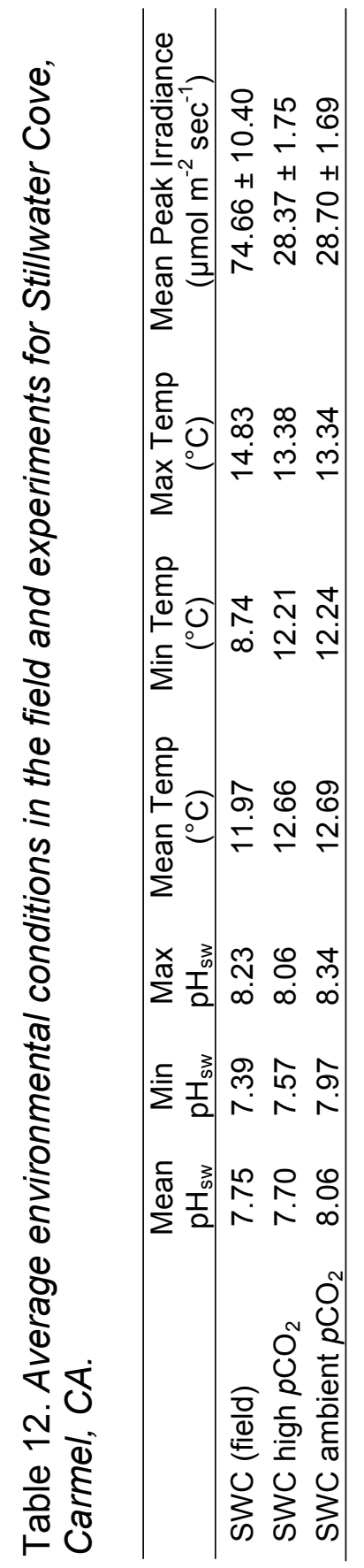




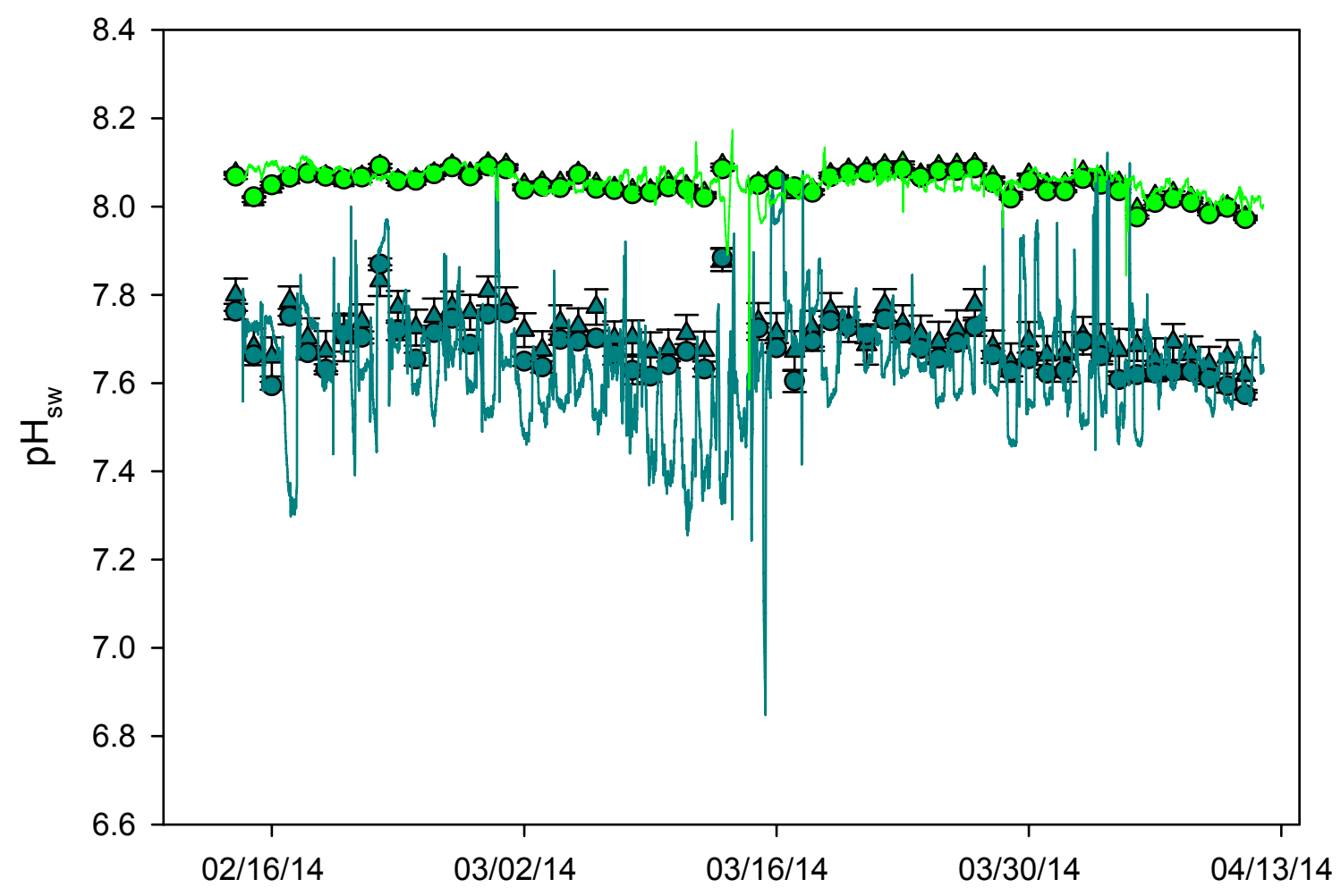

Continuous $\mathrm{pH}$, Ambient $\mathrm{pCO}_{2}$ Continuous $\mathrm{pH}$, High $\mathrm{pCO}_{2}$

$\triangle$ Ambient $p \mathrm{CO}_{2}$, +grazer

$\triangle$ Ambient $p \mathrm{CO}_{2}$, -grazer

O High $p \mathrm{CO}_{2}$, -grazer

- High $p \mathrm{CO}_{2}$, +grazer

Figure 17. Daily experimental $\mathrm{pH}$ and temperature conditions in mesocosms for the duration of the 56-day experiment. $\mathrm{pH}_{\mathrm{sw}}$, with symbols representing average daily $\mathrm{HACH} \mathrm{pH}$ glass electrode measurements $\pm \mathrm{SE}$. Solid lines represent continuous $\mathrm{pH}$ measurements from Honeywell Durafet. 

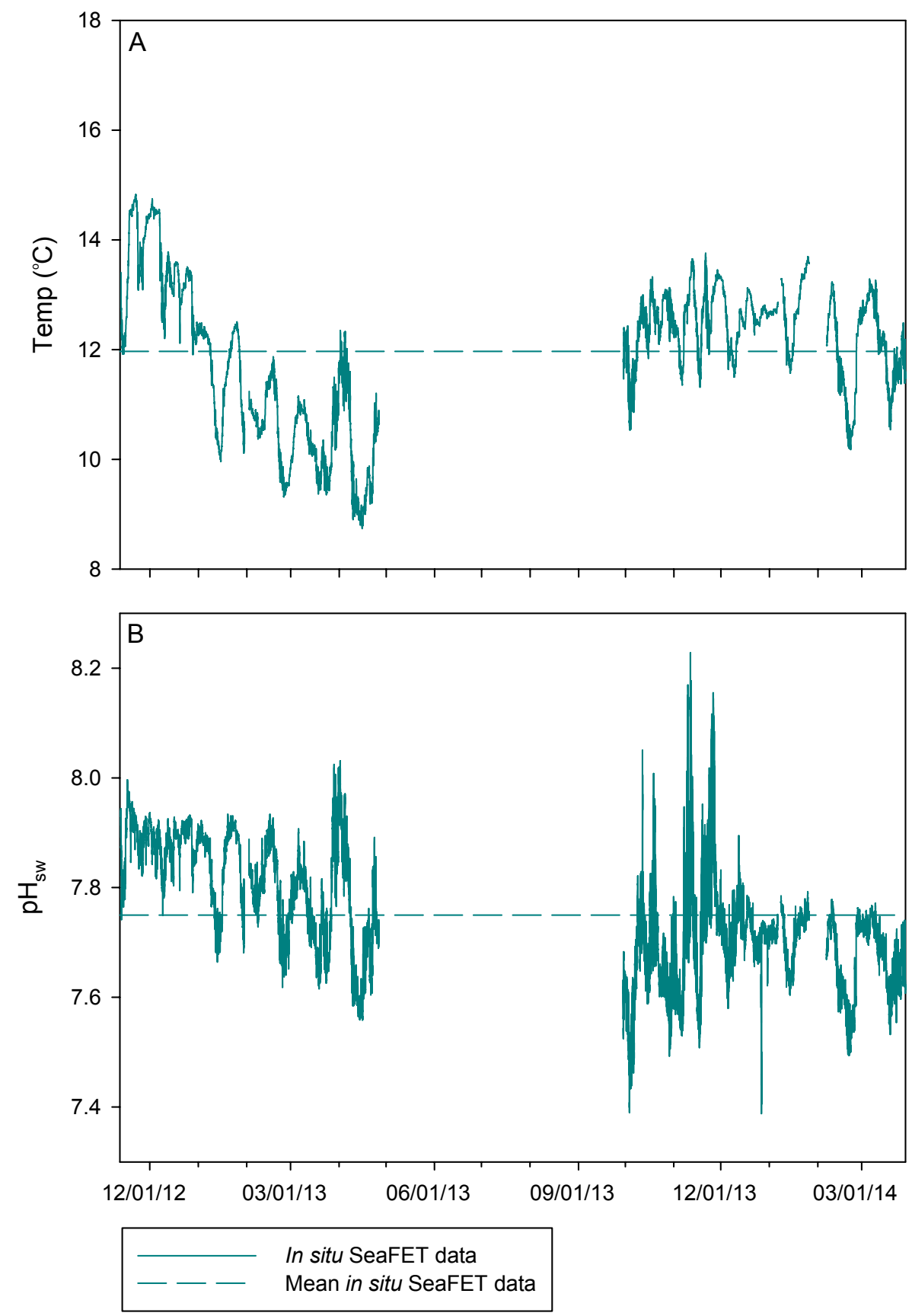

Figure 18. In situ $\mathrm{pH}$ and temperature data collected from autonomous SeaFET sensor deployed at Stillwater Cove, Carmel, CA. Instrument was deployed at $15 \mathrm{~m}$ and data were collected every $15 \mathrm{~min}$. Panel A shows temperature $\left({ }^{\circ} \mathrm{C}\right)$. Panel $\mathrm{B}$ shows $\mathrm{pH}_{\mathrm{sw}}$. 
Mean irradiance levels in treatment conditions were approximately 28 $\mu \mathrm{mol} \mathrm{m} \mathrm{sec}^{-1}$. In situ measurements of irradiance were $\sim 75 \mu \mathrm{mol} \mathrm{m}{ }^{-2} \mathrm{sec}^{-1}$ from October 6, 2013 to October 25, 2013 (Table 12; Fig. 19).

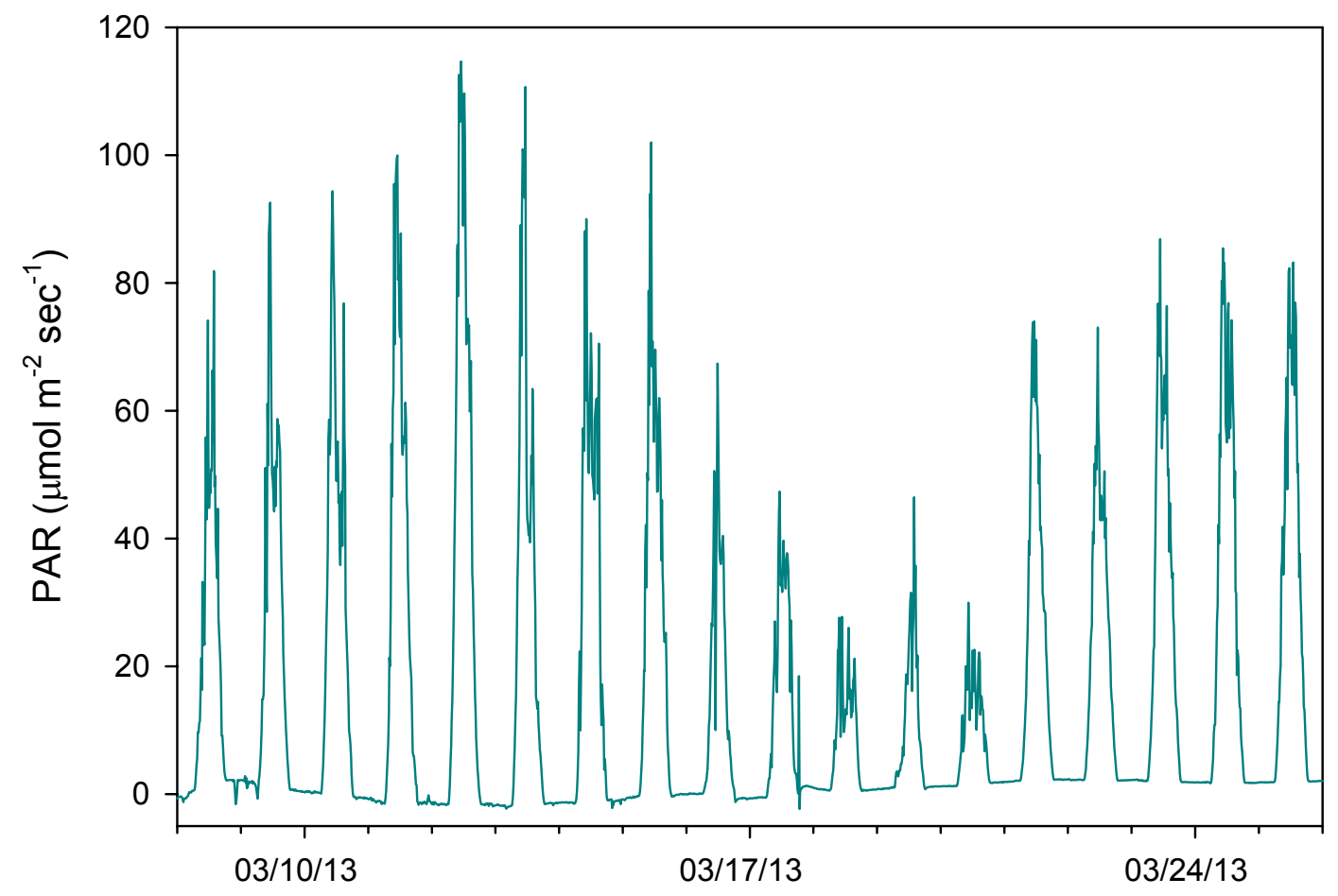

In situ PAR at Stillwater Cove, Carmel, CA

Figure 19. In situ irradiance measurements (PAR) at Stillwater Cove, Carmel, CA from March 7, 2013 to March 26, 2013.

\section{Buoyant Weight}

Final buoyant weights after 56 days in treatment conditions were almost always lower than initial buoyant weights (i.e., a net loss of calcium carbonate) across all treatments during the duration of the experiment. I observed a 
significant reduction in buoyant weight of the tiles from treatments with sea urchin grazing present, but did not detect any significant effects of $p \mathrm{CO}_{2}$, block, or the interaction of $p \mathrm{CO}_{2} \times$ grazing (Table 13; Fig. 20). Buoyant weights of tiles were approximately $90 \%$ and $85 \%$ (ambient and high $p \mathrm{CO}_{2}$ respectively) lower in the presence of sea urchins relative to similar $p \mathrm{CO}_{2}$ conditions in the absence of grazing.

Table 13. ANOVA results for the effects of $p \mathrm{CO}_{2}$ (ambient and high), grazers (presence and absence), and block ( $A, B$ and $C$ ) on the change in buoyant weight of tile communities from Stillwater Cove.

\begin{tabular}{lcccc}
\hline Source of variation & $d f$ & Sum of squares & $F$-statistic & $P$-value \\
\hline$p \mathrm{CO}_{2}$ & 1 & 2.3354 & 1.9815 & 0.1686 \\
Grazer & 1 & 0.0304 & 152.3239 & $<0.0001$ \\
$\mathrm{pCO}_{2} \times$ grazer & 1 & 0.0051 & 0.4262 & 0.5676 \\
Block & 2 & 0.0632 & 2.0619 & 0.1433 \\
Error & 33 & 0.5060 & & \\
\hline
\end{tabular}




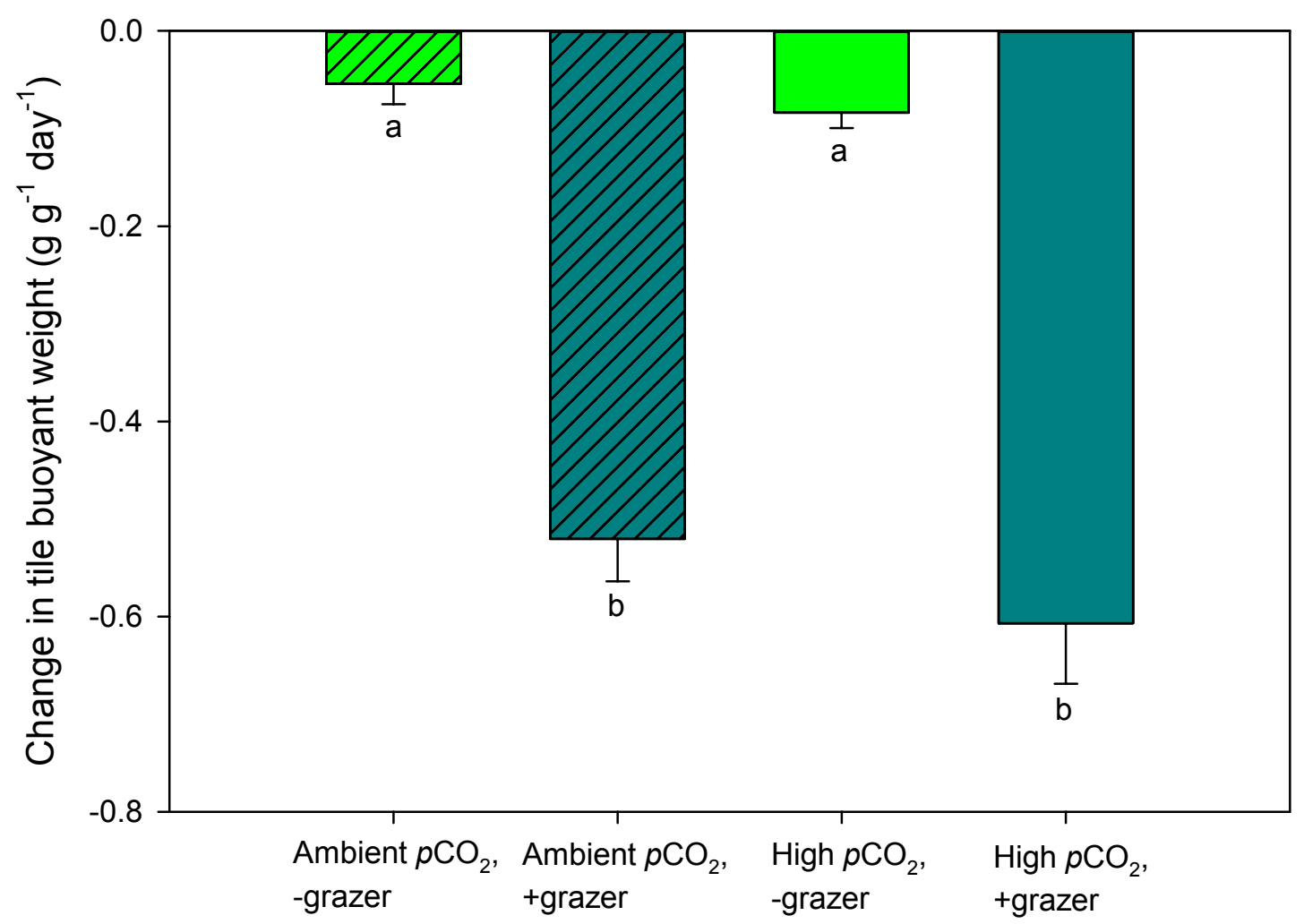

Figure 20. Percent change in buoyant weight of settlement tiles from Stillwater Cove, Carmel, CA. Shared letters below error bars indicate mean change in buoyant weight did not differ between treatments. Error bars denote \pm SE.

\section{Community Composition}

Six functional groups were identified on the tops and bottoms of tiles.

These groups included calcified invertebrates (bryozoans, barnacles and serpulid worms), non-calcified invertebrates (sponges and tunicates), calcified algae, fleshy algae, sediment, and bare space (Figs. 21, 22). Communities on the tops of the tiles from Stillwater Cove differed significantly as a function of sea urchin grazing (Table 14; Figure 23A), but did not exhibit any significant effects of $p \mathrm{CO}_{2}$, 
block, or the interaction of $p \mathrm{CO}_{2} \times$ grazing. The tiles from the treatments with sea urchin grazers cluster together in multivariate space, while the tiles from the treatments without sea urchins cluster separately. There was also a significant effect of grazing on community composition on the bottom of tiles, but no effect of $p \mathrm{CO}_{2}$, block, or the interaction of $p \mathrm{CO}_{2} \times$ grazing (Table 15; Fig. 23B). Similarly to the top of the tiles, the species assemblages from the +grazer treatments on the bottom of the tiles cluster together in multivariate space, while the tiles from the -grazer treatments cluster separately, regardless of the $\mathrm{pCO}_{2}$ treatment.
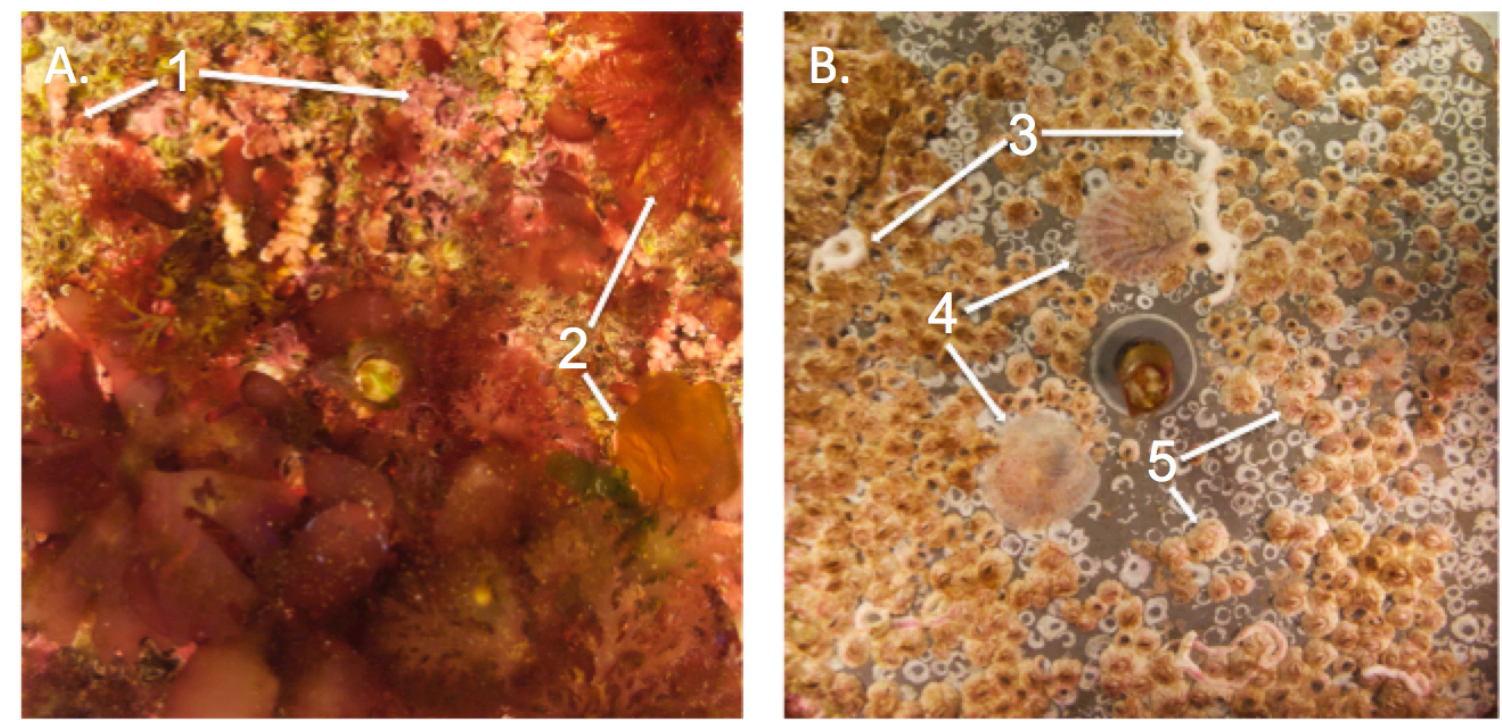

Figure 21. Settlement tile top (A) and bottom (B) from Stillwater Cove after 56 days in experimental rearing. Numbers indicate key taxa $(1=$ calcified algae, $2=$ fleshy macroalgae, 3 = serpulid worm, 4 = bivalve, 5 = barnacle). 

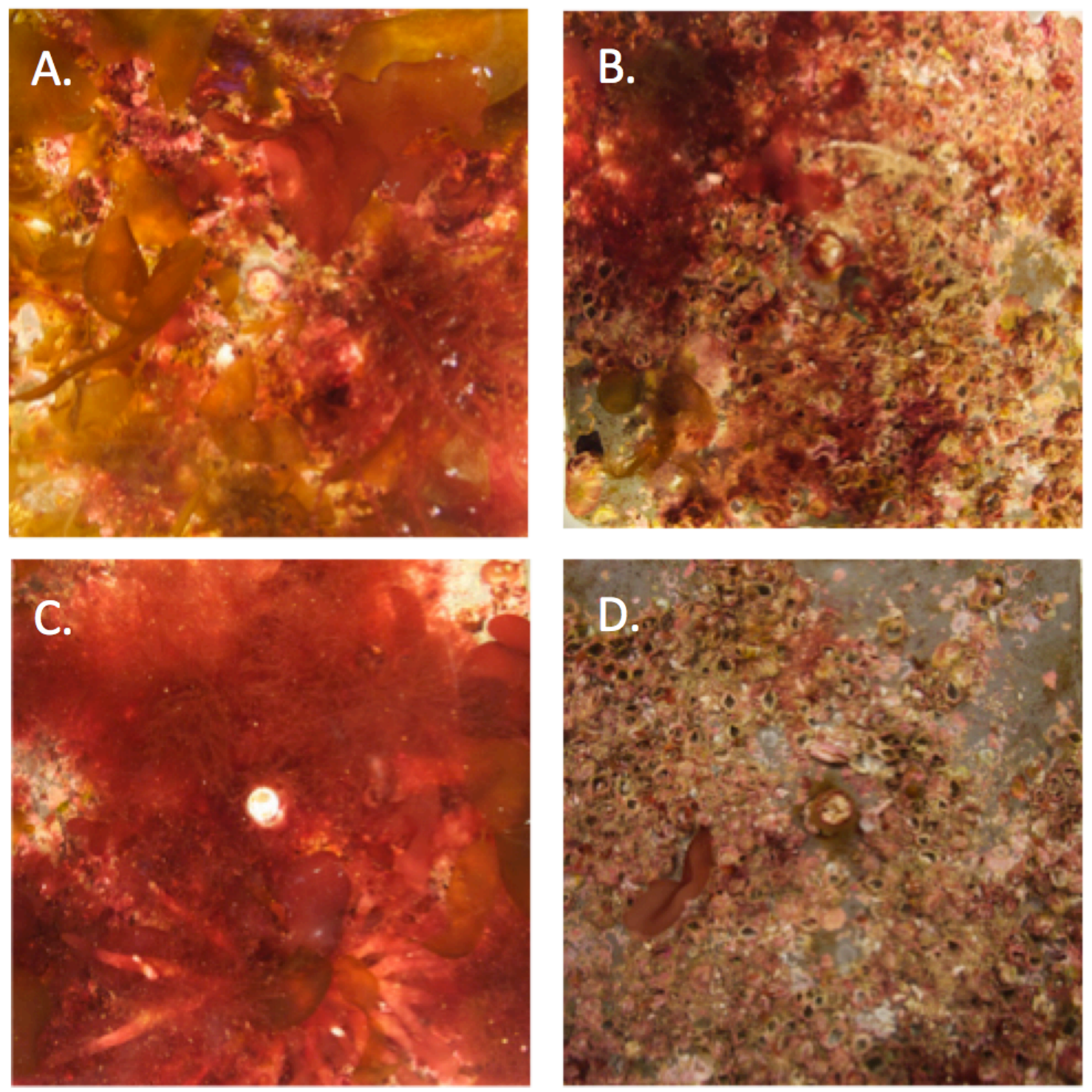

Figure 22. Images of representative settlement tile tops from Stillwater Cove, CA after 56 days in experimental conditions. A) ambient $p \mathrm{CO}_{2}$, -grazer; B) ambient $p \mathrm{CO}_{2}$, +grazer; C) high $p \mathrm{CO}_{2}$, -grazer; and D) high $p \mathrm{CO}_{2}$, +grazer. 
Table 14. PERMANOVA results of the effects of $\mathrm{pCO}_{2}$ (ambient and high), grazing (presence and absence), and block on community composition on the tops of settlement tiles from Stillwater Cove.

\begin{tabular}{lcccc}
\hline Source of variation & $d f$ & Mean squares & Pseudo- $F$ & $P($ perm $)$ \\
\hline$A l l$ & & & & \\
$p \mathrm{CO}_{2}$ & 1 & 40.5020 & 0.3615 & 0.7953 \\
Grazer & 1 & 2154.4000 & 19.2260 & $\mathbf{0 . 0 0 0 1}$ \\
Block & 2 & 190.5400 & 1.7004 & 0.1237 \\
$\mathrm{pCO}_{2} \times$ grazer & 1 & 44.5770 & 0.3978 & 0.7685 \\
Residuals & 33 & 112.0600 & & \\
\hline
\end{tabular}

Table 15. PERMANOVA results of the effects of $\mathrm{pCO}_{2}$ (ambient and high), grazing (presence and absence), and block on community composition on the bottoms of settlement tiles from Stillwater Cove.

\begin{tabular}{lcccc}
\hline Source of variation & $d f$ & Mean squares & Pseudo- $F$ & $P($ perm $)$ \\
\hline All & & & & \\
$p \mathrm{CO}_{2}$ & 1 & 186.1200 & 1.2262 & 0.2951 \\
Grazer & 1 & 928.7800 & 6.1193 & $\mathbf{0 . 0 0 6 3}$ \\
Block & 2 & 124.7900 & 0.8222 & 0.5112 \\
$p \mathrm{CO}_{2} \times$ grazer & 1 & 50.5670 & 0.3332 & 0.7430 \\
Residuals & 33 & 151.7800 & & \\
\hline
\end{tabular}



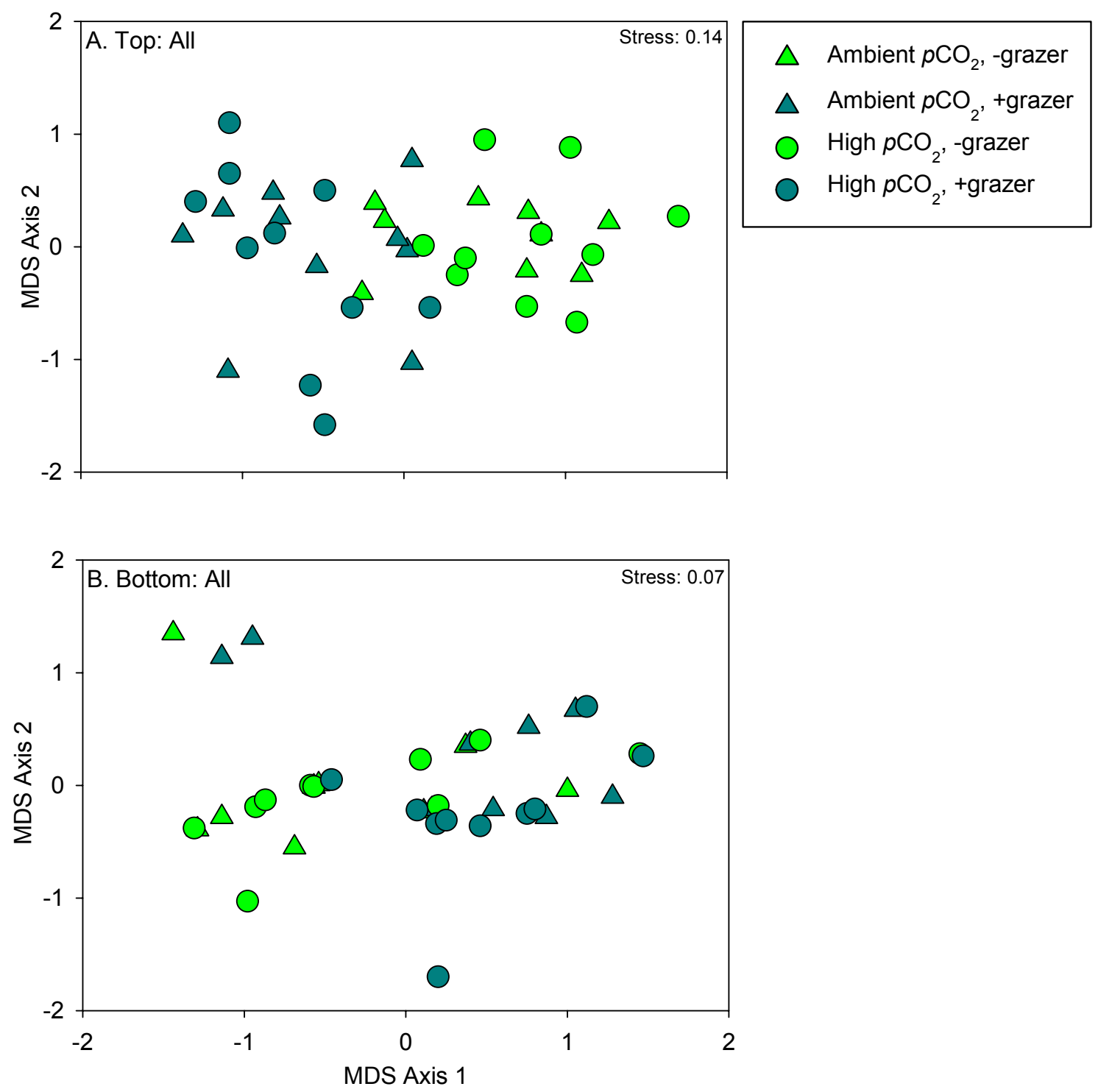

Figure 23. nMDS plots showing dissimilarities in community composition between settlement tile benthic assemblages from Stillwater Cove, CA reared in experimental $p \mathrm{CO}_{2}$ and grazer treatments. Points (tiles) closer together indicate communities more similar than points further apart. A, top of tiles; B, bottom of tiles. 
Significantly lower percent cover of calcified invertebrates and calcified algae occurred in assemblages on the tops of tiles with grazers present (Table 16, Fig. 24A). Calcified invertebrate percent cover declined by $34 \%$ and $42 \%$ in ambient and high $p \mathrm{CO}_{2}$ treatments with grazers relative to my controls (ambient $p \mathrm{CO}_{2}$, -grazer). Calcified algae abundance was even further reduced by $43 \%$ and $56 \%$ in ambient and high $p \mathrm{CO}_{2}$ treatments with urchins relative to my controls (ambient $p \mathrm{CO}_{2}$, -grazer). I also found an approximately $60 \%$ increase in the percent cover of bare space in the presence of urchin grazers, likely due to the loss of barnacles (the most abundant calcified invertebrate) and calcified algae. There were no effects of $p \mathrm{CO}_{2}$, block, or $p \mathrm{CO}_{2} \times$ grazer interaction on the communities on the bottom of the tiles from Stillwater Cove. 
Table 16. PERMANOVA results of the effects of $\mathrm{pCO}_{2}$ (ambient and high), grazing (presence and absence) and block on functional group taxa on the tops of settlement tiles from Stillwater Cove.

\begin{tabular}{|c|c|c|c|c|}
\hline Source of variation & $d f$ & Mean squares & Pseudo- $F$ & $P($ perm $)$ \\
\hline \multicolumn{5}{|c|}{ Calcified invertebrates } \\
\hline $\mathrm{pCO}_{2}$ & 1 & 10.9900 & 0.1748 & 0.7430 \\
\hline Grazer & 1 & 1795.4000 & 28.5600 & 0.0001 \\
\hline Block & 2 & 33.0440 & 0.5257 & 0.6421 \\
\hline$p \mathrm{CO}_{2} \times$ grazer & 1 & 52.2310 & 0.8309 & 0.3758 \\
\hline Residuals & 33 & 62.8620 & & \\
\hline \multicolumn{5}{|c|}{ Non-calcified invertebrates } \\
\hline $\mathrm{pCO}_{2}$ & 1 & 69.1640 & 0.2434 & 0.6304 \\
\hline Grazer & 1 & 156.1400 & 0.5495 & 0.4474 \\
\hline Block & 2 & 748.8900 & 2.6357 & 0.0951 \\
\hline$p \mathrm{CO}_{2} \times$ grazer & 1 & 13.9220 & 0.0490 & 0.8351 \\
\hline Residuals & 33 & 284.1400 & & \\
\hline \multicolumn{5}{|l|}{ Calcified algae } \\
\hline $\mathrm{pCO}_{2}$ & 1 & 192.8200 & 0.7080 & 0.4173 \\
\hline Grazer & 1 & 3284.4000 & 12.0600 & 0.0010 \\
\hline Block & 2 & 248.6100 & 0.9129 & 0.4108 \\
\hline$p \mathrm{CO}_{2} \times$ grazer & 1 & 275.7200 & 1.0124 & 0.3265 \\
\hline Residuals & 33 & 272.3400 & & \\
\hline \multicolumn{5}{|l|}{ Fleshy algae } \\
\hline$p \mathrm{CO}_{2}$ & 1 & 532.3900 & 1.6270 & 0.2105 \\
\hline Grazer & 1 & 1070.8000 & 3.2725 & 0.0622 \\
\hline Block & 2 & 686.1700 & 2.0970 & 0.1152 \\
\hline$p \mathrm{CO}_{2} \times$ grazer & 1 & 100.8700 & 0.3083 & 0.6824 \\
\hline Residuals & 33 & 327.2200 & & \\
\hline \multicolumn{5}{|l|}{ Sediment } \\
\hline $\mathrm{pCO}_{2}$ & 1 & 124.9900 & 0.2922 & 0.6816 \\
\hline Grazer & 1 & 1114.2000 & 2.6052 & 0.1010 \\
\hline Block & 2 & 608.3300 & 1.4224 & 0.2415 \\
\hline$p \mathrm{CO}_{2} \times$ grazer & 1 & 151.2300 & 0.3536 & 0.6255 \\
\hline Residuals & 33 & 427.6900 & & \\
\hline \multicolumn{5}{|l|}{ Bare space } \\
\hline$p \mathrm{CO}_{2}$ & 1 & 22.3810 & 0.6746 & 0.4285 \\
\hline Grazer & 1 & 1799.6000 & 54.2460 & 0.0001 \\
\hline Block & 2 & 80.9400 & 2.4398 & 0.0960 \\
\hline$p \mathrm{CO}_{2} \times$ grazer & 1 & 46.2700 & 1.3947 & 0.2385 \\
\hline Residuals & 33 & 33.1750 & & \\
\hline
\end{tabular}




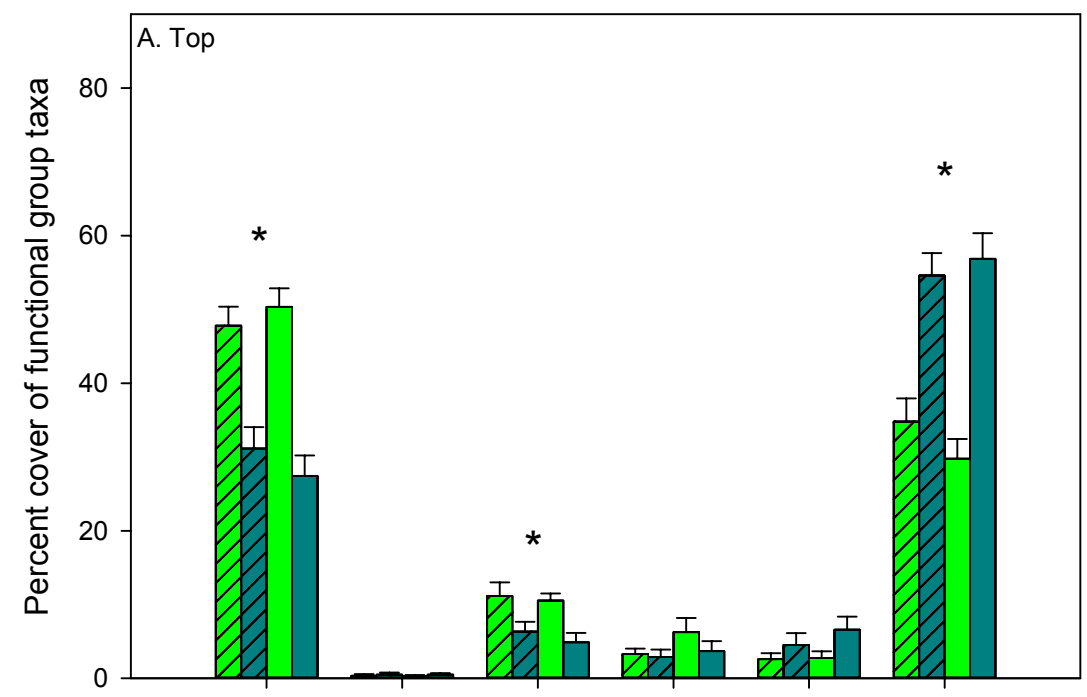

ZZA Ambient $p \mathrm{CO}_{2}$, -grazer

ZZA Ambient $p \mathrm{CO}_{2}$, +grazer

$\square$ High $p \mathrm{CO}_{2}$, -grazer

$\square$ High $p \mathrm{CO}_{2}$, +grazer

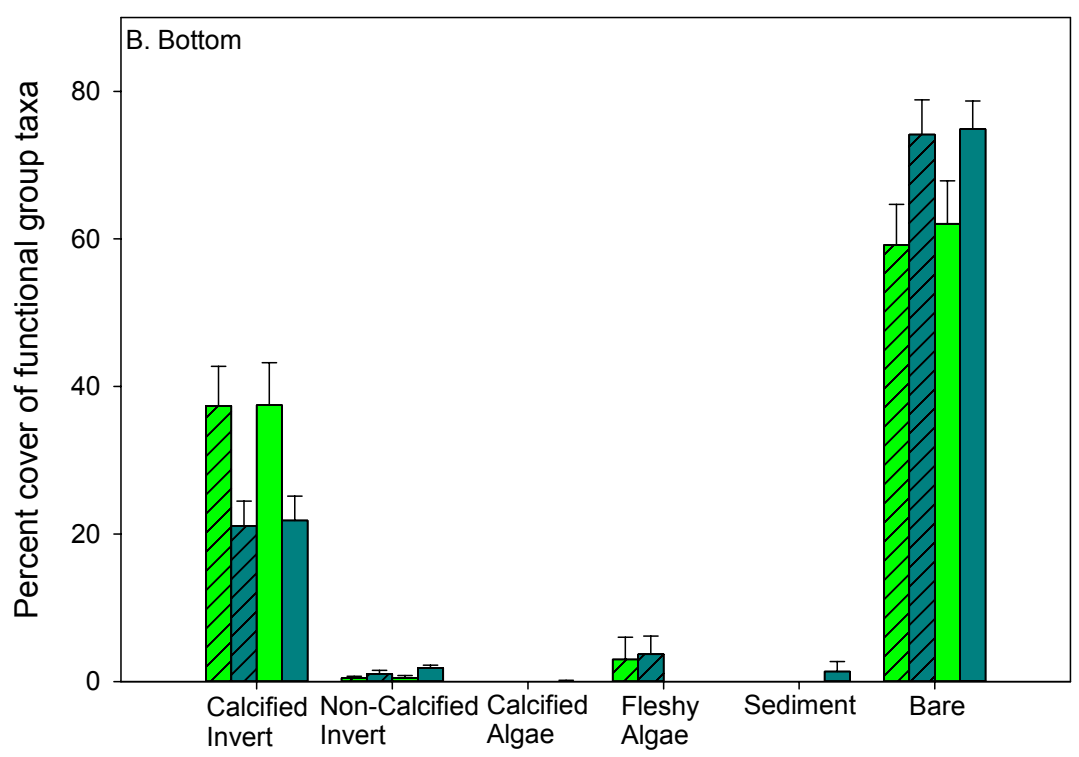

Figure 24. Percent cover of functional group taxa on the top (A) and bottom (B) of tiles from Stillwater Cove, Carmel, CA. Note: *, indicates a significant difference in percent cover between factor grazer; ${ }^{*}$, a significant difference in percent cover between $p \mathrm{CO}_{2}$ treatments; ${ }^{* * *}$, a significant difference in percent cover by block $(\alpha=0.05)$. Error bars denote \pm SE. 
Table 17. PERMANOVA results of the effects of $\mathrm{pCO}_{2}$ (ambient and high), grazing (presence and absence) and block on functional group taxa on the bottoms of settlement tiles from Stillwater Cove.

\begin{tabular}{|c|c|c|c|c|}
\hline Source of variation & $d f$ & $\begin{array}{c}\text { Mean } \\
\text { squares }\end{array}$ & Pseudo- $F$ & $P($ perm $)$ \\
\hline \multicolumn{5}{|c|}{ Calcified invertebrates } \\
\hline $\mathrm{pCO}_{2}$ & 1 & 15.2990 & 0.0659 & 0.8919 \\
\hline Grazer & 1 & 1629.9000 & 7.0169 & 0.0088 \\
\hline Block & 2 & 38.8640 & 0.1673 & 0.8948 \\
\hline$p \mathrm{CO}_{2} \times$ grazer & 1 & 9.4505 & 0.0407 & 0.9295 \\
\hline Residuals & 33 & 232.2900 & & \\
\hline \multicolumn{5}{|c|}{ Non-calcified invertebrates } \\
\hline $\mathrm{pCO}_{2}$ & 1 & 516.4400 & 1.3078 & 0.2481 \\
\hline Grazer & 1 & 1849.4000 & 4.6835 & 0.0389 \\
\hline Block & 2 & 307.0300 & 0.7775 & 0.4665 \\
\hline$p \mathrm{CO}_{2} \times$ grazer & 1 & 639.5500 & 1.6196 & 0.2098 \\
\hline Residuals & 33 & 394.8900 & & \\
\hline \multicolumn{5}{|l|}{ Fleshy algae } \\
\hline $\mathrm{pCO}_{2}$ & 1 & 1265.1000 & 4.3110 & 0.0410 \\
\hline Grazer & 1 & 53.8710 & 0.1836 & 0.6833 \\
\hline Block & 2 & 1200.8000 & 4.0921 & 0.0189 \\
\hline$p \mathrm{CO}_{2} \times$ grazer & 1 & 151.3700 & 0.5158 & 0.4816 \\
\hline Residuals & 33 & 293.4500 & & \\
\hline \multicolumn{5}{|l|}{ Sediment } \\
\hline $\mathrm{pCO}_{2}$ & 1 & 124.7500 & 1.1647 & 0.5153 \\
\hline Grazer & 1 & 92.2920 & 0.8617 & 0.3462 \\
\hline Block & 2 & 120.3100 & 1.1233 & 0.3403 \\
\hline $\mathrm{pCO}_{2} \times$ grazer & 1 & 114.5000 & 1.0691 & 0.3897 \\
\hline Residuals & 33 & 107.1000 & & \\
\hline \multicolumn{5}{|l|}{ Bare space } \\
\hline $\mathrm{pCO}_{2}$ & 1 & 6.3976 & 0.1669 & 0.6941 \\
\hline Grazer & 1 & 313.0500 & 8.1666 & 0.0079 \\
\hline Block & 2 & 10.2490 & 0.2674 & 0.7770 \\
\hline $\mathrm{pCO}_{2} \times$ grazer & 1 & 0.4330 & 0.0113 & 0.9456 \\
\hline Residuals & 33 & 38.3330 & & \\
\hline
\end{tabular}


On the bottom of tiles, there was a significant negative effect of grazing on the percent cover of calcified invertebrates and a significant positive effect on non-calcified invertebrates, and bare space (Table 17, Fig. 24B). Percent cover of calcified invertebrates was reduced by $\sim 40 \%$ in the presence of grazers under both ambient and high $p \mathrm{CO}_{2}$ conditions. Conversely, the percent cover of noncalcified invertebrates increased $125 \%$ and $\sim 300 \%$ in ambient and high $p \mathrm{CO}_{2}$ treatments in the presence of sea urchin grazers. However, it is important to note that non-calcified invertebrate abundances were around $1 \%$ cover versus the much higher $20-30 \%$ of calcified invertebrates. Bare space also increased in the presence of sea urchins ( $25 \%$ in both $p \mathrm{CO}_{2}$ treatments). In addition, there was a significant negative effect of $p \mathrm{CO}_{2}$ and a significant effect of block on fleshy algal abundance (Table 17, Fig. 24B). Fleshy algae were only found on one of the three blocks, therefore further analyses by block were not conducted. Juvenile kelp sporophytes were present on 24 of 39 tiles at the end of the experiment. ANOVAs with fixed factors of $p \mathrm{CO}_{2}$, grazers, and block were conducted on square-root transformed variables of kelp biomass (dry weight) and kelp density. Sea urchin grazers significantly reduced both biomass and density of kelp, but there was no effect of $p \mathrm{CO}_{2}$, block, or $p \mathrm{CO}_{2} \times$ grazer interaction (Table 18; Fig. 25A-B). Under ambient $p \mathrm{CO}_{2}$ conditions, the presence of sea urchins reduced both density and biomass of kelp by $\sim 98 \%$. At high $p \mathrm{CO}_{2}$ conditions, the presence of sea urchins reduced kelp density and biomass by $93 \%$ and $76 \%$ relative to our ambient $p \mathrm{CO}_{2}$, -grazer control. 
Table 18. ANOVA results of the effects of $\mathrm{pCO}_{2}$ (ambient and high) and grazing (presence and absence) on the density and biomass of juvenile kelp on settlement tiles from Stillwater Cove.

\begin{tabular}{lcccc}
\hline Source of variation & $d f$ & Sum of squares & $F$-statistic & $P$-value \\
\hline Kelp density & & & & \\
$p \mathrm{CO}_{2}$ & 1 & 14.1334 & 1.8251 & 0.1859 \\
Grazer & 1 & 125.3992 & 16.1931 & $\mathbf{0 . 0 0 0 3}$ \\
$p \mathrm{CO}_{2}$ x grazer & 1 & 19.1288 & 2.4701 & 0.1256 \\
Block & 2 & 5.4663 & 0.3529 & 0.7052 \\
Error & 33 & 255.5521 & & \\
& & & & \\
$\mathrm{Kelp} \mathrm{biomass}$ & & & & \\
$p \mathrm{CO}_{2}$ & 1 & 0.0165 & 0.5185 & 0.4765 \\
$\mathrm{Grazer}$ & 1 & 0.5396 & 16.9583 & $\mathbf{0 . 0 0 0 2}$ \\
$\mathrm{BCO}_{2} \times$ grazer & 1 & 0.0715 & 2.2482 & 0.1433 \\
Block & 2 & 0.0437 & 0.6865 & 0.5104 \\
Error & 33 & 1.0501 & & \\
\hline
\end{tabular}



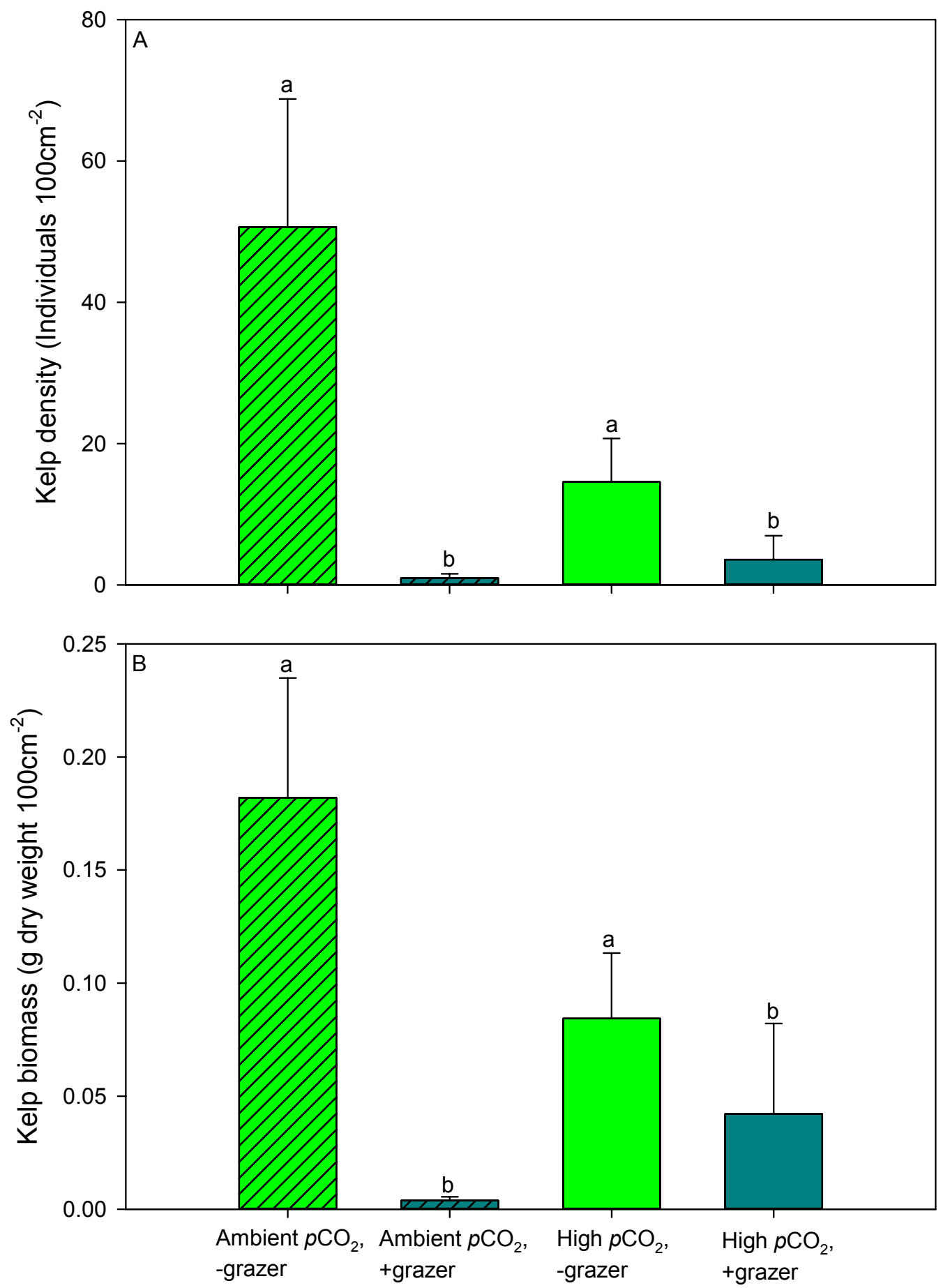

Figure 25. Density (A) and biomass (B) of juvenile kelp on settlement tiles in different $p \mathrm{CO}_{2}$ and grazer treatments. Error bars denote \pm SE. 


\section{Sea Urchin Growth and Grazing}

Initial mean sea urchin buoyant weight and sea urchin diameter did not differ between treatments (t-test buoyant weight, $t_{18}=-0.574, P=0.5731$; Kruskal-Wallis test diameter, $\left.X^{2}=0.0702, d f=1, P=0.7911\right)$. Sea urchin growth rates (i.e., change in buoyant weight and test diameter) did not differ between $p \mathrm{CO}_{2}$ treatments (Kruskal-Wallis percent change in buoyant weight, $X^{2}$

$=2.2857, d f=1, P=0.1306$, t-test percent change in test diameter, $t_{18}=-0.302$, $P=0.7663 ;$ Fig. 26A-B). 

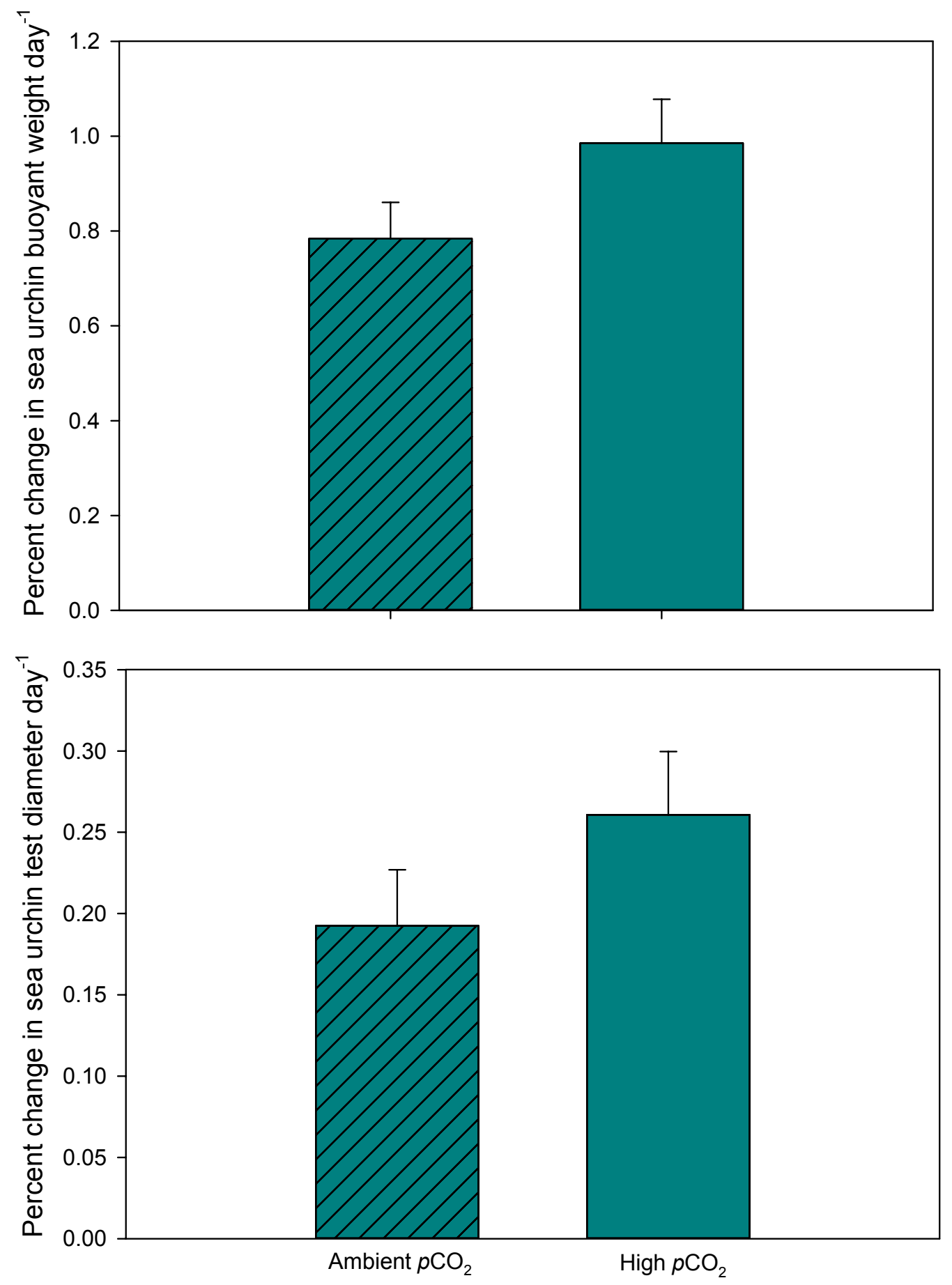

Figure 26. Growth rates of sea urchins reared on settlement tiles from Stillwater Cove in ambient and high $p \mathrm{CO}_{2}$ conditions standardized to initial size after 56 days in experimental rearing $\pm \mathrm{SE}$. 
Ten sea urchins were removed from settlement tiles exposed to ambient and high $p \mathrm{CO}_{2}$ conditions at the end of the experiment for use in grazing assays. In contrast to the results of experiments from Mia's Reef, results from my grazing trial on tiles from Stillwater Cove found no significant differences in grazing rates of sea urchins subjected to ambient and high $\mathrm{pCO}_{2}$ treatments following 60 days of exposure (t-test, $t_{18}=-0.061, P=0.952 ;$ Fig. 27).

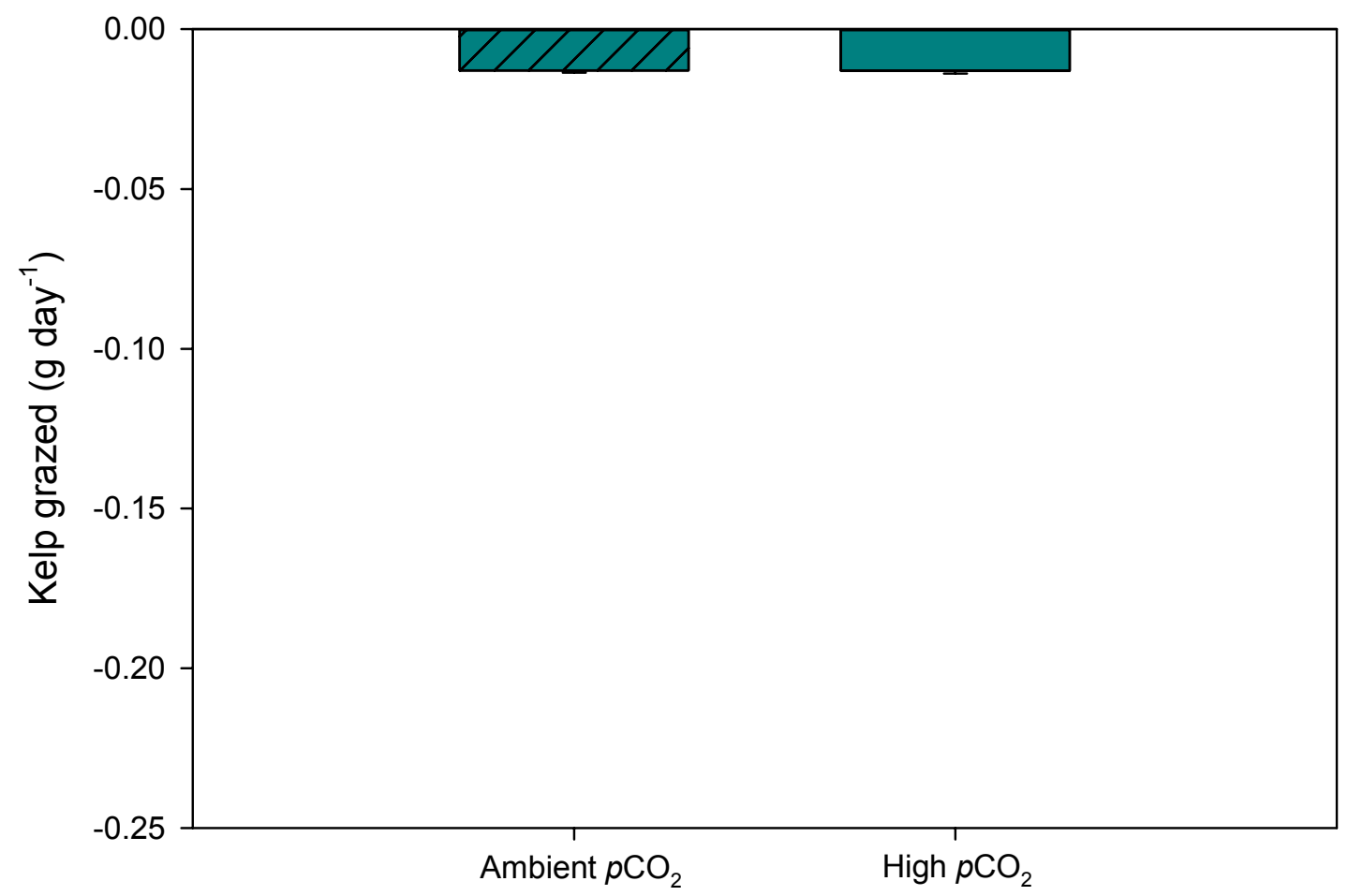

Figure 27. Results from grazing assay with urchins from settlement tiles accrued at Stillwater Cove after 56 days of rearing in ambient or high $p \mathrm{CO}_{2}$. A decrease in $\mathrm{g} \mathrm{day}^{-1}$ indicates a removal of algal biomass via grazing. Error bars denote +s.e.m. 


\section{Discussion}

Global change will almost certainly impact marine ecosystems due to species-specific changes to biology, physiology and ecology. However, it is challenging to predict how these species-specific responses will manifest at the ecosystem level without controlled studies conducted on species assemblages as a whole. This study focused on the emergent effects of ocean acidification at two kelp forest locations acclimated to different $\mathrm{pH}$ and temperature regimes. In addition, I addressed how mobile grazers will aggravate or ameliorate the impacts of ocean acidification on benthic community composition.

\section{Calcification and Community Structure}

Climate change stressors such as decreased $\mathrm{pH}(\mathrm{OA})$ and/or increased temperature have been shown to dramatically change the landscape scale patterns seen on tropical coral reefs and at natural $\mathrm{CO}_{2}$ vent locations. The present study was conducted using species assemblages accrued at two kelp forest locations along the California coast, where the main habitat-forming kelp, Macrocysistis pyrifera, dominates. The initial species assemblages differed greatly between sites. In Carmel, CA, barnacles were the dominant living taxa on tiles, covering nearly $50 \%$ and $30 \%$ of tile surfaces (top and bottom respectively). However, in San Diego, the top surface of tiles was nearly $40 \%$ fleshy macroalgae with the bottom surface dominated by bryozoans ( $50 \%)$. The community level responses varied greatly both between sites (Carmel versus 
San Diego) as well as within a site (San Diego) likely due to geographic differences in the initial structure of the assemblages inhabiting the settlement tiles, as well as in prior exposure history to low $\mathrm{pH}$ conditions during the year in which the tiles were deployed in the field.

In San Diego, CA, where natural variability in $\mathrm{pH}$ is more static and mean $\mathrm{pH}$ values are on average 8.06, I found that OA could affect net ecosystem calcification on the tiles. Negative changes in the percent buoyant weight of calcifying organisms throughout all treatments could suggest an experimental artifact or could just be due to seasonal differences in calcification rates of organisms on the tiles. However, despite an overall decrease in calcium carbonate across treatments, I found a significantly greater reduction in calcium carbonate on tiles reared under high $p \mathrm{CO}_{2}$ conditions. Net loss of calcium carbonate was also found in a subtropical coral reef community reared under high $p \mathrm{CO}_{2}$ conditions for $\sim 8$ months (ambient $p \mathrm{CO}_{2}=568 \mu$ atm, high $p \mathrm{CO}_{2}=$ $1147 \mu \mathrm{atm})$ (Andersson et al., 2009). High $\mathrm{pCO}_{2}$ or low $\mathrm{pH}$ conditions are known to reduce the calcification rates of numerous taxa in single species experiments (Kroeker et al., 2010). This is largely assumed to be due to a decrease in the availability of $\mathrm{CO}_{3}{ }^{2-}$, a necessary building block of biogenic carbonates. Coral reef communities have been shown to exhibit decreased net accretion rates of corals and coralline red algae under elevated $p \mathrm{CO}_{2}$ (Hoegh-Guldberg et al., 2007; Jokiel et al., 2008). It's likely that the $p \mathrm{CO}_{2}$ effect seen here is due to both reduced calcification, via decreased growth and thinner calcium carbonate 
skeletons, as well as increased dissolution. Furthermore, high $p \mathrm{CO}_{2}$ had a greater effect than sea urchin grazing in San Diego. However, the reduction in calcified biomass, or net dissolution in the presence of sea urchins, may be due in part to both consumption of calcareous organisms or erosive processes as mobile sea urchins grazed on fleshy species.

I found that the $\mathrm{pCO}_{2}$ effects on community structure were dependent on the initial communities in our experiment from San Diego, CA. Since functional group taxa responded differently between blocks, overall effects were masked when blocks were pooled together. Interestingly, each block only exhibited minor differences in the abundances of functional group taxa at the onset of my experiment. These species assemblages were obtained from the same reef outcrop (spaced five meters away from each other and differing in depth by less than one meter) and experienced similar environmental conditions (e.g., temperature, $\mathrm{pH}$, grazing) before being exposed to ocean acidification and grazing. This finding is surprising as such small-scale heterogeneity on reefs has largely been unstudied in the context of climate change, yet it may play an important role in the persistence of marine ecosystems. Recent work by Cornwall et al. (2014) suggests that diffusive boundary layers around algal assemblages could alter the effects of $\mathrm{OA}$ by decreasing flow and allowing $\mathrm{pH}$ to increase within the algal assemblage. Therefore, minor variability in not just the abundance, but also the spatial arrangement of species within a community could change the response to acidification. It's possible that minor differences in 
flow and light levels within the kelp forests at Mia's Reef could alter assembly processes and therefore lead to different species arrangements and subsequent responses to both $\mathrm{OA}$ and grazing between blocks.

Although the differential responses of taxa between blocks may be driven by spatial arrangement, it's also possible that the experimental duration was not sufficient to detect landscape level impacts on community structure. Past studies subjecting intact assemblages to acidification vary greatly in the length of study, but the general pattern of detrimental impacts to calcifying organisms and positive effects on non-calcifying taxa are supported. Temperate intertidal communities comprised of articulated coralline red algae and fleshy red macroalgae subjected to high $p \mathrm{CO}_{2}(1486 \mu$ atm) for 86 days found decreased calcification in the articulated coralline red alga, Corallina officinalis, and increased cover of the fleshy red alga, Chondrus crispus (Hofmann et al. 2012). James et al. (2014) found reduced growth of crustose coralline red algae in early successional communities reared at a pH of 7.60 (compared to ambient $\mathrm{pH}=$ 8.05) for only 6 weeks. My experiment lasted 56 days, which is within the range of past studies on community impacts of OA in temperate systems. However, intact communities dominated by adults and persistent taxa may be more resilient to $\mathrm{OA}$ and therefore in order to detect changes in community structure within dynamic ecosystems should be conducted over longer time scales.

Species assemblages from Carmel, CA responded differently to OA and grazing than assemblages from San Diego, CA. This is likely due to differences 
in community composition, but also potentially due to local adaptation or acclimation to different $\mathrm{pH}$ regimes. Local adaptation to environmental stressors such as temperature and $\mathrm{pH}$ have been documented in numerous species both in the field as well as in laboratory experiments (Sanford and Kelly 2011). In addition to adaptation in a single species, geographic mosaics of coevolution can result in variability in species interactions due to differences in selection pressures driven by abiotic stressors, such as temperature (Sanford 2003). Mean $\mathrm{pH}$ conditions in the field in Carmel, $\mathrm{CA}(\mathrm{pH}=7.75)$, where the tiles were deployed for a year to accrue mixed assemblages, were only $0.05 \mathrm{pH}$ units higher than mean $\mathrm{pH}$ in our high $p \mathrm{CO}_{2}$ treatment. Carmel Bay is a location of strong and persistent upwelling of deep water from the nearby Carmel Canyon and organisms living in this area are exposed to $\mathrm{pH}$ levels significantly lower than in San Diego or the global average. Therefore, it's not surprising that there was a lack of $p \mathrm{CO}_{2}$ effect on most of the response variables reported in this experiment. This also stresses the need to manipulate $\mathrm{pCO}_{2}$ treatment conditions specific to the site (or region) of study as ocean acidification in one region may be indicative of natural conditions in another. Unfortunately, long term monitoring of $\mathrm{pH}$ is not available in all locations and I did not have the opportunity to process the in situ sensor data from my two study locations prior to the start of the laboratory experiment.

I did find strong impacts of sea urchin grazing on both calcification rates as well as community structure in Carmel, CA. Sea urchins of the genus 
Strongylocentrotus are known to alter algal species composition by preferentially removing algal biomass (Paine and Vadas 1969). One study by Breitburg (1985) found that in Santa Barbara kelp forests only grazer-resistant algal crusts (i.e. crustose coralline algae), diatom films and ephemeral filamentous algae were abundant in the presence of sea urchin and sea star grazers. However, when grazers were excluded communities consisted of filamentous red algae, encrusting bryozoans, barnacles and tubicolous amphipods. My study found a significant reduction in the percent cover of both calcified invertebrates (mainly barnacles) and coralline red algae in the presence of grazers. However, the coralline algae in my study were small crusts and articulated individuals (less than $\sim 3 \mathrm{~cm}$ tall) and therefore may have been more susceptible to grazing than the grazer-resistant crusts in Breitburg's study. Sea urchins have also been implicated in phase shifts from high diversity fleshy macroalgae dominated kelp forests to low diversity coralline algae dominated sea urchin barrens (Pearse 2006). The dramatic reductions in calcification seen in grazer treatments from tiles from Carmel, CA were mainly caused by removal of barnacles by sea urchins. Sea urchins likely both consumed barnacles directly and caused their removal as sea urchins fed on fleshy macroalgae. This is also mirrored in the dramatic increase in bare space after the removal of barnacles on tiles. 


\section{Impacts of OA and Grazing on Juvenile Kelp}

Interest in the consequences of climate change for kelp forest ecosystems has increased since recent studies have shown that early life history stages of kelp may be particularly vulnerable to high $p \mathrm{CO}_{2}$ and temperature (Gaitán-Espitia et al. 2014). Early life history stages are likely to become increasingly important to the recovery of kelp forests in future oceans as disturbances that act to remove kelp plants become more frequent and intense (Byrnes et al. 2011). Although it was not my initial intention, this study provided an interesting opportunity to preliminarily assess the emergent effects of climate change and grazing on giant kelp, Macrocystis pyrifera. At the outset of both lab experiments, no kelp were visible to the naked eye on tile surfaces, suggesting that they were present at some unknown microscopic stage upon removal from the reef. No differences in density or biomass were seen as a result of $p \mathrm{CO}_{2}$ at either site, suggesting that the impacts of OA on kelp growth and survival may not be impacted at this early stage, as has been shown in previous studies when only $p \mathrm{CO}_{2}$ was manipulated to simulate OA (Roleda et al. 2012). I have no way of knowing what stage of the lifecycle M. pyrifera individuals were in when they were placed in my experiment or whether densities were similar across treatments. However, this is the first study to assess how juvenile kelp sporophytes may respond to ocean acidification. I found no apparent effect of $\mathrm{OA}$ at the juvenile sporophyte stage as evidenced by my finding that there was no significant difference between the density and biomass of juvenile kelp 
between ambient and high $p \mathrm{CO}_{2}$ treatments. However, since cryptic microstages have been shown to be susceptible to environmental stressors (Gaitán-Espitia et al. 2014) it will be important to directly assess how impacts at various microscopic stages (i.e., settlement, germination, sporophyte production) may alter the landscape scale patterns of kelp forest recovery dynamics.

Although grazing did not alter community structure in San Diego, CA, I did find a reduction in the density of juvenile kelp sporophytes in the presence of sea urchin grazers. Changes to sporophyte density in response to grazing would likely alter other physical properties of the environment. One study by Alsterberg et al. (2013) found both direct and indirect effects of OA, warming, and grazers on benthic microalgae in a seagrass community. In the presence of grazers, the direct and indirect effects of $\mathrm{OA}$ and warming did not significantly affect benthic microalgae. However, in the absence of grazers, benthic microalgae were indirectly negatively affected by sediment-associated microalgal detritus and macroalgal shading, yet directly positively affected by acidification and warming. Although few direct effects of grazing on community structure were evident on tiles from San Diego, CA for the duration of our experiment, it is likely that the indirect effects of macroalgal shading and changes to flow regimes could alter the $\mathrm{CO}_{2}$ response of benthic communities over longer timescales.

In my first experiment with tiles and sea urchins collected from San Diego, $\mathrm{CA}$, I found that sea urchin growth and grazing rates were significantly depressed in high $p \mathrm{CO}_{2}$ treatments. Russell et al. (2013) also found that the herbivorous 
gastropod, Littorina littorea, showed decreased consumption rates in high $p \mathrm{CO}_{2}$ conditions. However, in my second experiment with tiles from Carmel, CA and sea urchins collected from San Diego, CA we found no $\mathrm{pCO}_{2}$ effect on growth or grazing rates. Sea urchins were collected once and used in both experiments. In between experiments sea urchins were held in a large aquarium and fed giant kelp ad libitum. During this time sea urchins doubled in size and may have become acclimatized to laboratory conditions or more resistant to the effects of $p \mathrm{CO}_{2}$. This may also explain the strong grazing effects on both community composition and density and biomass of kelp on tiles from Carmel, CA. Therefore, any comparisons of grazing impacts between sites should be made with caution. However, the differential responses of OA on grazing are important to understand as changes to the strengths of algal-grazer interactions could have major consequences for marine ecosystems, such as favoring shifts from kelp forests to sea urchin barrens.

\section{Conclusion}

Climate change impacts on kelp forest ecosystems are likely to vary spatially both at local and regional scales. Here I show differences in the susceptibility of kelp forest benthic communities to ocean acidification and the interactive effects of grazing. In San Diego, CA, ocean acidification reduced calcification and altered community structure whereas sea urchin grazing showed few emergent effects. However, in Monterey, CA, ocean acidification had no 
effect, but sea urchin grazing had a strong impact on community composition. These findings support predictions that local adaption may play a role in species susceptibility to acidification. Those inhabiting naturally more corrosive seawaters may have evolved mechanisms to tolerate low $\mathrm{pH}$. Findings like this can be encouraging; however, our understanding of how these mechanisms have evolved limits our ability to predict whether some species will be able to keep up with the rate of accelerating global change. 


\section{Literature Cited}

Alsterberg C, Eklöf JS, Gamfeldt L, Havenhand JN, Sundbäck K (2013)

Consumers mediate the effects of experimental ocean acidification and warming on primary producers. Proc Natl Acad Sci USA

Andersson AJ, Mackenzie FT, Bates NR (2008) Life on the margin: implications of ocean acidification on Mg-calcite, high latitude and cold-water marine calcifiers. Mar Ecol Prog Ser 373:265-273

Breitburg DL (1984) Residual effects of grazing : inhibition of competitor recruitment by encrusting coralline algae. Ecol 65:1136-1143

Breitburg DL (1985) Development of a subtidal epibenthic community: factors affecting species composition and the mechanisms of succession. Oecol 65:173-184

Byrnes JEK, Cardinale BJ, Reed DC (2013) Interactions between sea urchin grazing and prey diversity on temperate rocky reef communities. Ecol 94:1636-1646

Byrnes JE, Reed DC, Cardinale BJ, Cavanaugh KC, Holbrook SJ, Schmitt RJ (2011) Climate-driven increases in storm frequency simplify kelp forest food webs. Glob Change Biol 17:2513-2524

Cornwall CE, Boyd PW, McGraw CM, Hepburn CD, Pilditch CA, Morris JN, Hurd $C L$ (2014) Diffusion boundary layers ameliorate the negative effects of ocean acidification on the temperate coralline macroalga Arthrocardia corymbosa. PLoS ONE 9:1-9

Dayton PK, Currie V, Gerrodette T, Keller BD, Rosenthal R, Ven Tresca D (1984) Patch dynamics and stability of some California USA kelp communities. Ecol Monogr 54:253-290

Edwards MS (1998) Effects of long-term kelp canopy exclusion on the abundance of the annual alga Desmerestia ligulata. J Exp Mar Biol Ecol 228:309-326

Enochs IC, Manzello DP, Donham EM, Kolodziej G, Okano R, Johnston L, Young C, Iguel J, Edwards CB, Fox MD, Valentino L, Johnson S, Benavente D, Clark SJ, Carlton R, Burton T, Eynaud Y, Price NN (2015) Shift from coral to macroalgae dominance on a volcanically acidified reef. Nat Clim Change 5:1083-1088 
Fabricius KE, Langdon C, Uthicke S, Humphrey C, Noonan S, De'ath G, Okazaki R, Muehllehner N, Glas MS, Lough JM (2011) Losers and winners in coral reefs acclimatized to elevated carbon dioxide concentrations. Nat Clim Change 1:165-169

Feely RA, Sabine CL, Hernandez-Ayon JM, lanson D, Hales B (2008) Evidence for upwelling of corrosive "acidified" water onto the continental shelf. Science 320:1490-1492

Gaitán-Espitia JD, Hancock JR, Padilla-Gamiño JL, Rivest EB, Blanchette CA, Reed DC, Hofmann GE (2014) Interactive effects of elevated temperature and pCO2 on early-life-history stages of the giant kelp Macrocystis pyrifera. J Exp Ma Biol Ecol 457:51-58

Hale R, Calosi P, McNeill L, Mieszkowska N, Widdicombe S (2011) Predicted levels of future ocean acidification and temperature rise could alter community structure and biodiversity in marine benthic communities. Oikos 120:661-674

Hall-Spencer JM, Rodolfo-Metalpa R, Martin S, Ransome E, Fine M, Turner SM, Buia M-C (2008) Volcanic carbon dioxide vents show ecosystem effects of ocean acidification. Nature 454:96-99

Harley CDG, Anderson KM, Demes KW, Jorve JP, Kordas RL, Coyle TA, Graham MH (2012) Effects of climate change on global seaweed communities. J Phycol 48:1064-1078

Harrold C, Reed DC (1985) Food availability, sea urchin grazing, and kelp forest community structure. Ecol 66:1160-1169

Harvey BP, Gwynn-Jones D, Moore PJ (2013) Meta-analysis reveals complex marine biological responses to the interactive effects of ocean acidification and warming. Ecol Evo 2013:1-15

Hauri C, Gruber N, Vogt M, Doney SC, Feely RA, Lachkar Z, Leinweber A, McDonnell AMP, Munnich M, Plattner G-K (2013) Spatiotemporal variability and long-term trends of ocean acidification in the California Current System. Biogeosciences 10:193-216

Hoegh-Guldberg O, Mumby PJ, Hooten AJ, Steneck RS, Greenfield P, Gomez E, Hatziolos ME (2007) Coral reefs under rapid climate change and ocean acidification. Science 318:1737-1742

Hofmann L, Straub S, Bischof K (2012) Competition between calcifying and 
noncalcifying temperate marine macroalgae under elevated $\mathrm{CO}_{2}$ levels. Mar Ecol Prog Ser 464:89-105

IPCC (2007) Climate Change 2007: the physical science basis. contribution of working group I to the fourth assessment report of the intergovernmental panel on climate change. Cambridge University Press, Cambridge

James RK, Hepburn CD, Cornwall CE, McGraw CM, Hurd CL (2014) Growth response of an early successional assemblage of coralline algae and benthic diatoms to ocean acidification. Mar Biol 10

Jokiel PL, Rodgers KS, Kuffner IB, Andersson AJ, Cox EF, Mackenzie FT (2008) Ocean acidification and calcifying reef organisms: a mesocosm investigation. Coral Reefs 27:473-483

Kroeker KJ, Kordas RL, Crim RN, Singh GG (2010) Meta-analysis reveals negative yet variable effects of ocean acidification on marine organisms. Ecol Lett13:1419-1434

Kroeker KJ, Micheli F, Gambi MC, Martz TR (2011) Divergent ecosystem responses within a benthic marine community to ocean acidification. Proc Natl Acad Sci USA 108:14515-14520

Kroeker KJ, Micheli F, Gambi MC (2012) Ocean acidification causes ecosystem shifts via altered competitive interactions. Nat Clim Change 2:1-4

Kroeker KJ, Kordas RL, Crim R, Hendriks IE, Ramajo L, Singh GS, Gattuso J-P (2013) Impacts of ocean acidification on marine organisms: quantifying sensitivities and interaction with warming. Glob Change Biol 19:1884-1896

Martz TR, Connery JG, Johnson KS (2010) Testing the Honeywell Durafet for seawater $\mathrm{pH}$ applications. Limnol Oceanogr Methods 8:172-184

Paine RT, Vadas RL (1969) The effects of grazing by sea urchins, Strongylocentrotus spp., on benthic algal populations. Limnol Oceanogr 14:710-719

Pearse JS (2006) Ecological role of purple sea urchins. Science 314:940-941

Porzio L, Buia MC, Hall-Spencer JM (2011) Effects of ocean acidification on macroalgal communities. J Exp Mar Biol Ecol 400:278-287

Price N, Hamilton S, Tootell J, Smith J (2011) Species-specific consequences of ocean acidification for the calcareous tropical green algae Halimeda. Mar 


\section{Ecol Prog Ser 440:67-78}

Price NN, Martz TR, Brainard RE, Smith JE (2012) Diel variability in seawater pH relates to calcification and benthic community structure on coral reefs. PloS One 7: e43843

Roleda MY, Morris JN, McGraw CM, Hurd CL (2012) Ocean acidification and seaweed reproduction: increased $\mathrm{CO}_{2}$ ameliorates the negative effect of lowered $\mathrm{pH}$ on meiospore germination in the giant kelp Macrocystis pyrifera (Laminariales, Phaeophyceae). Glob Change Biol 18:854-864

Russell BD, Thompson J-AI, Falkenberg LJ, Connell SD (2009) Synergistic effects of climate change and local stressors: $\mathrm{CO} 2$ and nutrient-driven change in subtidal rocky habitats. Glob Change Biol 15:2153-2162

Russell BD, Connell SD, Findlay HS, Tait K, Widdicombe S, Mieszkowska N (2013) Ocean acidification and rising temperatures may increase biofilm primary productivity but decrease grazer consumption. Philosl Trans R Soc B 368

Sanford E (2003) Local selection and latitudinal variation in a marine predatorprey interaction. Science 300:1135-1137

Sanford E, Kelly MW (2011) Local adaptation in marine invertebrates. Annu Rev Mar Sci 3:509-535

Schiel DR, Steinbeck JR, Foster MS (2004) Ten years of induced ocean warming causes comprehensive changes in marine benthic communities. Ecol 85:1833-1839

Watanabe JM, Harrold C (1991) Destructive grazing by sea urchins Strongylocentrotus spp. in a central California kelp forest: potential roles of recruitment, depth, and predation. Mar Ecol Prog Ser 71:125-141

Widdicombe S, Spicer JI (2008) Predicting the impact of ocean acidification on benthic biodiversity: What can animal physiology tell us? J Exp Mar Biol Ecol 366:187-197 


\section{Conclusion to Thesis}

Marine ecosystems worldwide are threatened by $\mathrm{CO}_{2}$-driven global changes, such as ocean warming and acidification. How these changes will impact marine ecosystems and the services these ecosystems provide is still unclear. In Chapter 1, I assessed the response of an ecologically important and high-risk coralline algal species, Calliarthron cheilosporioides, to warming and acidification. My findings suggest that this species is likely to be negatively impacted by global change stressors. I found that growth and calcification were reduced in high $p \mathrm{CO}_{2}$ and elevated temperature treatments, yet the two stressors did not act synergistically. I also found evidence that high $p \mathrm{CO}_{2}$ can affect photophysiology of coralline algae by increasing the maximum photosynthetic rate $\left(P_{\max }\right)$. This study did not find evidence for mineralogical plasticity, but did document variation in $\mathrm{Mg}$ incorporation in different cell types of coralline red algae. Together these results suggest that unless $C$. cheilosporioides is capable of acclimating to ocean acidification and warming over time scales longer than my current experiment, I expect to see reductions in both the abundance and distribution of this species.

In Chapter 2, I scaled up to examine the emergent effects of ocean acidification and grazing on benthic communities from two different geographic regions of the California Current, central and southern California, that differ in the intensity of upwelling and thus the level of $\mathrm{pH}$ naturally experienced by the 
benthos. I found that the community responses differed greatly between sites and even within a single site (San Diego). San Diego, CA exhibited decreased calcification rates and changes to the abundances of key functional group taxa in response to acidification, but few responses to sea urchin grazing. Monterey, $\mathrm{CA}$, on the other hand, expressed decreased calcification and a reduction in the abundances of calcified invertebrates and algae due to sea urchin grazing, but no response to acidification. Although my study only contained two locations (one in central and one in southern $\mathrm{CA}$ ), the changes to community structure due OA at both sites are in line with predictions based on prior exposure and the potential for local adaptation.

Together these chapters suggest that temperate kelp forest ecosystems may be negatively impacted by climate change. Future research is necessary to understand the potential for populations inhabiting higher $\mathrm{pH}$ conditions to acclimate to acidification over longer time scales as well as the thresholds beyond which low-pH adapted populations also feel the effects of OA. 


\section{Literature Cited}

Caldeira K, Wickett M (2003) Anthropogenic carbon and ocean pH. Nature 425:365

Doney SC, Fabry VJ, Feely RA, Kleypas JA (2009) Ocean acidification: The other $\mathrm{CO}_{2}$ problem. Annu Rev Mar Sci 1:169-192

Feely RA, Doney SC, Cooley SR (2009) Ocean acidification present conditions and future changes in a high- $\mathrm{CO}_{2}$ World. Oceanogr 22:36-47

Gruber N, Hauri C, Lachkar Z, Loher D, Frölicher TL, Plattner G-K (2012) Rapid progression of ocean acidification in the California Current System. Science 337:220-223

Harley CDG, Anderson KM, Demes KW, Jorve JP, Kordas RL, Coyle TA, Graham MH (2012) Effects of Climate Change on Global Seaweed Communities. J Phycol 48:1064-1078

Hoegh-Guldberg O, Mumby PJ, Hooten AJ, Steneck RS, Greenfield P, Gomez E, Hatziolos ME (2007) Coral reefs under rapid climate change and ocean acidification. Science 318:1737-1742

Lüthi D, Le Floch M, Bereiter B, Blunier T, Barnola J-M, Siegenthaler U, Stocker TF (2008) High-resolution carbon dioxide concentration record 650,000800,000 years before present. Nature 453:379-382

Sabine CL, Feely RA, Gruber N, Key RM, Lee K, Bullister JL, Rios AF (2004) The oceanic sink for anthropogenic CO2. Science 305:367-371 